\title{
Infektologie und Tropenmedizin
}

\author{
T. Löscher
}

22.1 Einleitung 536

22.1.1 Diagnostik von Infektionskrankheiten 536

22.1.1.1 Klinische Diagnostik und Diagnoseverdacht 536

22.1.1.2 Mikrobiologische Diagnostik 536

22.1.1.3 Laboruntersuchungen und apparative Diagnostik 538

22.2 Infektionssyndrome 538

22.2.1 Sepsis 538

22.2.1.1 Anamnese, Symptome und Befunde 540

22.2.1.2 Diagnostik 541

22.2.2 ZNS-Infektionen 542

22.2.2.1 Meningitis 542

22.2.2.2 Enzephalitis und Myelitis 544

22.2.2.3 Hirnabszeß und septische Herdenzephalitis 545

22.2.3 Infektiöse Mononukleose und ähnliche Syndrome 546

22.2.3.1 Infektiöse Mononukleose 546

22.2.3.2 Zytomegalie 547

22.2.3.3 Toxoplasmose 547

22.2.3.4 Katzenkratzkrankheit 548

22.2.4 Infektiöse Enteritis 548

22.2.5 HIV-Infektion und Aids 552

22.2.5.1 Opportunistische Infektionen und Tumorerkrankungen 553

22.2.6 Sexuell übertragbare Erkrankungen 556

22.2.6.1 Gonorrhö 556

22.2.6.2 Genitale Chlamydieninfektionen 557

22.2.6.3 Genitale Mykoplasmeninfektionen 558

22.2.6.4 Lues (Syphilis) 558

22.2.6.5 Ulcus molle 559

22.2.6.6 Granuloma inguinale 559

22.2.6.7 Trichomoniasis 559

22.2.7 Fieber unbekannter Ursache 559

22.2.8 Importierte Infektionskrankheiten 562

22.3 Bakterielle Infektionskrankheiten 568

22.3.1 Scharlach 568

22.3.2 Toxinschocksyndrom 569

22.3.3 Diphtherie 569

22.3.4 Milzbrand (Anthrax) 569

22.3.5 Tetanus 569

22.3.6 Botulismus 570

22.3.7 Gasbrand 570

22.3.8 Listeriose 570

22.3.9 Typhus und Paratyphus abdominalis 571

22.3.10 Pertussis 571

22.3.11 Yersiniosen 571

22.3.12 Brucellosen 571

22.3.13 Legionellosen 572

22.3.14 Leptospirosen 572

22.3.15 Lyme-Borreliose 572
22.3.16 Tuberkulose 573

22.3.17 Nichttuberkulöse Mykobakteriosen 573

22.3.18 Lepra 573

22.3.19 Aktinomykose 574

22.3.20 Nokardiose 574

22.3.21 Whipple-Krankheit 574

22.3.22 Rickettsiosen 574

22.3.23 Ehrlichiosen 575

22.3.24 Chlamydieninfektionen 575

22.3.24.1 Infektionen durch Chlamydia trachomatis 575

22.3.24.2 Psittakose (Ornithose) 575

22.3.24.3 Infektionen durch Chlamydia pneumoniae 576

22.3.25 Mykoplasmeninfektionen 576

22.4 Virusinfektionen 576

22.4.1 Herpes simplex 576

22.4.2 Varizellen und Zoster 577

22.4.3 Masern 577

22.4.4 Röteln 577

22.4.5 Parvovirusinfektion 578

22.4.6 Mumps 578

22.4.7 Poliomyelitis 578

22.4.8 Influenza 578

22.4.9 Tollwut 579

22.4.10 Hantavirusinfektionen 579

22.4.11 Dengue-Fieber und andere Arbovirosen 579

22.4.12 Virale hämorrhagische Fieber (VHF) 580

22.5 Mykosen innerer Organe 580

22.5.1 Candidiasis 580

22.5.2 Aspergillose 581

22.5.3 Sonstige Systemmykosen 581

22.6 Parasitosen 582

22.6.1 Malaria 582

22.6.2 Leishmaniosen 584

22.6.2.1 Kutane Leishmaniosen 584

22.6.2.2 Mukokutane Leishmaniose 584

22.6.2.3 Viszerale Leishmaniose (Kala-Azar) 584

22.6.3 Schlafkrankheit 584

22.6.4 Chagas-Krankheit 585

22.6.5 Amöbiasis 585

22.6.6 Giardiasis (Lambliasis) 585

22.6.7 Schistosomiasis (Bilharziose) 585

22.6.8 Filariosen 586

22.6.9 Trichinose 586

22.6.10 Echinokokkose 586

22.6.10.1 Zystische Echinokokkose 586

22.6.10.2 Alveoläre Echinokokkose 586

22.6.11 Zystizerkose 587 


\section{1}

\section{Einleitung}

Weltweit gehören infektiös bedingte Erkrankungen trotz erheblicher Fortschritte bei ihrer Behandlung und Prävention nach wie vor zu den führenden Ursachen von Morbidität und Mortalität (Schätzung der WHO: $33 \%$ aller Todesursachen im Jahr 1997). Durch den Rückgang klassischer Infektionskrankheiten in den entwickelten Ländern verbreitete sich während der letzten Jahrzehnte die Ansicht, daß Infektionen weitgehend zurückgedrängt bzw. unter Kontrolle und bald nur noch von historischem Interesse sind. Tatsächlich spielen Infektionen in Deutschland und anderen Industrieländern jedoch eine bedeutsame Rolle als primäre Krankheitsursachen und als Komplikationen bei zahlreichen Grunderkrankungen:

- Vor allem durch die Fortschritte der Medizin bei der Behandlung von Tumorerkrankungen, Hämoblastosen und chronischen Grunderkrankungen kommt es bei einer zunehmenden Zahl von Patienten mit Abwehrstörungen zu schwerwiegenden Infektionen durch fakultativ pathogene oder normalerweise apathogene Erreger (opportunistische Infektionen).

- Die Zunahme von Resistenzen zahlreicher Erreger gegen die zur Verfügung stehenden antimikrobiellen Wirkstoffe ist ein erhebliches Problem, insbesondere bei nosokomialen Infektionen, und muß nicht nur bei der Therapie sondern auch bei der Diagnostik berücksichtigt werden.

- Neue Infektionskrankheiten wie HIV-Infektion und Aids sind aufgetreten („emerging infectious diseases"), bereits unter Kontrolle geglaubte Infektionen haben sich wieder ausgebreitet (z. B. Tuberkulose, Diphtherie), und zahlreiche neue Erreger wurden als Ursache bereits bekannter Erkrankungen identifiziert (z. B. Helicobacter pylori, LymeBorreliose) oder stehen in begründetem Verdacht (z. B. Chlamydia pneumoniae).

- Durch veränderte Lebens- und Umweltbedingungen muß mit einem veränderten Spektrum von Infektionen oder mit in Deutschland nicht bzw. nicht mehr vorkommenden Infektionen gerechnet werden. Wichtige Beispiele sind:

- Freizeitverhalten (z. B. Lyme-Borreliose, FSME, Hantavirusinfektion),

- i.v.-Drogengebrauch (z. B. HIV-Infektion, Hepatitis C, Endokarditis),

- internationale Migration und Reisetätigkeit (importierte Infektionen).
22.1.1

Diagnostik von Infektionskrankheiten

22.1.1.1

\section{Klinische Diagnostik und Diagnoseverdacht}

Die klinischen Manifestationen von Infektionen bzw. Infektionskrankheiten umfassen nahezu das gesamte Spektrum der Medizin und bei einer Vielzahl von Krankheitsbildern ist eine infektiöse Genese bei der diagnostischen Abklärung zu berücksichtigen. Zwar finden sich bei Infektionen gehäuft bestimmte allgemeine (z. B. Fieber, Schüttelfrost, Schweißausbruch), lokale (z. B. Rötung, Schwellung, Schmerzen) und organspezifische (z. B. Meningismus, Husten und Auswurf, Durchfälle, Dysurie, Exantheme, Lymphadenopathie) Symptome und Befunde. Diese können meist jedoch auch durch eine Vielzahl nichtinfektiöser Erkrankungen hervorgerufen werden.

Bei einigen Infektionskrankheiten ist das klinische Bild so typisch, daß die Diagnose bereits klinisch gestellt (z. B. exanthematische Kinderkrankheiten, Erysipel, Erythema migrans, Herpes simplex labialis oder genitalis) und auf mikrobiologische Untersuchungen verzichtet werden kann oder diese nur in schwer verlaufenden Fällen (z. B. Varizella zoster, Herpes simplex) oder bei epidemiologischer Relevanz (z. B. Masern) angezeigt sind.

Bei akuten und schwerwiegenden Infektionen ( $z$. B. Sepsis, Meningitis, Pneumonie, Harnwegsinfektionen) muß häufig eine empirische Initialtherapie begonnen werden, bevor ein definitiver Erregernachweis vorliegt. Dennoch ist der Nachweis des oder der Erreger (ggf. einschließlich Resistenzbestimmung) sowie ggf. der genauen Lokalisation oder Quelle der Infektion von großer und $z$. T. entscheidender Bedeutung für die weitere Behandlung. Die hierzu erforderlichen diagnostischen Maßnahmen sollten soweit möglich vor Einleitung einer antimikrobiellen Therapie erfolgen.

Viele Infektionen manifestieren sich jedoch nicht unter dem klinisch offensichtlichen Bild einer speziellen Infektionskrankheit oder eines typischen Infektionssyndroms. Hier ist es besonders wichtig, aufgrund der genauen Analyse von Klinik, Vorgeschichte und Befunden die Möglichkeit einer infektiösen Genese in die Verdachtsdiagnose und die diagnostische Abklärung einzubeziehen. In Zweifelsfällen und bei unklaren Erkrankungen empfiehlt sich die konsiliarische Einbeziehung eines Infektiologen.

\subsubsection{2}

\section{Mikrobiologische Diagnostik}

Siehe auch Teil A, Kap. 3

Bei Verdacht auf Vorliegen einer Infektion bzw. Infektionskrankheit sollte außer bei geringfügigen Erkrankungen und/oder klinisch eindeutiger Diagnose 
stets versucht werden, die Diagnose durch Nachweis des/der verantwortlichen Erreger zu sichern. Dazu ist es notwendig, vor Einleitung einer Chemotherapie alle erforderlichen Untersuchungsmaterialien zu gewinnen. Bei schwerwiegenden und diagnostisch unklaren Erkankungen ist es zudem empfehlenswert, Serumproben vom Zeitpunkt der Erstuntersuchung sowie Aliquots von Untersuchungsmaterialien, die nicht beliebig erneut zu gewinnen sind (z. B. Liquor, Punktate, Biopsien), einzufrieren. Dies ermöglicht es, Untersuchungen v. a. immundiagnostischer und molekularbiologischer Art auch zu einem späteren Zeitpunkt nachzuholen bzw. im Verlauf zu verfolgen (z. B. Antikörperspiegelverläufe).

\section{Erregernachweis}

Bei zahlreichen Infektionen ist es möglich, die Erreger direkt bzw. kulturell nachzuweisen. Dies ist meist auch Voraussetzung für Resistenzbestimmung und weitere Typisierung (Pathotypisierung, Toxinnachweis, epidemiologische Analyse). Erfolg und Aussagewert der Erregerisolierung hängen wesentlich von Gewinnung, Transport und Verarbeitung des Untersuchungsmaterials ab (Teil A, Kap. 3). Bei Verdacht auf Infektionen mit hochkontagiösen Erregern sind dabei die entsprechenden Vorschriften und Infektionsschutzmaßnahmen zu beachten (Teil A, Kap. 3).

Bei einigen Erregern sind für den Nachweis spezielle Untersuchungsverfahren erforderlich. Neben den routinemäßigen Untersuchungsprogrammen müssen ggf. auch schwierig oder nur mit besonderen Verfahren anzüchtbare Bakterien sowie Viren, Pilze und/oder Parasiten berücksichtigt werden. Entscheidend ist hierbei die gezielte Information des Mikrobiologen durch den Kliniker über Anamnese, Symptomatik, Befunde, Verdachtsdiagnosen und zu untersuchendes Erregerspektrum. Am besten ist eine Rücksprache bereits vor der Materialgewinnung.

Bei Viren ist eine kulturelle Isolierung meist aufwendig, und die Indikation hierzu ist in der Regel auf schwerwiegende Erkrankungen und/oder begründete Verdachtsfälle seuchenhygienisch relevanter Infektionen sowie bestimmte klinische Situationen (schwere Erkrankungen bei Immunsupprimierten und bei Neugeborenen, kongenitale Infektionen) und Verdacht auf Resistenz (z. B. HSV, CMV, HIV) beschränkt.

\section{Immundiagnostik und molekularbiologische Diagnostik}

Die Immundiagnostik ist v. a. bedeutsam bei Erregern, deren direkter oder kultureller Nachweis schwierig oder nicht möglich ist. Dies gilt für zahlreichen Viruserkrankungen und einigen Erkrankungen durch schwierig nachzuweisende Bakterien (z. B. Bartonellosen, Borreliosen, Brucellosen, Ehrlichiosen, Leptospirosen, Q-Fieber, Rickettsiosen, Treponematosen, Tularämie, Yersiniosen) oder Parasiten (z. B. Toxoplasmose,
Echinokokkose, Zystizerkose, Toxocariasis). Neben dem Nachweis spezifischer Antikörper verschiedener Isotypen (IgG, IgM, IgA, IgE) mit z. T. unterschiedlicher diagnostischer Bedeutung stehen zunehmend auch Methoden zum immunologischen Nachweis von Erregern bzw. Erregerantigenen in Blut, verschiedenen anderen Untersuchungsmaterialien und in Schnittpräparaten (Immunhistologie) zur Verfügung.

Der Nachweis spezifischer Antikörper hat bei einigen Infektionen nur eine eingeschränkte Aussagekraft entweder aufgrund mangelnder Sensitivität und/oder Spezifität oder weil die Bildung von Antikörpern dem akuten Krankheitsgeschehen hinterherhinkt und für eine dringlich erforderliche Diagnosestellung zu spät kommt (z. B. Herpesvirusenzephalitis, akute HIV-Infektion, Legionellosen, Malaria, Typhus abdominalis). Zudem kann die Aussagekraft der serologischen Diagnostik bei Immunkompromittierten erheblich eingeschränkt oder aufgehoben sein.

Molekularbiologische Diagnostikmethoden (PCR, RFLP, Sequenzierung, DNS-Hybridisierung u. a. ) sind mittlerweile bei einer großen Zahl von Infektionskrankheiten beschrieben. In der Praxis werden sie derzeit jedoch nur bei einem begrenzten Spektrum von Erregern und Fragestellungen durchgeführt (Teil A, Kap. 3, Tabellen 3-6 und 3-7):

- zur Diagnostik bei Hepatitis C (Anti-HCV positive Patienten); ggf. auch bei Bartonellosen, Borreliosen, Chagas-Krankheit, schwere Zytomegalieerkrankungen, Ehrlichiosen, FSME, Hantavirusinfektionen, HIV-Infektion, HSV -Enzephalitis u. a. Virusenzephalitiden, Mikrosporidiosen, Tropherymawhippelii-Infektion, Tollwut, Toxoplasmose, Tuberkulose, schwere VZV-Infektionen, virale hämorrhagische Fieber u. a. Infektionen;

- Genotypisierung bei HCV; ggf. auch bei HIV, Entamoeba histolytica/E. dispar und Leishmanien sowie aus epidemiologischen Gründen auch bei anderen Erregern (z. B. Beweis von Infektionsketten bei Tuberkulose oder nosokomialen Infektionen); - quantitative Amplifikationsverfahren zum Therapiemonitoring bei HIV und HCV;

- genotypische Resistenzbestimmung bei HIV; ggf. auch bei CMV, HSV und Mykobakterien.

Aufgrund des erheblichen Aufwandes und der hohen Kosten sind die Indikationen in der Routinediagnostik derzeit noch beschränkt auf bestimmte Erkrankungen mit schwerem Verlauf (z. B. Enzephalitiden, Infektionen bei Immunkompromittierten) oder seuchenhygienischer Relevanz (virale hämorrhagische Fieber, Tollwut) und auf Fälle, bei denen ein begründeter Krankheitsverdacht besteht und ein Erregernachweis nicht anders möglich (z. B. HCV) bzw. mit konventionellen Methoden nicht gelungen ist (z. B. Tuberkulose). 


\subsubsection{3}

\section{Laboruntersuchungen und apparative Diagnostik}

Zahlreiche Laborbefunde können auf das Vorliegen einer Infektion und auf mögliche Organbeteiligungen hinweisen (Tabelle 22-1). Sie sind zudem oft bedeutsam für Erfassung und Beurteilung von Schweregrad, Komplikationen und Verlauf.

Tabelle 22-1. Laborbefunde und diagnostische Hinweise auf Infektionen

\begin{tabular}{|c|c|}
\hline Laborbefund & Erkrankungen \\
\hline \multicolumn{2}{|c|}{ Entzündungsparameter } \\
\hline $\begin{array}{l}\text { BSG, CRP, Procal- } \\
\text { citonin } \uparrow\end{array}$ & $\begin{array}{l}\text { Besonders erhöhte Werte bei systemi- } \\
\text { schen bakteriellen Infektionen }\end{array}$ \\
\hline \multicolumn{2}{|c|}{ Blutbildveränderungen } \\
\hline Leukozytose & $\begin{array}{l}\text { Pyogene bakterielle Infektionen, Sepsis, } \\
\text { initial auch bei einigen Virusinfektionen } \\
\text { (z. B. EBV-Infektion) }\end{array}$ \\
\hline Linksverschiebung & Pyogene bakterielle Infektionen, Sepsis \\
\hline Leukopenie & $\begin{array}{l}\text { Virusinfektionen, HIV-Infektion, Sepsis, } \\
\text { Typhus abdominalis, Malaria, Ehrlichiose }\end{array}$ \\
\hline $\begin{array}{l}\text { Lymphomono- } \\
\text { zytose }\end{array}$ & Virusinfektionen \\
\hline Eosinophilie & $\begin{array}{l}\text { Helminthosen, Kokzidioidomykose, „eo- } \\
\text { sinophile Morgenröte }{ }^{*} \text { bei abklingenden } \\
\text { Infektionen (z. B. Scharlach) }\end{array}$ \\
\hline Aneosinophilie & Typhus abdominalis \\
\hline Thrombozytose & Bakterielle Infektionen \\
\hline Thrombopenie & Virusinfektionen, Malaria tropica \\
\hline Transaminasen $\uparrow$ & $\begin{array}{l}\text { Virushepatitiden, Begleithepatitis bei an- } \\
\text { deren Infektionen (z. B. infektiöse Mono- } \\
\text { nukleose und ähnliche Syndrome, Lepto- } \\
\text { spirose, Malaria), Sepsis }\end{array}$ \\
\hline $\begin{array}{l}\text { Alkalische Phos- } \\
\text { phatase } \uparrow\end{array}$ & $\begin{array}{l}\text { Cholangitis, Virushepatitis, Leberabszes- } \\
\text { se, Begleithepatitis bei anderen Infektio- } \\
\text { nen (s. oben), Knochentuberkulose u. a. } \\
\text { Ostitiden }\end{array}$ \\
\hline Kreatinkinase $\uparrow$ & $\begin{array}{l}\text { Myokarditis, schwere Sepsis, Myositis, } \\
\text { Trichinose }\end{array}$ \\
\hline $\begin{array}{l}\text { Laktatdehydro- } \\
\text { genase } \uparrow\end{array}$ & $\begin{array}{l}\text { Sepsis, Pneumocystis-carinii-Pneumonie, } \\
\text { Malaria, virale hämorrhagische Fieber, } \\
\text { ausgeprägte Hämolyse bei anderen Infek- } \\
\text { tionen }\end{array}$ \\
\hline Bilirubin $\uparrow$ & $\begin{array}{l}\text { Virushepatitis, Cholangitis, Begleithepa- } \\
\text { titis (s. oben) und ausgeprägte Hämolyse } \\
\text { bei anderen Infektionen }\end{array}$ \\
\hline Serumkreatinin $\uparrow$ & $\begin{array}{l}\text { Schwere Sepsis, Hantavirusinfektionen, } \\
\text { Leptospirose, Malaria, Begleitnephritis } \\
\text { bei anderen Infektionen }\end{array}$ \\
\hline Hypoglykämie & $\begin{array}{l}\text { Sepsis, Malaria tropica, Menigitis, Enze- } \\
\text { phalitis u. a. schwere Infektionen }\end{array}$ \\
\hline
\end{tabular}

Die apparative Diagnostik, insbesondere die bildgebende Diagnostik, ergibt häufig entscheidende Hinweise für Verdachtsdiagnose und Lokalisation von Infektionen sowie für Ausdehnung, Komplikationen, Grunderkrankungen und Abgrenzung anderer nichtinfektiöser Krankheitsursachen.
Bei einigen Infektionen und Lokalisationen gelingt der Erregernachweis nur in mittels invasiver Diagnostik gewonnenem Untersuchungsmaterial (z. B. Knochenmark, BAL, Liquor, Organpunktionen und -biopsien). Die Indikation hierzu richtet sich nach Differentialdiagnostik, Krankheitsverdacht und Untersuchungsbefunden (v. a. der bildgebenden Diagnostik). Es ist darauf zu achten, daß neben dem histopathologischen Untersuchungsmaterial stets ausreichend Material für alle erforderlichen mikrobiologischen Untersuchungen gewonnen und adäquat verarbeitet wird. Bei der histopathologischen Diagnostik können spezielle Färbungen oder ultrastrukturelle Untersuchungen für den Nachweis bestimmter Erreger (z. B. Mykobakterien, Treponemen, Borrelien, Bartonellen, Pilze, Parasiten) erforderlich sein. Bei einer zunehmenden Zahl von Erregern stehen heute auch immunhistologische und molekularpathologische Nachweismethoden zur Verfügung (z. B. Zytomegalie, Herpesviren, Hepatitis B und $C)$. Entscheidend ist hier ebenfalls die gezielte Information des Pathologen durch den Kliniker, am besten mit Rücksprache bereits vor der Materialgewinnung.

\section{2 \\ Infektionssyndrome}

Häufig präsentieren sich Patienten unter einem klinischen Bild, bei dem klinische Verdachtsdiagnose und diagnostische Abklärung nicht von einer Infektionskrankheit durch einen spezifischen Erreger ausgehen, sondern bei dem sogenannte Infektionssyndrome im Vordergrund stehen. Diese können durch eine Vielzahl unterschiedlicher Erreger verursacht werden und sind entweder durch bestimmte systemische oder organbzw. organsystembezogene Krankheitsbilder (Sepsis, Meningitis, Enzephalitis, infektiöse Mononukleose und ähnliche Syndrome, infektiöse Enteritis, HIV-Infektion und Aids) gekennzeichnet oder betreffen spezifische Patientengruppen oder Umstände unter denen die Infektion erworben wurde (Fieber unbekannter Ursache, sexuell übertragbare Erkrankungen, importierte Infektionskrankheiten).

Weitere in anderen Kapiteln des speziellen Teils dargestellte internistische Infektionssyndrome sind Pneumonie (Kap. 19), Harnwegsinfektionen (Kap. 26), Endokarditis (Kap. 18) und Hepatitis (Kap. 23).

\subsection{1}

\section{Sepsis}

Die Sepsis ist eine durch eine Infektion ausgelöste systemische entzündliche Reaktion (SIRS) mit ausgeprägten Krankheitserscheinungen (Definition: Tabelle 22-2). 
Tabelle 22-2. Definition und klinische Kriterien der Sepsis und verwandter Störungen

Tabelle 22-3. Sepsisform (nach Häufigkeit) und vermutliches Keimspektrum

\begin{tabular}{|c|c|}
\hline Infektion & $\begin{array}{l}\text { Entzündliche Reaktion auf das Vorhandensein von Mikro- } \\
\text { organismen oder auf ihre Invasion von normalerweise ste- } \\
\text { rilem Gewebe }\end{array}$ \\
\hline Bakteriämie & Anwesenheit vermehrungsfähiger Erreger im Blut \\
\hline $\begin{array}{l}\text { Systemisches Entzündungs-Syn- } \\
\text { drom (SIRS, „systemic inflammato- } \\
\text { ry response syndrome“): systemi- } \\
\text { sche entzündliche Reaktion auf eine } \\
\text { Vielzahl schwerer Schädigungen } \\
\text { (Trauma, Ischämie, Verbrennung, } \\
\text { Infektion, Pankreatitis, hämorrhagi- } \\
\text { scher Schock, immunologisch be- } \\
\text { dingte Organschädigung, exogene } \\
\text { Gabe von Entzündungsmediatoren } \\
\text { u. a.) }\end{array}$ & $\begin{array}{l}\text { Mindestens } 2 \text { der folgenden Symptome: } \\
\text { - Fieber }\left(>38^{\circ} \mathrm{C} \text { ) oder Hypothermie }\left(<36^{\circ} \mathrm{C}\right)\right. \\
\text { - Tachykardie }>90 / \mathrm{min} \text {. (unklarer Genese) } \\
\text { - Atemfrequenz }>20 / \text { min oder arterieller pCO } \mathrm{CO}_{2}<32 \mathrm{mmHg} \\
\text { - Leukozyten }>12.000 / \mu \mathrm{l} \text { oder }<4000 / \mu \mathrm{l} \text { oder }>10 \% \mathrm{Stab} \text { - } \\
\text { keringe im Differentialblutbild }\end{array}$ \\
\hline Sepsis & SIRS + Infektion \\
\hline Schwere Sepsis & $\begin{array}{l}\text { Sepsis + Hypotonie (systolischer RR }<90 \mathrm{~mm} \mathrm{Hg} \text { oder Re- } \\
\text { duktion um }>40 \mathrm{mmHg} \text { vom Ausgangswert) und/oder Zei- } \\
\text { chen einer Organfunktionsstörung (z. B. Oligurie, Laktat- } \\
\text { anstieg, Bewußtseinsstörung) }\end{array}$ \\
\hline Septischer Schock & $\begin{array}{l}\text { Schwere Sepsis mit persistierender (trotz ausreichender } \\
\text { Volumensubstitution) bzw. katecholaminpflichtiger Hypo- } \\
\text { tonie zusammen mit Perfusionsstörungen, die zu Laktat- } \\
\text { azidose, Oligurie und/oder akuten Bewußtseinsstörungen } \\
\text { führen }\end{array}$ \\
\hline Multiorganversagen & $\begin{array}{l}\text { Vorliegen so schwerer Organfunktionsstörungen bei einem } \\
\text { akut kranken Patienten, daß eine Homöostase ohne Inter- } \\
\text { ventionen nicht aufrechterhalten werden kann }\end{array}$ \\
\hline
\end{tabular}

\begin{tabular}{|c|c|}
\hline Sepsisform & Häufigste Erreger \\
\hline $\begin{array}{l}\text { Urosepsis } \\
\text { - spontan } \\
\text { - nach Eingriff }\end{array}$ & $\begin{array}{l}\text { - E. coli, Enterobakterien, Pseudomonas } \\
\text { - Pseudomonas, Proteus, Enterobacter, Serratia }\end{array}$ \\
\hline $\begin{array}{l}\text { Sepsis vom weiblichen Genitale aus- } \\
\text { gehend }\end{array}$ & $\begin{array}{l}\text { - E. coli, Bacteroides spp., anaerobe Streptokokken, } \\
\text { haemolysierende Streptokokken, Gonokokken }\end{array}$ \\
\hline $\begin{array}{l}\text { Postoperative Sepsis } \\
\text { - Darm-/gynäkologische Operation } \\
\text { - Wundinfektion }\end{array}$ & $\begin{array}{l}\text { - Enterobakterien, Anaerobier } \\
\text { - resistente Staphylococcus aureus (MRSA), Enterobakte- } \\
\text { rien }\end{array}$ \\
\hline $\begin{array}{l}\text { Kathetersepsis und Fremdkörper- } \\
\text { sepsis }\end{array}$ & $\begin{array}{l}\text { - Resistente Staphylococcus aureus (MRSA), koagulase- } \\
\text { negative Staphylokokken, Enterokokken, Candida }\end{array}$ \\
\hline Infusionsassoziierte Sepsis & - Nonfermenter, kryophile Keime \\
\hline Beatmungssepsis & - Pseudomonas, E. coli, Klebsiellen, Serratia \\
\hline $\begin{array}{l}\text { Sepsis bei ambulant erworbenener } \\
\text { Pneumonie }\end{array}$ & - Pneumokokken, Haemophilus influenzae \\
\hline Sepsis bei Knochenmarkinsuffizienz & - Pseudomonas, E. coli, Enterobakterien, Staphylokokken \\
\hline Cholangiosepsis & - E. coli, Enterobakterien, Anaerobier (postoperativ) \\
\hline Akute Endokarditis & - Staphylokokken \\
\hline Meningitis & - Meningokokken, Penumokokken \\
\hline Osteomyelitis & - Staphylococcus aureus \\
\hline Sepsis nach Hautverletzung & - Staphylokokken, Streptokokken \\
\hline Sepsis bei Verbrennung & - Staphylokokken, Pseudomonas, Enterobakterien \\
\hline Dentogene/tonsillogene Sepsis & $\begin{array}{l}\text { - Streptokokken, Staphylokokken, Anaerobier (schwerer } \\
\text { Verlauf, postoperativ) }\end{array}$ \\
\hline Sepsis nach Tierbiß & - Pasteurella multocida, Capnocytophaga spp. \\
\hline $\begin{array}{l}\text { Sepsis bei Splenektomierten bzw. } \\
\text { funktioneller Asplenie }\end{array}$ & $\begin{array}{l}\text { - Pneumokokken, Haemophilus influenzae, Meningokok- } \\
\text { ken, Salmonellen, Babesien }\end{array}$ \\
\hline
\end{tabular}


Während die klassische Definition das Vorhandensein von dauernd oder schubweise im Blut nachweisbaren Erregern forderte, umfaßt der heutige Sepsisbegriff alle als SIRS definierten systemischen Entzündungs-Syndrome im Zusammenhang mit einer nachgewiesenen oder wahrscheinlichen Infektion. Dabei ist es unerheblich ob SIRS die Folge einer hämatogenen Generalisierung ist oder durch Toxine der Erreger bzw. durch eine Infektion ohne hämatogene Ausbreitung verursacht wird.

Bakterielle Erreger werden am häufigsten als Ursache einer Sepsis nachgewiesen (seltener auch Pilze). Häufig besteht eine Blutstrominvasion der Erreger (positive Blukulturen in 50-60\%), die von einem in der Mehrzahl der Fälle nachweisbaren oder klinisch wahrscheinlichen Sepsisherd ausgeht (Tabelle 22-3). Es kann zur hämatogenen Absiedlung septischer Metastasen in verschiedenen Organen einschließlich der Haut kommen (Tabelle 22-4). Teilweise ist die Eintrittspforte der Erreger jedoch nicht oder nicht mehr nachzuweisen (primäre Sepsis) oder von sekundären septischen Metastasen klinisch nicht zu differenzieren. Sepsis und Sepsisrezidive unter Therapie können auch von solchen sekundären Metastasen unterhalten werden. Vor allem bei abwehrgeschwächten Patienten kann die Invasion der Erreger auch von physiologisch besiedelten Schleimhäuten (Gastrointestinaltrakt, Atemwege, Urogenitaltrakt) ausgehen, ohne daß eine lokale Infektion oder Organschädigung vorliegt.

Tabelle 22-4. Septische Metastasierung bei den häufigsten Sepsiserregern

\begin{tabular}{ll}
\hline Erreger & Metastasierung \\
\hline $\begin{array}{l}\text { Staphylococcus } \\
\text { aureus }\end{array}$ & $\begin{array}{l}\text { Haut, Gehirn, Niere, Endokard, Lunge, } \\
\text { Knochen }\end{array}$ \\
Streptokokken & Haut, Gelenke \\
Enterokokken & Endokard \\
Pneumokokken & Meningen, Haut, Gelenke \\
Meningokokken & Haut, Meningen, Gelenke \\
Anaerobier & Beckenvenen, Lunge, Leber, Gehirn \\
Salmonellen & Knochen, parenchymatöse Organe \\
Gonokokken & Haut, Gelenke \\
\hline
\end{tabular}

\subsubsection{1}

\section{Anamnese, Symptome und Befunde}

Die Vorgeschichte gibt häufig entscheidende Hinweise auf die Art bzw. mögliche Ausgangsherde der Sepsis (Tabelle 22-3). Wichtige Grunderkrankungen und Risikofaktoren sind

- pyämische Lokalinfektionen (z. B. Harnwegsinfektion, Gallenblasenempyem, Divertikulitis, Bronchiektasen, Weichteil- und Organabszesse, Pneumonie, Meningitis, Endokarditis),
- intravasale und sonstige Fremdkörper (z. B. Venenkatheter, künstliche Herzklappen, Urinkatheter),

- vorausgegangene Traumen, Operationen und instrumentelle Eingriffe,

- Tumorerkrankungen,

- Abwehrschwäche (z. B. Knochenmarkinsuffizienz, Antikörpermangelsyndrom, Splenektomie, Diabetes mellitus, Leberzirrhose, Alkoholismus, i.v.-Drogenabusus).

Der klinische Verdacht hinsichtlich dem Vorliegen einer Sepsis liegt nahe bei folgenden Symptomen:

- intermittierendes hohes Fieber,

- Schüttelfröste,

- Nausea, Erbrechen,

- Unruhe, Verwirrtheit, Bewußtseinsstörungen,

- Atemnot und Herzjagen

und bei folgenden Befunden:

- Hyper- oder Hypothermie,

- Tachykardie,

- Hypotonie,

- Tachypnoe,

- Splenomegalie.

Vor allem bei sehr jungen oder alten Patienten, bei Abwehrschwäche, schweren Grundleiden und antibiotischer Vorbehandlung können eindeutige Symptome jedoch fehlen und z. B. eine unklare Hypotension mit Verwirrtheit, Somnolenz oder Hyperventilation die einzigen Symptome darstellen.

Bei einem Teil der Patienten liegen Hauterscheinungen vor in Form von Hämorrhagien (Petechien, Ekchymosen; besonders bei Meningokokkensepsis) und/ oder vesikulopustulösen septischen Metastasen (Staphylokokken, Streptokokken, Pneumokokken, Gonokokken) z. T. mit Ulzeration (z. B. Ecthyma gangraenosum; besonders bei Pseudomonassepsis).

Insbesondere bei gramnegativer Sepsis (Endotoxine) kann eine klinisch relevante disseminierte intravasale Gerinnungsstörung mit Verbrauchskoagulopathie auftreten.

Der Übergang zum septischen Schock ist fließend (Tabelle 22-2). In der Frühphase besteht meist ein Vasomotorenkollaps mit warmer Peripherie (warme rote Haut) und deutlich verlangsamter Reperfusion (z. B. von Fingerdruckstellen). In der Folge kommt es zu Blutdruckabfall, Oligurie, zunehmender Hyperventilation und Bewußtseinsstörung mit motorischer Unruhe. Der septische Schock entwickelt sich häufig rasch weiter mit Zentralisierung (kalte Marmorierung), Bewußtseinsstörung bis zum Koma, Kreislaufzusammenbruch und Multiorganversagen (akutes Atemnotsyndrom, Nierenversagen, Leberversagen, hypoxische Schädigung intestinaler Organe und von Myokard und ZNS). 


\subsubsection{2}

\section{Diagnostik}

Entscheidend ist die möglichst frühzeitige Stellung der Verdachtsdiagnose einer Sepsis aufgrund klinischer Kriterien (Tabelle 22-2). Diese kann durch Laborbefunde (s. unten) unterstützt aber nicht bewiesen werden. Für Auswahl und Modifikation der antimikrobiellen Initialtherapie, die als empirische Interventionstherapie begonnen wird, sollte stets versucht werden, wahrscheinliche Sepsisform und mögliche Sepsisherde aufgrund von Vorgeschichte (Grunderkrankungen, Risikofaktoren), Klinik und Untersuchungsbefunden $\mathrm{zu}$ identifizieren (Tabelle 22-3). Voraussetzung für Anpassung bzw. Fortführung der Initialtherapie in Form einer gezielten antimikrobiellen Therapie ist der Nachweis des bzw. der Sepsiserreger. Folgende diagnostische Schritte sind nötig:

- Abnahme von mehreren Blutkulturen (BK) vor Beginn der antimikrobiellen Therapie unter Beachtung folgender Kautelen: jeweils gesonderte sterile Punktion einer peripheren Vene nach sorgfältiger Hautdesinfektion (alkoholische Desinfektionsmittel, Einwirkzeit $1 \mathrm{~min}$ ), jeweils aerobe und anaerobe Kultur, vorgewärmte BK-Flaschen, sofortige Bebrütung; Transport und Verarbeitung s. Teil A, Kap. 3.

- In bedrohlichen Fällen Abnahme von 2-3 BK in kurzen Abständen (10-20 min) und sofortiger Beginn der empirischen antimikrobiellen Therapie (Interventionstherapie). Die Beimpfung von mindestens 2 BK-Sets stellt sicher, daß ein ausreichendes Blutvolumen verarbeitet und die Erkennung von Kontaminanten erleichtert wird.

- Bei Verdacht auf katheterassoziierte Sepsis: wenn der Katheter entfernt werden kann (oft gleichzeitig die entscheidende therapeutischeMaßnahme) mikrobiologische Untersuchung von Katheterspitze bzw. Segmenten (Teil A, Kap. 3),

- ansonsten BK jeweils aus peripherer Vene (s. oben) und Katheter (quantitative BK z. B. mit Isolatorsystem empfehlenswert; 5- bis 1ofach höhere Koloniezahl im über Katheter entnommenen Blut spricht für katheterassoziierte Sepsis).

- Zusätzliche Kulturen von Urin, Sputum, Stuhl, Nasen-Rachen-Abstrich, Liquor (bei allen komatösen Patienten und bei allen unklaren Sepsisfällen) sowie ggf. von Wundabstrichen, Abszeßpunktaten, septischen Hautmetastasen und allen sonstigen infektionsverdächtigen lokalen Prozessen.

- Gegebenenfalls Schnelltests (s. Teil A, Kap. 3) zum Nachweis erregerspezifischer Antigene (B-Streptokokken, A/C-Meningokokken, Escherichia coli, Haemophilus influenzae Typ B, Pneumokokken, Pseudomonas, ggf. Candida, Cryptococcus) in Serum, Urin, Liquor und Sputum (auch nach antibiotischer Anbehandlung sinnvoll).
- Klinischer Status, (Fremd-)Anamnese, Labordiagnostik (s. unten) und apparative Diagnostik (s. unten) mit besonderer Berücksichtigung möglicher (auch anscheinend banaler) Sepsisherde bzw. Eintrittspforten (Tabelle 22-3) und evtl. septischer Metastasen (Tabelle 22-4). Erfassung, Dokumentation und Verlaufskontrolle des Schweregrades (z. B. Apache-II-Score).

Anmerkungen: Genaue Angaben an den Mikrobiologen (Teil A, Kap. 3) zu Vorgeschichte, Grunderkrankungen und klinischem Bild (inklusive möglicher Sepsisherde) sind von großer Bedeutung für Auswahl und Umfang der mikrobiologischen Untersuchungen (z. B. Berücksichtigung opportunistischer Erreger bei Immunkompromittierten).

Bei Patienten, die sich zuvor in einem Malariagebiet aufgehalten haben, ist immer eine Malaria auszuschließen (s. Abschn. 22.6.1), da diese klinisch nicht sicher von einer Sepsis zu unterscheiden ist.

\section{Laboruntersuchungen}

Hämatologische und klinisch-chemische Befunde können eine Sepsis weder beweisen noch widerlegen, sie sind jedoch essentiell für die Beurteilung des Schweregrads der Erkrankung, Art und Ausmaß von Organfunktionsstörungen sowie für die Verlaufskontrolle.

Häufig bestehen Leukozytose mit Linksverschiebung (z. T. jedoch auch Leukopenie), Thrombopenie und Laktatämie.

Es sollte bestimmt werden: komplettes Blutbild, Gerinnungsparameter (Quick, PTT, Fibrinogen, Fibrinspaltprodukte, AT III), arterielle Blutgase, Elektrolyte, Glukose, Kreatinin, Transaminasen, alkalische Phosphatase, Bilirubin, Kreatinkinase, Laktat, CRP und Urinstatus. Der Procalcitoninspiegel ist bei Sepsis und anderen systemischen Infektionen durch Bakterien, Pilze und Malaria erhöht und kann zur Differenzierung von viralen Infektionen und SIRS nichtinfektiöser Genese herangezogen werden. Die Bestimmung von weiteren Entzündungsparametern und von Zytokinen gehört derzeit nicht zur Routinediagnostik.

\section{Apparative Untersuchungen}

EKG (zusätztlich zur Monitorüberwachung), Thoraxröntgenaufnahme und abdominelle Sonographie gehören zur Basisdiagostik (Nachweis möglicher Sepsisherde, septischer Metastasen und Organkomplikationen) und müssen bei klinischem Verdacht entsprechender Organkomplikationen im Verlauf wiederholt werden.

Die Indikation zur weiteren bildgebenden Diagnostik richtet sich nach klinischem Bild, weiteren Befunden und Grunderkrankungen bzw. Vorgeschichte. Computer- und/oder kernspintomographisch können intraabdominale, intrathorakale oder intrakranielle Organ- oder Weichteilinfektionen nachweisbar sein, 
die sich ansonsten nicht oder nur unzureichend darstellen lassen. Echokardiographisch ist v. a. nach Vegetationen und Perikardergüssen zu fahnden.

Endoskopische Untersuchungen des Intestinaltrakts sind indiziert bei Blutungskomplikationen, Verdacht auf Sepsisquelle im Intestinaltrakt (z. B. Tumore, Divertikulose) und Sepsis mit Durchfällen (z. B. pseudomembranöse Kolitis meist nach antibiotischer Vorbehandlung).

Gegebenenfalls muß Material zur Kultur durch Punktionen (z. B. Leberabszesse, Pleuraempyeme) oder auch durch chirugische Inzision/Drainage (z. B. postoperative Wundinfektionen, Pyarthros) gewonnen werden.

\subsection{2}

\section{ZNS-Infektionen}

\subsubsection{1}

Meningitis

Meningitiden werden meist durch Bakterien oder Viren, seltener durch Pilze oder Parasiten verursacht. Ein Patient mit Verdacht auf eine bakterielle Meningitis ist stets ein Notfall (Letalität 10-30\%). Im Gegensatz zu den bakteriellen ist bei den viralen Meningitiden die klinische Symptomatik meist geringer ausgeprägt und der Verlauf fast immer gutartig.

\section{Klinischer Diagnoseverdacht}

Der Verdacht auf das Vorliegen einer Meningitis ergibt sich meist ohne Schwierigkeiten bei typischen Symptomen wie

- Fieber,

- Meningismus,

- Kopfschmerzen,

- Lichtscheu,

- Nausea und Erbrechen,

- in schweren Fällen auch Bewußtseinsstörungen bis zum Koma und Krampfanfälle.

Bei der klinischen Untersuchung fallen meist Nackensteife, positive Kernig- und Brudzinski-Zeichen auf. Vor allem bei sehr jungen oder alten Patienten, Alkoholikern und Immunkompromittierten können typische Symptome und Befunde jedoch fehlen und wenig charakteristische Bilder mit Apathie, Wesensveränderung und Bewußtsteinsstörungen bis zum Koma im Vordergrund stehen.

Die tuberkulöse Meningitis (2-5\% der bakteriellen Meningitiden in Deutschland) verläuft meist subakut und beginnt mit Kopfschmerzen, Apathie, Wesensveränderungen und subfebrilen Temperaturen. Im weiteren Verlauf kommen Fieber, Meningismus, Nausea und Erbrechen hinzu. Da bevorzugt die Hirnbasis befallen ist, sind Hirnnervenlähmungen (z. B. Abducensparese) häufiger; weitere Manifestationen und Komplikationen sind SIADH mit Hyponatriämie, spastische Paresen, tonisch-klonische Krämpfe, Querschnittssyndrome, Hydrozephalus und zunehmende Eintrübung bis zum Koma. Am Augenhintergrund sind gelegentlich Tuberkelknötchen zu sehen.

\section{Erstmaßnahmen}

Die unverzügliche Einleitung einer antibiotischen Therapie bei akut Erkrankten und die schnelle Klärung der Ätiologie als Grundlage einer gezielten Therapie sind vorrangig.

Bei perakutem Krankheitsbeginn mit Bewußtseinsstörung $(<24 \mathrm{~h})$ ist der sofortige Therapiebeginn zur Vermeidung von Frühtodesfällen entscheidend:

- Legen eines venösen Zugangs,

- Abnahme einer Blutkultur,

- sofortiger Beginn der empirischen antimikrobiellen Initialtherapie (Interventionstherapie)

Dann erst eingehende Untersuchung und Liquorgewinnung (s. unten). Bei voraussichtlich längerdauerndem (>2 h) Transport zur nächsten Klinik (ggf. Rettungshubschrauber) ist in diesen Fällen der Beginn einer parenteralen Antibiotikatherapie auch gerechtfertigt, wenn keine Blutkultur angelegt werden kann. Ansonsten kein Therapiebeginn vor Klinikeinweisung, Blutkulturabnahme und Liquorgewinnung.

\section{Diagnostik}

- Bei wachen Patienten ohne ausgeprägte neurologische Herdsymptome und ohne Stauungspapille (beidseitige Augenhintergrundspiegelung) muß ohne Verzögerung Liquor entnommen werden (bei Erwachsenen durch Lumbalpunktion).

- Bei soporösen oder komatösen Patienten und/oder bei ausgeprägten Herdsymptomen oder Stauungspapille soll zunächst mittels kranialer Computertomographie (CCT) geklärt werden, ob eine Liquorpunktion gefahrlos möglich ist. In diesen Fällen sollte zur Vermeidung von Zeitverlust die antibiotische Behandlung vor der Liquorentnahme begonnen werden. Stellt sich in der CCT ein schweres Hirnödem oder eine Raumforderung mit Mittellinienverlagerung dar, soll auf die Liquorentnahme verzichtet werden.

- Der Liquor muß umgehend mikroskopisch und biochemisch (s. Teil A, Abschn 2.19) sowie mikrobiologisch (Teil A, Kap. 3) untersucht werden; stets Grampräparat (auch bei fehlender Pleozytose!). Die Liquorprobe soll rasch dem mikrobiologischen Labor zur sofortigen Bearbeitung zugeführt werden. Ist dies nicht möglich, Lagerung und Transport bei $37^{\circ} \mathrm{C}$ und sofortige Verimpfung (v. a. Meningokokken sind sehr empfindlich) von je $2 \mathrm{ml}$ (bei Kindern ggf. weniger) in aerob und anaerob zu bebrütende Blutkulturen. 
- Der Mykobakteriennachweis (Ziehl-Neelsen-Präparat, Kultur) ist nicht sehr sensitiv; eine PCR sollte daher in allen Verdachtsfällen (s. oben) zusätzlich veranlaßt werden.

- Bei Immunkompromittierten zusätzlich Kryptokokkosediagnostik (s. Abschn. 22.2.5).

- Bei purulentem Liquor ohne Bakterien- oder Pilznachweis muß auch an eine primäre Amöbenmeningoenzephalitis (Tabelle 22-26) gedacht werden.

- Stets Blutkultur und Rachenabstrich; HNO-ärztliche Untersuchung (Infektionsherde), Thoraxröntgenaufnahme (Pneumonie, Tuberkulose), klinischer und Laborstatus, (Fremd-)anamnese.

- Lebensalter, Vorgeschichte (Grunderkrankungen) und Untersuchungsbefunde geben wichtige Hinweise auf vermutliche Genese und zu erwartendes Erregerspektrum (Tabelle 22-5).

Die Liquorbefunde zeigt Tabelle 22-6. Die bakterielle Meningitis zeigt typischerweise einen trüben (eitrigen) Liquor mit polymorphzelliger Pleozytose (Zellzahl $>1000 / \mu \mathrm{l})$, erhöhtem Eiweiß, LDH und Laktat sowie erniedrigter Glukose ( $<60 \%$ der Blutglukose). Auch virale Meningitiden können manchmal mit Zellzahlen $>1000 / \mu \mathrm{l}$ (meist vorwiegend monolymphozytär, initial auch granulozytär!) einhergehen. Umgekehrt findet man auch bei bakterieller Meningitis gelegentlich niedrige Zellzahlen (initial, perakuter Beginn; tuberkulöse, anbehandelte, Listerienmeningitis) mit serösem Liquor.

In bis zu $80 \%$ der unbehandelten bakteriellen Meningitiden läßt sich im Grampräparat eine vorläufige mikroskopische Diagnose stellen (Pneumokokken, Meningokokken, Haemophilus influenzae, gramnegative Stäbchen) mit entscheidender Bedeutung für die Wahl der Initialtherapie. Vor allem bei negativem Grampräparat und antibiotischer Vorbehandlung können Schnelltests (Teil A, Abschn. 3.6.3) auf keimspezifi-
Tabelle 22-5. Hinweise auf das vermutliche Erregerspektrum bei akuter Meningitis

\begin{tabular}{|c|c|}
\hline Hinv & Mö \\
\hline $\begin{array}{l}\text { Alter: } \\
\text { - Neugeborene } \\
\text { - } 6 \text { Wochen bis } \\
\text { ca. } 6 \text { Jahre } \\
\text { - > } 6 \text { Jahre }\end{array}$ & $\begin{array}{l}\text { - E. coli, B-Streptokokken, Listerien und } \\
\text { Enterobakterien } \\
\text { - Haemophilus influenzaea, Pneumokok- } \\
\text { ken, Meningokokken } \\
\text { - Pneumokokken, Meningokokken }\end{array}$ \\
\hline $\begin{array}{l}\text { Kontaktfälle in der } \\
\text { Umgebung }\end{array}$ & $\begin{array}{l}\text { Meningokokken, Haemophilus influenzae } \\
\text { (Kinder }<6 \text { Jahre) }{ }^{\mathrm{a}}\end{array}$ \\
\hline & $\begin{array}{l}\text { Enterobakterien, Staphylococcus aureus, } \\
\text { Pseudomonas }\end{array}$ \\
\hline & $\begin{array}{l}\text { Pneumokokken, Enterobakterien, Sta- } \\
\text { phylococcus aureus }\end{array}$ \\
\hline Sinusitis, Otitis & $\begin{array}{l}\text { Haemophilus influenzae } \\
\text { Ta }\end{array}$ \\
\hline $\begin{array}{l}\text { Chroni } \\
\text { Alkoho }\end{array}$ & Listerien, Pneumokokken \\
\hline $\begin{array}{l}\text { Immunsuppres- } \\
\text { sion }\end{array}$ & $\begin{array}{l}\text { kterien, Listerien, Kryptokok- } \\
\text { Pilze, Pneumokokken, Myko- }\end{array}$ \\
\hline $\begin{array}{l}\text { Eitrige Meningitis } \\
\text { ohne Bakterien- } \\
\text { nachweis im } \\
\text { Grampräparat }\end{array}$ & $\begin{array}{l}\text { Listerien, Mykobakterien, Kryptokokken } \\
\text { u. a. Pilze, primäre Amöbenmeningo- } \\
\text { enzephalitis (s. Tabelle 22-26) }\end{array}$ \\
\hline $\begin{array}{l}\text { Seröse (asepti- } \\
\text { sche) Meningitis }\end{array}$ & $\begin{array}{l}\text { Virusmeningitis, Listeriose, tuberkulöse } \\
\text { Meningitis, Neuroborreliose, Leptospiro- } \\
\text { se, Kryptokokkose, Brucellose, Rickett- } \\
\text { siosen }\end{array}$ \\
\hline
\end{tabular}

${ }^{a}$ Geringe Wahrscheinlichkeit bei vollständig geimpften Kindern.

sche Antigene (A/C-Meningokokken, Haemophilus influenza Typ B, Pneumokokken, B-Streptokokken, Kryptokokken) im Liquor, Serum und/oder Urin einen Hinweis auf die Ätiologie geben.

Weitere Diagnostik: Bei bakterieller Meningitis und Verdacht auf fokale Infektionsquelle sind zusätzliche
Tabelle 22-6. Typische Liquorbefunde bei der bakteriellen, viralen und tuberkulösen Meningitis

\begin{tabular}{|c|c|c|c|}
\hline Parameter & Bakterielle Meningitis & Virale Meningitis & Tuberkulöse Meningitis \\
\hline $\begin{array}{l}\text { Liquordruck } \\
\left(\mathrm{cm} \mathrm{H}_{2} \mathrm{O}\right)\end{array}$ & - Meist erhöht (>20) & - Normal $(<20)$ & - Variabel \\
\hline $\begin{array}{l}\text { Leukozytenzahl } / \mu \mathrm{l}^{\mathrm{a}} \\
(\text { Normalwert: bis } 12 / 3 \\
=4 / \mu \mathrm{l})\end{array}$ & - Meist > 1000 & - Meist $<1000$ & - Meist $<1000$ \\
\hline Dominante Zellart & $\begin{array}{l}\text { - Neutrophile Granu- } \\
\text { lozyten }\end{array}$ & - Lymphozyten & $\begin{array}{l}\text { - Lymphozyten/Mono- } \\
\text { zyten (Granulozyten) }\end{array}$ \\
\hline $\begin{array}{l}\text { Eiweißkonzentration } \\
{[\mathrm{g} / \mathrm{l}] \text { (Normalwert: bis }} \\
0,45 \mathrm{~g} / \mathrm{l})\end{array}$ & $>1,0$ & $<1,0$ & $>1,0$ \\
\hline $\begin{array}{l}\text { Laktatkonzentration } \\
\text { (mmol/1; Normalwert: } \\
\text { bis } 2,2 \mathrm{mmol} / \mathrm{l} \text { ) }\end{array}$ & $>3,5$ & $<3,5$ & $>3,5$ \\
\hline $\begin{array}{l}\text { Glukosekonzentration } \\
\text { (Normalwert: } 70-80 \% \\
\text { des BZ) }\end{array}$ & $\downarrow$ & - Normal & $\downarrow$ \\
\hline
\end{tabular}

${ }^{a}$ Erfolgt die Zellzählung in einer Fuchs-Rosenthal-Kammer, bei der das Füllungsvolumen eines Quadrats

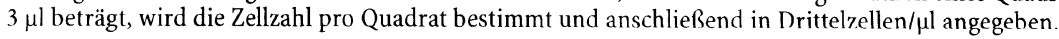


apparative bzw. bildgebende diagnostische Maßnahmen erforderlich:

- CCT bei Sinusitis, Otitis, Verdacht auf intrazerebrale oder parameningeale Läsionen, mögliche posttraumatische oder postoperative Infektionsherde;

- Echokardiographie bei Verdacht auf Endokarditis (besonders bei Staphylococcus-aureus-Meningitis).

Bei seröser Menigitis richtet sich die Indikation für zusätzliche mikrobiologische Untersuchungen nach Schweregrad, klinischem Verlauf (akut, subakut, chronisch), Vorgeschichte und sonstigen Befunden. Von besonderer Bedeutung ist dabei die Diagnose bzw. der Ausschluß einer Herpes-simplex-Meningoenzephalitis (s. Enzephalitis) wegen des oft schweren Verlaufs und der Möglichkeit einer spezifischen Therapie. Bei zahlreichen weiteren Viren (Tabelle 22-7) ist der Nachweis mittels PCR und Antikörperdiagnostik im Liquor und Serum (s. Enzephalitis) möglich, in der Regel ergibt sich jedoch keine therapeutische Konsequenz. Nach Auslandsaufenthalten ist auch an exotische Viren (z. B. japanische Enzephalitis) zu denken (s. Abschn. 22.4.10).

Tabelle 22-7. Häufige Erreger viraler Meningitiden und Enzephalitiden

\begin{tabular}{lcc} 
Erreger & Meningitis [\%] & Enzephalitis [\%] \\
\hline Enteroviren & 40 & 20 \\
Mumpsvirus & 25 & 10 \\
Herpes-simplex-Virus & 1 & 15 \\
Andere Herpesviren & 1 & 5 \\
LCM-Virus & 5 & 5 \\
Masern & 5 & 10 \\
HIV & 1 & 10 \\
Arboviren (FSME u. a.) & 10 & 5 \\
Andere Erreger & 20 & 20
\end{tabular}

${ }^{a}$ LCM: lymphozytäre Choriomeningitis.

\subsubsection{2}

\section{Enzephalitis und Myelitis}

Häufigste Erreger sind Viren (Tabelle 22-7), die je nach Lokalisation zur diffusen oder herdförmigen Enzephalitis, Meningitis, Myelitis oder Radikulomyelitis führen oder nicht selten auch zu kombiniert auftretenden Manifestationen (Enzephalomyelomeningitis). Bakterien, Pilze und Parasiten verursachen meist keinen generalisierten Befall des Hirnparenchyms, sondern manifestieren sich vorwiegend als Hirnabszeß oder Herdenzephalitis (s. unten).

3 ätiologisch unterschiedliche Formen virusinduzierter Erkrankungen des Hirnparenchyms lassen sich unterscheiden:

- akute und subakute Enzephalitiden und Myelitiden (direkt erregerbedingt),
- post- oder parainfektiöse Enzephalomyelitiden (immunpathogenetisch bedingt),

- Slow-virus-Infektionen des ZNS (langsam progredienter Krankheitsprozeß bei persistierendem Erreger).

Virusmyelitiden sind seltener als Meningitiden oder Enzephalitiden und werden vermutlich relativ häufig von Herpesviren verursacht. Querschnittsmyelitiden können sich sowohl durch direkten Virusbefall als auch im Rahmen eines immunpathogenetischen Prozesses (post- oder parainfektiös) entwickeln. Manche Viren weisen eine besondere Affinität zu bestimmten ZNSStrukturen auf (z. B. Poliovirus: 2. Motoneuron; Tollwut- und Herpes-simplex-Virus: limbisches System). Immunpathogenetisch entstandene Enzephalitiden spielen sich im Marklager bzw. in der weißen Substanz ab. Bei ihnen ist die Viruspenetration in das ZNS nicht erforderlich. Sie entwickeln sich vielmehr im Rahmen eines virusinduzierten, T-Zell- oder Makrophagen-vermittelten Entmarkungsprozesses.

\section{Klinischer Diagnoseverdacht}

Die Symptomatik ist vielgestaltig und abhängig von den befallenen Strukturen. Häufige Symptome einer Enzephalitis sind Vigilanzstörungen, Benommenheit bis zur Bewußtlosigkeit, neurologische Herdsymptome wie Paresen, Krampfanfälle, extrapyramidalmotorische Symptome und Hirnnervenstörungen sowie psychotische Symptome. Zudem sind hypothalamisch-hypophysäre Störungen möglich (Hyper/Hypothermie, Diabetes insipidus, SIADH). Der Fieberverlauf ist variabel, z. T. auch a- oder subfebril. Bei meningealer Beteiligung kommt es zusätzlich zu Kopfschmerzen, Nakkensteife, Lichtscheu, Übelkeit und meist zu Fieber.

Bei Myelitis und Radikulitis finden sich Paresen (initial meist schlaff), Schmerzen und Sensibilitätsstörungen (nicht bei Poliomyelitis); Komplikationen sind Blasen- und Enddarmlähmung, Querschnittssyndrome und Atemmuskellähmung mit respiratorischer Insuffizienz.

\section{Erstmaßnahmen}

Von besonderer Bedeutung sind rasche Diagnose und Behandlung einer Herpes-simplex-Virus(HSV)-Enzephalitis (Letalität unbehandelt $>70 \%$ ). Der Verdacht ergibt sich bei

- typischerweise biphasischer Vorgeschichte mit grippalem Prodromalstadium und anschließenden neurologischen Herdysymptomen (Krampfanfälle, Paresen) und/oder

- Bewußseinsstörung mit gering- bis mäßiggradiger Liquorpleozytose $(5-350 / \mu l)$.

Diese Befundkonstellation ist eine Indikation für eine 
umgehende Magnetresonanztomographie (MRT, s. unten) und den Beginn der empirischen antiviralen Therapie gegen HSV. Zur Verifizierung der Diagnose dient der PCR-Nachweis von HSV im Liquor. Die kraniale Computertomographie (CCT) ist in der Frühphase häufig unauffällig. Bleibt die diagnostische Zuordnung zunächst unklar, so soll die begonnene Therapie fortgesetzt werden, bis die Ergebnisse der PCR vorliegen.

\section{Diagnostik}

Das Liquorsyndrom der viralen Enzephalitis und Myelitis entspricht meist dem der viralen Meningitis (Tabelle 22-6); die Pleozytose ist oft gering ausgeprägt, selbst normale Liquorleukozytenzahlen kommen vor. Nur in ca. $50 \%$ aller Virusenzephalitiden gelingt die Identifikation des Erregers (Tabelle 22-7). Klinisch am bedeutendsten sind die Enzephalitiden durch Viren der Herpesgruppe, weil sie schwerer verlaufen und spezifisch therapiert werden können.

Die Diagnostik der viralen ZNS-Erkrankungen ist durch die modernen bildgebenden und gentechnologischen Verfahren einfacher geworden:

- Die MRT hat für die Diagnostik viraler Enzephalitiden und Myelitiden eine große Bedeutung erlangt. Durch sie lassen sich entzündliche Herde früher und mit höherer Auflösung als in der CCT darstellen. Besonders sensitiv sind $\mathrm{T}_{2}$-gewichtete und FLAIR-Sequenz, die Regionen mit erhöhtem Wassergehalt (Entzündung, Ödem) hyperintens erscheinen lassen. Die in der MRT sichtbaren Läsionen geben Hinweise auf den verursachenden Erreger (bei HSV-Enzephalitis vorwiegend temporobasal, periinsulär und zingulär gelegene Läsionen mit Beteiligung der grauen Substanz) oder den Pathomechanismus. So muß bei auf das Marklager beschränkten Läsionen ohne HSV-Nachweis und fehlender Beteiligung des Temporallappens an eine akute demyelinisierende Enzephalitis (ADEM) gedacht werden.

- Das Elektroenzephalogramm eignet sich in den meisten Fällen nur für die Beschreibung der Funktionsstörungen und nicht für die ätiologische $\mathrm{Zu}$ ordnung. Bei der subakuten sklerosierenden $\mathrm{Pa}$ nenzephalitis sowie bei den spongiformen Enze- phalopathien haben typische EEG-Veränderungen aber eine hohe diagnostische Spezifität.

- Der verantwortliche Erreger kann mit Hilfe verschiedener Methoden identifiziert werden: Der Nachweis von Virusgenom mittels PCR (Teil A, Kap. 3, Tabelle 3-10) zeichnet sich unter optimalen Bedingungen durch hohe Spezifität und Sensitivität aus und ist für verschiedene Viren (Herpesviren, JC-Virus, HIV, Enteroviren u. a.) evaluiert. Ein negatives PCR-Ergebnis schließt eine Herpesvirusenzephalitis mit hoher Wahrscheinlichkeit aus. Die PCR wird erst nach einigen Tagen effektiver Therapie negativ.

- Die Antikörperdiagnostik ist nur aussagekräftig beim Nachweis einer signifikanten intrathekalen Produktion des untersuchten erregerspezifischen Antikörpers (Teil A, Kap. 3). Erhöhte Antikörperspiegel werden intrathekal (wie auch peripher) meist erst mit einer Latenz von ein bis zwei Wochen nachweisbar und sind im frühen, akuten Stadium daher oft falsch-negativ.

- Der direkte Virusnachweis aus Liquor oder Biopsiematerial (Elektronenmikroskopie, Zellkultur, Nachweis virusspezifischer Antigene) wird in der Regel nur in ausgewählten Fällen angewandt. Die Hirnbiopsie stellt eine Ultima ratio dar und ist nur noch bei anderweitig nicht identifizierbaren entzündlichen ZNS-Prozessen rascher Progredienz indiziert, um behandelbare Ursachen zu erkennen.

\subsubsection{3}

\section{Hirnabszeß und septische Herdenzephalitis}

Als Erreger kommen zahlreiche Bakterien (häufig polymikrobiell unter Beteiligung von Anaerobiern), aber auch Pilze und Parasiten in Frage (Tabelle 22-8). Ätiologie: in ca. $50 \%$ fortgeleitet von primären Infektionen benachbarter Strukturen (Mittelohr, Nasennebenhöhlen, dentogene Infektionen); gelegentlich auch als Folge von Schädel-Hirn-Trauma, penetrierender SchädelHirn-Verletzung oder neurochirurgischen Eingriffen; selten als Komplikation einer bakteriellen Meningitis. In ca. $25 \%$ läßt sich ein hämatogener Streuherd nachweisen (z. B. Bronchiektasen, Pneumonie, Lungenab-
Tabelle 22-8. Wichtigste Erreger bei Hirnabszeß und Herdenzephalitis

\begin{tabular}{lll}
\hline Bakterien (Häufigkeit) & Pilze & Parasiten \\
\hline $\begin{array}{l}\text { Streptokokken (40\%) (vorzugsweise Streptococcus } \\
\text { milleri und andere vergrünende und nichthämoly- } \\
\text { sierende Arten, aber auch obligat anaerobe Erreger } \\
\text { des Genus Peptostreptococcus) }\end{array}$ & $\begin{array}{l}\text { Aspergillus } \\
\text { Mucor }\end{array}$ & $\begin{array}{l}\text { Toxoplasmen } \\
\text { Acanthamoeba }^{\mathrm{a}}\end{array}$ \\
$\begin{array}{l}\text { Bacteroides-Spezies }(10-15 \%) \\
\text { Kryptokokken }^{\mathrm{a}}\end{array}$ & $\begin{array}{l}\text { Zystizerkose } \\
\text { Echinokokkose } \\
\text { Gramnegative Stäbchenbakterien }(15 \%)^{\mathrm{a}}\end{array}$ & $\begin{array}{l}\text { E. histolytica } \\
\text { Staphylococcus aureus (15\%) }\end{array}$ \\
$\begin{array}{l}\text { Nocardia und Actinomyces } \\
\text { Mykobakterien }^{\mathrm{a}}\end{array}$ & & \\
\hline
\end{tabular}

a Besonders bei Immunkompromittierten. 
szeß, Endokarditis). Bei Vitien mit Rechts-links-Shunt oder arteriovenösen Mißbildungen der Lunge besteht ein erhöhtes Risiko.

\section{Klinischer Diagnoseverdacht}

Die klinische Symptomatik ist variabel und hängt $a b$ von Zahl, Größe und Lokalisation der Abszesse sowie von der Immunantwort des Wirts und dem Ausmaß des umgebenden Hirnödems. Häufige Symptome sind Kopfschmerzen, Wesensveränderungen und Bewußtseinsstörungen, z. T. auch Übelkeit und Erbrechen. Neurologische Herdsymptome lassen sich in 50-75\% der Fälle nachweisen, in ca. 30\% treten epileptische Anfälle und/oder Meningismus auf. Fieber besteht in etwa der Hälfte der Fälle. Typisch für Abszesse im Frontalhirn sind Veränderungen von Antrieb und Affektivität.

\section{Diagnostik}

- Entscheidend ist die Durchführung einer CCT mit Kontrastmittel oder einer MRT (höhere Sensitivität). Da die CCT im Frühstadium lediglich eine Hypodensität aufweist und erst im weiteren Verlauf die typische ringförmige Kontrastmittelanreicherung zeigt, muß die CCT bei initial unklarem Befund wiederholt werden. CT-Befunde, die einen Hirnabszeß vortäuschen können, sind insbesondere Gliome und Metastasen. Der Nachweis kleiner Gasbläschen beweist in unklaren Fällen die Diagnose Abszeß, sofern zuvor keine Operation und kein Trauma stattgefunden hat.

- Die Lumbalpunktion ist kontraindiziert, da die Gefahr einer Herniation besteht und die diagnostische Aussagekraft gering ist (uncharakteristische Liquorveränderungen mit meist nur mäßiger Pleozytose und Eiweißvermehrung, meist kein Erreger nachweisbar).

- Wenn möglich, soll vor Beginn der Therapie eine Abszeßpunktion (bei multiplen Abszessen Punktion des größten bzw. am besten zugänglichen $\mathrm{Ab}$ szesses) oder eine neurochirurgische Exzision (bei bereits abgekapselten und gut zugänglichen $\mathrm{Ab}$ szessen) durchgeführt werden. Ausgenommen sind HIV-Infizierte, bei denen meist eine zerebrale Toxoplasmose vorliegt, die zunächst empirisch therapiert wird (s. Abschn. 22.2.5).

Zur mikrobiologischen Diagnostik sind neben den üblichen aeroben und anaeroben Kulturverfahren auch kulturelle und mikroskopische Untersuchungen zum Nachweis von Mykobakterien, Nocardien und Pilzen erforderlich. Darüber hinaus ist eine Fokussuche erforderlich, die insbesondere eine Mastoiditis, Sinusitis, einen dentogenen Prozeß, eine pulmonale Infektion sowie eine Endokarditis erfassen soll.

\subsection{3}

\section{Infektiöse Mononukleose und ähnliche Syndrome}

Mononukleoseartige Syndrome sind gekennzeichnet durch variables Fieber (z. T. auch nur subfebrile Temperaturen), generalisierte oder regionale Lymphadenopathie, Allgemeinsymptome wie Müdigkeit, Abgeschlagenheit und Leistungsminderung sowie eine Lymphomonozytose im Blutbild. Weitere häufige Symptome und Befunde sind Muskel- und Gelenksschmerzen, Kopfschmerzen (z. T. meningeale Reizung), eine Pharyngitis mit Halsschmerzen und Hepatosplenomegalie.

Ursächlich kommen v. a. Epstein-Barr-Virusinfektion (infektiöse Mononukleose), Zytomegalie, Toxoplasmose, akute HIV-Infektion (s. Abschn. 22.2.5) und Katzenkratzkrankheit in Frage. Gelegentlich werden ähnliche Syndrome auch durch andere Virusinfektionen (HSV-2, Varizella-Zoster-Virus, HHV-6, Röteln, Adenoviren, Hepatitis A und B) verursacht oder bei der glandulären Verlaufsform der Listeriose und bei hämatologischen Systemerkrankungen beobachtet.

\subsubsection{1}

\section{Infektiöse Mononukleose}

Die klassische infektiöse Mononukleose (Pfeiffersches Drüsenfieber) ist eine selbstlimitierende, akute Erkrankung durch das Epstein-Barr-Virus (EBV). Die EBV-Infektion hinterläßt meist eine lebenslange latente Infektion (durch CD8+B-Lymphozyten kontrolliert).

Nach kurzer Prodromalphase kommt es zum zeitgleichen Fieberanstieg und Auftreten zervikal betonter Lymphknotenschwellungen. Die Patienten sind abgeschlagen, haben Nacken- und Kopfschmerzen. Es besteht eine exsudative Pharyngitis, die Beläge bleiben auf die Tonsillen beschränkt und bluten beim Abstreifen nicht. Am Hinterrand des harten Gaumens findet sich nicht selten ein hämorrhagisches Enanthem. Es kann eine deutliche Hepatosplenomegalie vorliegen, gelegentlich mit Ikterus.

Komplikationen sind ZNS-Manifestationen (Meningoenzephalitis, Mononeuritis, Guillain-Barré-Syndrom u. a.), Milzruptur, interstitielle Pneumonie und Myokarditis (Herzrhythmusstörungen). Unter Ampicillintherapie (kontraindiziert) tritt fast regelmäßig ein stammbetontes makulopapulöses Exanthem auf, das ohne antibiotische Therapie nur bei ca. $10 \%$ der Patienten festzustellen ist.

Im Kindesalter manifestiert sich die EBV-Infektion seltener unter dem Bild einer typischen infektiösen Mononukleose, sondern eher unter dem Bild einer Otitis media, Infektion der oberen Atemwege, Durchfall und abdominellen Schmerzen. Bei Immundefekten und bei der X-gebundenen lymphoproliferativen Erkrankung sind fatale Verläufe möglich. 
Eine Assoziation mit EBV besteht für Nasopharynxkarzinom und endemisches Burkitt-Lymphom (besonders in Afrika), HIV-assoziierte maligne Lymphome, M. Hodgkin, polyklonale Lymphoproliferationen nach Organtransplantation und wird auch für das virusassoziierte Hämophagozytosesyndrom sowie, bei immundefizienten Patienten, für Leiomyosarkome diskutiert.

Eine Assoziation mit dem chronischen Müdigkeitssyndrom („chronic fatigue syndrome“) wird diskutiert, ist jedoch unbewiesen.

\section{Laborbefunde}

Es besteht eine mäßige Leukozytose mit relativer und absoluter Lymphozytose. Mindestens $10 \%$ der Lymphozyten weisen eine erhöhte Kern-Zytoplasma-Relation, eine deutliche Basophilie sowie einen großen gelappten Kern auf und sind charakteristisch vakuolisiert (lymphomonozytäre Reizformen). Weitere Blutbildveränderungen sind mäßige Thrombopenie; es kann auch eine Panzytopenie oder eine Hämolyse (z. B. Kälteagglutinine) auftreten. Bei einem Teil der Patienten sind die Transaminasen mäßiggradig erhöht.

\section{Diagnostik}

Diese erfolgt serologisch: IgG-Antikörper gegen das virale Capsidantigen (VCA) zeigen Seropositivität an. VCA-IgM-Antikörper sind typisch für eine akute Infektion, können jedoch auch fehlen, zudem sind persistierende oder reaktivierte VCA-IgM-Antworten möglich. Positive EBNA-1-Antikörper schließen eine akute Infektion aus, ein negativer Befund zusammen mit positiven VCA-IgG oder Early-Antigen-IgG (EA-IgG) weist auf eine frische Infektion hin. Allerdings wird Anti-EBNA-1 bei massiver Immunsuppression $u$. U. wieder negativ. Um primär negatives Anti-EBNA-1 von sekundär negativem („Anti-EBNA-1-Verlust“) zu unterscheiden, ist die Aviditätsmessung der VCA-IgG angezeigt: Niedrigavides VCA-IgG ist beweisend für frische Infektion.

\subsubsection{2}

\section{Zytomegalie}

Die Zytomegalievirus(CMV)-Infektion verläuft bei immunkompetenten Kindern und Erwachsenen meist asymptomatisch oder unter dem Bild der infektiösen Mononukleose und hinterläßt eine lebenslange latente Infektion. Wesentlich bedeutsamer sind die konnatale und die perinatale CMV-Infektion sowie die schwerwiegenden Krankheitsbilder bei Transplantierten (meist als Pneumonie) und anderen schwer Immunsupprimierten sowie bei der HIV-Infektion (s. Abschn. 22.2.5).

Die schwere intrauterin erworbene Infektion verläuft mit Exanthem, Hyperbilirubinämie, Hepatosplenomegalie, Thrombozytopenie, multiplen Organmanifestationen, Taubheit und intrazerebralen Verkalkungen.
Etwa 5\% aller mononukleoseartigen Syndrome gehen auf CMV -Infektionen zurück und sind klinisch nur schwer von der EBV-bedingten Form zu unterscheiden (s. oben). Nach manchen Studien bestehen Pharyngitis, Exanthem und Lymphadenopathie seltener bzw. sind weniger ausgeprägt als bei der EBV-bedingten Mononukleose. Weitere Manifestationen und mögliche Komplikationen sind Hepatitis (u. U. granulomatös), interstitielle Pneumonie, neurologische Veränderungen (z. B. Guillain-Barré-Syndrom), Hämolyse, Panzytopenie und sekundäre Myelodysplasie. Sehr selten treten bei immunkompetenten Patienten Adrenalitis, gastrointestinale Ulzera, Chorioretinitis und Myo-/Perikarditis auf.

\section{Diagnostik}

Die CMV-Primärinfektion ist in der Regel durch eine deutliche CMV-IgG- und IgM-Antwort gekennzeichnet (ELISA, KBR), während bei abgelaufener Infektion nur das CMV-IgG nachweisbar bleibt. Allerdings zeigen auch Reaktivierungen IgG-Titeranstiege und u. U. sogar eine IgM-Reaktivierung. Bei akuter und reaktivierter Infektion kann CMV im Urin nachgewiesen werden. Bei immunsupprimierten Patienten (z. B. HIV-Infektion, Organtransplantation) ist die Immundiagnostik weniger aussagekräftig, der Nachweis viraler Strukturproteine (pp65-Antigen) in Granulozyten kann jedoch das Auftreten einer CMV-Erkrankung voraussagen. Der definitive Nachweis bei schweren disseminierten und Organerkrankungen von Immunkompromittierten (s. Abschn. 22.2.5) beruht auf dem kulturellen und molekularbiologischen (möglichst quantitative PCR) Erregernachweis sowie der Immunhistologie oder Insitu-Hybridisierung in Biopsien. Wegen der Häufigkeit latenter Infektionen ist die nichtquantitative PCR auBer bei den neurologischen Manifestationen bzw. der Liquordiagnostik nur eingeschränkt aussagekräftig.

\subsubsection{3 \\ Toxoplasmose}

Die akute Toxoplasmose ist eine Erkrankung durch das Protozoon Toxoplasma gondii, die akut verläuft und in eine lebenslange latente Infektion (Zysten in Muskel, Leber, Hirn) übergeht. Die immunologische Kontrolle ist TZell-abhängig. Bei HIV-Infizierten (s. Abschn. 22.2.5) und bei anderen Immunkompromittierten sind schwere Erkrankungen möglich, die ganz überwiegend auf Reaktivierung der latenten Infektion beruhen.

Die akute Toxoplasmose bei immunkompetenten Kindern und Erwachsenen verläuft nur in etwa 10\% klinisch apparent und zeigt dann am ehesten ein mononukleoseartiges Bild mit Lymphadenopathie (häufig besonders zervikal), Fieber, Nachtschweiß, Myalgien, Pharyngitis, Exanthem und Hepatosplenomegalie. Die vergrößerten Lymphknoten sind meist weich, gut ver- 
schieblich und ohne Tendenz zur Einschmelzung. Die Lymphadenitis kann lange anhalten, so daß die $\mathrm{Ab}$ grenzung zu malignen Prozessen dringlich wird.

Seltenere Organkomplikationen sind Hepatitis, Chorioretinitis und Myokarditis. Die Chorioretinitis des älteren Kindes bzw. des Erwachsenen ist meistens die Folge einer konnatalen Toxoplasmose, kommt aber auch bei $1 \%$ der Patienten mit erworbener Toxoplasmose vor. Augenschmerzen, Sehstörungen, Photophobie oder Tränenfluß sind häufige Symptome. Rezidive sind trotz erfolgreicher Akuttherapie häufig.

\section{Diagnostik}

Die Lymphknoten zeigen histologisch das Bild der Lymphadenitis nach Piringer [nichtverkäsende epitheloidzellreiche Granulome, Lymphknotenstruktur kann zerstört sein, lymphoide Hyperplasie (unreife Sinushistiozytose)]. Im Blutausstrich können atypische Lymphozyten beobachtet werden, die sich morphologisch von der infektiösen Mononukleose durch ihre mehr lymphoplasmozytäre Differenzierung unterscheiden.

Der Nachweis einer primären Infektion mit Toxoplasma gondii erfolgt serologisch über den Nachweis von IgM- und IgG-Antikörpern (Teil A, Kap. 3). Die Seropositivität (IgG-Antikörper) ist zweifelsfrei zu bestimmen. Hingegen ist aufgrund der $z$. T. langanhaltenden IgM-Antwort der genaue Infektionszeitpunkt retrospektiv nicht leicht festzulegen. Umgekehrt kann die IgM-Antwort auch kürzer als die klinisch sichtbare Lymphknotenschwellung anhalten; in diesem Fall sollte ein IgM-Nachweis im ISAGA versucht werden.

Die Diagnose einer Toxoplasmose während der Schwangerschaft stellt nicht selten ein Problem dar. Daher sollte jede Frau, bereits bevor sie schwanger wird, auf das Vorhandensein von toxoplasmaspezifischen Antikörpern untersucht werden. Aus Kostengründen sollte das serologische Screening sequenziell erfolgen (Tabelle 22-9). Ergeben die Basistests niedrige Titer, ist eine latente Infektion wahrscheinlich. Zeigen weitere Kontrollen einen signifikanten Titeranstieg, ist eine akute Infektion wahrscheinlich. Hierfür sprechen auch der Nachweis von IgM- und insbesondere IgA-Antikör-

Tabelle 22-9. Stufendiagnostik der Toxoplasmose

\begin{tabular}{ll}
\hline 1. Screeningtests & - Direkte Agglutination \\
(Suche nach IgG- & - Sabin-Feldman-Test \\
Antikörpern) & - Indirekter Immunfloreszenztest \\
& - Komplementbindungsreaktion \\
2. Differenzierende Tests & - ELISA \\
(Suche nach IgM, IgA, & - ISAGA \\
IgE) & - Immunoblot \\
3. Direkter Parasiten- & - PCR \\
nachweis & - Inokulationstest (Tierversuch) \\
& - Zellkultur \\
4. Neue Testverfahren & - IgG-Avidity-ELISA \\
& - rekombinante Antigene
\end{tabular}

pern. In Zweifelsfällen einer Schwangerschaftstoxoplasmose sollte der direkte Erregernachweis aus Fruchtwasser oder auch Nabelschnurblut mittels PCR und ggf. Tierversuch durchgeführt werden.

Bei den schweren Erkrankungen von Immunsupprimierten (insbesondere bei T-Zelldefekten) ist die Serodiagnostik mit Ausnahme der Feststellung einer latenten Infektion (und damit einer grundsätzlichen Gefährdung hinsichtlich einer Reaktivierung) meist wenig hilfreich. Eine diagnostisch verwertbare Immunantwort (signifikanter Antikörperanstieg, IgM- oder IgA-Antwort) als Zeichen einer aktuellen Infektion bleibt meist aus. Die Diagnostik ist hier auf klinische und bildgebende Befunde und den meist schwierigen direkten Erregernachweis angewiesen (s. Abschn. 22.2.5).

\subsubsection{4}

\section{Katzenkratzkrankheit}

Bartonella henselae verursacht bei Immunkompetenten typischerweise eine ausgeprägte regionale, granulomatöse, gelegentlich spontan drainierende Lymphadenopathie, z. T. mit mäßiggradigem Fieber, meist 13 Wochen nach Kratz- oder Bißwunden durch Katzen (z. T. entzündlicher Primäraffekt an der Inokulationsstelle). Weitere Manifestationen und Komplikationen sind Osteomyelitis, Hepatitis, herdförmige Pneumonie, Enzephalitis, Uveitis/Chorioretinitis und Endokarditis. Bei HIV-Infizierten sind Manifestationen unter dem Bild eines anhaltenden oder periodischen Fiebers unklarer Genese häufiger. Bei Aids-Patienten kann es zur bazillären Angiomatose kommen (s. Abschn. 22.2.5).

\section{Diagnostik}

Der Diagnoseverdacht ergibt sich aus dem klinischen Bild und kann durch den Nachweis spezifischer IgMAntikörper und/oder hoher IgG-Antikörperspiegel erhärtet werden. Ein Nachweis des Erregers in der Kultur (Teil A, Kap. 3) oder mittels PCR aus entsprechenden Läsionen (Gewebsbiopsien) und aus Blut ist möglich. Histologisch können die Erreger durch die Färbung nach Warthin-Starry dargestellt werden (nicht spezifisch).

\subsection{4}

\section{Infektiöse Enteritis}

Infektiöse Enteritiden können durch eine große Zahl verschiedener Erreger verursacht werden (Tabelle 2210). Während akut auftretende Enteritiden bzw. Durchfallerkrankungen ganz überwiegend durch Infektionen und Intoxikationen bedingt sind, müssen bei chronischen Diarrhöen zahlreiche nichtinfektiöse Ursachen berücksichtigt werden. 
Tabelle 22-10. Erreger von Durchfallerkrankungen

Tabelle 22-11. Klinische Symptomatik und spezifische Enteropathogene

\begin{tabular}{|c|c|c|}
\hline Viren & Bakterien & Parasiten \\
\hline $\begin{array}{l}\text { Rotaviren }^{a} \\
\text { Enterale Adenoviren } \\
\text { Norwalk-Viren } \\
\text { „Norwalk-like virus } \\
\text { Caliciviren } \\
\text { Astroviren } \\
\text { Coronaviren }\end{array}$ & 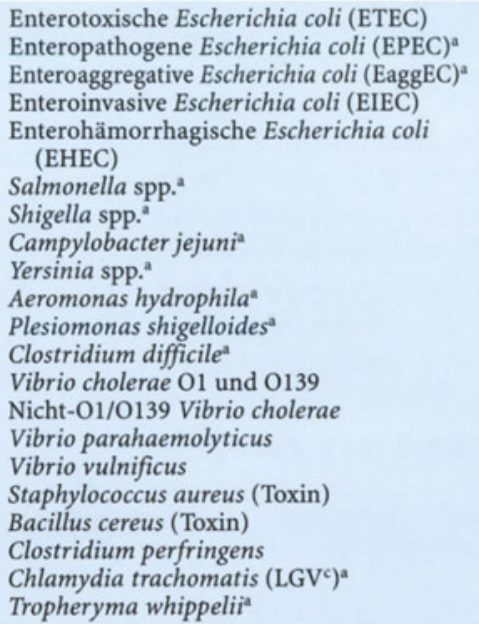 & 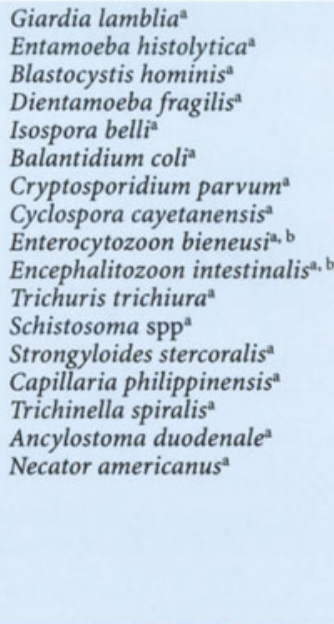 \\
\hline
\end{tabular}

${ }^{\text {a }}$ Mögliche Ursache chronischer Diarrhöen (Dauer $>3$ Wochen).

${ }^{b}$ Fast nur bei Immunkompromittierten.

${ }^{c} L G V$ : Lymphogranuloma venereum.

\footnotetext{
a $\mathrm{ETEC}=$ enterotoxigene Escherichia coli, EIEC = enteroinvasive E. coli, EHEC = enterohämorrhagische E. coli.

${ }^{\mathrm{b}}$ Fast ausschließlich bei Immunkompromittierten.
}

\section{Klinische Verdachtsdiagnose}

Leitsymptom sind meist Durchfälle (mehr als 3 ungeformte Entleerungen pro Tag), die gelegentlich jedoch fehlen oder nur intermittierend auftreten. Zudem sind zahlreiche weitere Symptome gastrointestinaler (z. B. Völlegefühl, Meteorismus, Nausea, Erbrechen, abdominelle Schmerzen, Krämpfe, Tensemen) und allge- meiner Art (z. B. Fieber, Gelenk- und Gliederschmerzen) möglich sowie in schweren Fällen auch die Folgen von ausgeprägtem Wasser- und/oder Elektrolytverlust (Hypotonie, Exsikkose, Krämpfe, Oligurie, Herzrhythmusstörungen, Bewußtseinstörungen, Schock).

Durchfallfrequenz, Stuhlbeschaffenheit sowie zusätzliche Symptome und Befunde geben wichtige Hin- 
weise auf die Ätiologie, erlauben jedoch keine spezifische Diagnose (Tabelle 22-11). Von besonderer Bedeutung ist zudem die Vorgeschichte:

- Akute Enteritiden nach vermutlich definierter Exposition (Restaurantbesuch etc.) oder bei gleichzeitige Erkrankung mehrerer Personen (Gruppenerkrankung, Kleinepidemien) deuten auf Intoxikationen (Toxine von Staphylococcus aureus oder Bacillus cereus) oder Infektionen durch bestimmte bakterielle (z. B. E. coli, Salmonellen, Shigellen, Campylobacter), virale (z. B. Rotavirus, NorwalkVirus) oder parasitäre (z. B. Lamblien, Kryptosporidien, Cyclospora) Erreger hin, die auf mikrobiel- ler Kontamination von Nahrungsmitteln oder Wasser beruhen.

- Insbesondere bei Durchfällen nach vorausgegangener Antibiotikatherapie (insbesondere mit Clindamycin u. a. Breitspektrumantibiotika), aber auch bei Patienten mit schweren Grunderkrankungen, alten Patienten und Säuglingen muß differentialdiagnosisch stets an eine Kolitis durch toxinbildende Clostridium difficile gedacht werden (Kap. 23).

- Bei Patienten mit HIV-Infektion und bei anderen Immunkompromittierten sind zusätzliche opportunistische Erreger zu berücksichtigen (Abschn. 22.2.5 und Tabelle 22-12).

\section{Diagnostik}

Minimalprogramm

a) mikroskopisch

b) bakteriologisch

c) parasitologisch

Sinnvolle Ergänzungen zum Minimalprogramm

\section{Bemerkungen}

- Nativpräparat, ggf. Anfärbung (z. B. Lugol-Lösung)

- mindestens 2 Medien unterschiedlicher Selektivität (für Salmonellen, Shigellen, E. coli u. a. Enterobakterien, Vibrionen, Yersinien)

+ mindestens 1 Anreicherung mit Ausimpfung auf 2 Medien (s. oben) +1 Campylobacter-Medium

- gefärbter Ausstrich + Anreicherung (z. B. MIF oder SAF) + Nativstuhl

- Yersinienmedium (z. B. CIN-Agar, $28^{\circ} \mathrm{C}$ )

- EHEC-Diagnostik, besonders bei Dysenterie

- Vibrionenmedium (z. B. TCBS)

- bei choleriformer Diarrhö ohne Vibrio-Nachweisa: ETEC-Diagnostik (LT-GM1-ELISA, Zellkulur/Bioassay, Koloniehybridisierung, PCR)

- Koproantigen-ELISA für Giardia lamblia und Entamoeba histolytica

Zusatzuntersuchungen bei

a) Verdacht auf Yersi- - Kälteanreicherung + Öberimpfung auf Yersinienmedium (s. oben) niose

b) Verdacht auf antibiotikaassoziierte Kolitis

c) Verdacht auf Chole$\mathrm{ra}^{\mathrm{a}} /$ choleriforme Diarrhö

d) Kleinkindern und Säuglingen

e) Verdacht auf Helminthose ${ }^{a}$ (z. B. Eosinophilie)

Zusatzuntersuchungen bei Immunkompromittierten

Chronische Diarrhö
- Clostridium-difficile-Medium (z. B. CCF-Agar) und Toxinnachweis

- Anreicherung in alkalischem Peptonwasser, ETEC-Diagnostik (s. oben)

- EPEC/EIEC-Diagnostik: Serotypisierung, ggf. Zellkultur/Bioassay, PCR

+ EHEC-Diagnostik (besonders bei Dysenterie + Verdacht auf HUS)

+ Rotavirusdiagnostik (Koproantigen-ELISA odere andere Methode)

- Strongyloidiasisdiagnostik (s. unten), ggf. Schistosomiasisserologie

- Clostridium-difficile-Diagnostik (s. oben)

- EaggEC-Diagnostik (besonders Kinder; Serotypisierung, Zellkulturassays, $\mathrm{PCR}$ )

- Kryptosporidien/Cyclosporadiagnostik (Kinyoun- oder modifizierte Ziehl-Neelsen-Färbung, Koproantigen-ELISA für Kryptosporidien)

- Mikrosporidien: modifizierte Trichromfärbung (sehr dünner Stuhlausstrich)

- Koproantigen-ELISA für Giardia lamblia und Entamoeba histolytica

- Verdacht auf Strongyloidiasis: Koprokultur (Baermann-Apparat, Agar-Platte)

- bioptische Abklärung (Mykobakterien, Chlamydien, CMV, HSV, Mikrosporidien, Pilze u. a.)

- Wiederholung (mindestens 3mal) der bakteriologischen + parasitologischen Untersuchungen

- EAEC-Diagnostik (s. oben), Yersiniendiagnostik (s. oben), Clostridium-difficile-Diagnostik (s. oben)

- Koproantigen-ELISA für Giardia lamblia und Entamoeba histolytica ${ }^{a}$

- Kryptosporidien-/Cyclosporadiagnostik (s. oben)

- Strongyloidiasisdiagnostik (s. oben $)^{a}$

- weitere gastroenterologische und ggf. tropenmedizinische ${ }^{a}$ Abklärung
Tabelle 22-12. Mikrobiologische Diagnostik bei Verdacht auf infektiöse Enteritis

a Bei Verdacht auf importierte Durchfallerkrankung. 
- Nach Rückkehr von Auslandsaufenthalten (besonders tropische Entwicklungsländer) ist mit einem erweiterten Spektrum von Erregern zu rechnen (z. B. Cholera, Amöben, Wurminfektionen). Aufgrund der relativ kurzen Inkubation manifestieren sich bakteriell und viral bedingte Enteritiden meist innerhalb kurzer Zeit (1-2 Wochen) nach Rückkehr, während parasitäre Erreger variable und lange Inkubationszeiten aufweisen können.

- Durchfälle oder sonstige Symptome einer Enteritis können auch im Rahmen systemischer Infektionen auftreten (Tabelle 22-13). Nach Rückkehr von Tropenaufenthalten ist dabei immer auch an eine Malaria zu denken (Abschn. 22.6.1).

Tabelle 22-13. Durchfälle im Rahmen systemischer Infektionen

\begin{tabular}{|c|c|}
\hline Akute Infektionen & Chronische Infektionen \\
\hline $\begin{array}{l}\text { - Legionellose } \\
\text { - Listeriose } \\
\text { - Malaria } \\
\text { - Masern } \\
\text { - Ornithose } \\
\text { - Rickettsiosen } \\
\text { - akute Schistosomiasis }{ }^{\mathrm{a}} \\
\text { (Katayama-Syndrom) } \\
\text { - Sepsis } \\
\text { - Toxinschocksyndrom } \\
\text { - Trichinose } \\
\text { - Typhus/Paratyphus } \\
\text { - Virushepatitis (beson- } \\
\text { ders A und E) }\end{array}$ & $\begin{array}{l}\text { - Chagas-Krankheit (chronisches } \\
\text { Stadium) } \\
\text { - Darmtuberkulose } \\
\text { - Histoplasmose } \\
\text { - HIV-Infektion } \\
\text { - Lymphogranuloma venereum } \\
\text { - Mycobacterium avium-intracel- } \\
\text { - } \text { luare-Infektion }^{\mathrm{b}} \\
\text { - Schistosomiasis (intestinal) } \\
\text { - Schlafkrankheit } \\
\text { - } \text { viszerale Leishmaniose }^{\mathrm{a}} \\
\text { - Whipple Erkrankung } \\
\text { - Zytomegalie }\end{array}$ \\
\hline
\end{tabular}

${ }^{a}$ Bevorzugt oder ausschließlich als importierte Infektion.

${ }^{b}$ Fast nur bei Immunkompromittierten.

\section{Diagnostisches Vorgehen}

Dies richtet sich nach Schweregrad der Erkrankung, Lebensalter des Patienten, Vorgeschichte und vorliegenden Grunderkrankungen:

Bei unkomplizierten akuten Durchfallerkrankungen von Jugendlichen und Erwachsenen ohne Grunderkrankungen ist eine unspezifische symptomatische Therapie ohne gezielte Diagnostik ausreichend. Eine ätiologische Abklärung ist weder nutzen- noch kosteneffektiv.

Warnsymptome, die auf einen komplizierten Verlauf hinweisen, sind

- profuse Diarrhöen und/oder massives Erbrechen,

- Blutbeimengungen im Stuhl oder blutig-schleimige Durchfälle (Dysenterie),

- hohes und/oder anhaltes Fieber,

- ausgeprägte Allgemeinsymptome.

In diesen Fällen ist eine gezielte Diagnostik (s. unten; Abb. 22-2; Tabelle 22-12) und bei Hinweisen für Enteroinvasivität (Dysenterie, Fieber) ggf. auch eine empirische antimikrobielle Initialtherapie angezeigt.

Weitere Indikationen zur gezielten Diagnostik sind
- Durchfallerkrankungen mit epidemiologischer Relevanz (Gruppenerkrankungen, Epidemien),

- chronische bzw. chronisch rezidivierende Durchfälle,

- Durchfälle bei Immunkompromittierten.

\section{Diagnostik}

Das Minimalprogramm der mikrobiologischen Diagnostik muß sensitive und spezifische Methoden zum Nachweis der wichtigsten Enteropathogene umfassen und ist entsprechend Anamnese, Krankheitsbild, Lebensalter und eventuellen Grunderkrankungen des $\mathrm{Pa}$ tienten zu ergänzen (Tabelle 22-12):

\section{- Bereits die direkte mikroskopische Untersuchung} von Nativstuhl und gramgefärbtem Stuhlausstrich ergibt wichtige Informationen: vermehrte fäkale Leukozyten bei enteroinvasiven Infektionen; Erythrozyten bei Hämorrhagien und/oder Schleimhautdisintegrität (auch wenn makroskopisch noch keine Blutbeimengung erkennbar ist). Stark bewegliche und in der Färbung gramnegative, gekrümmte Stäbchenbakterien weisen auf Campylobacter oder Vibrio spp. hin; bei Verdacht auf Cholera ist eine orientierende Schnelldiagnose mit immobilisierenden Antiseren (Immobilisationstest) oder Koproantigentests möglich. Trophozoiten von Giardia lamblia, Entamoeba histolytica, und einigen anderen Intestinalprotozoen können bereits im Nativstuhl identifiziert werden. Wichtig ist hierbei die möglichst sofortige Untersuchung von frischem Stuhl bzw. Rektalabstrich oder endoskopisch gewonnenem Material.

- Bei Verdacht auf eine Kolitis durch toxinbildende Clostridium difficile (s. oben) ist eine gezielte Diagnostik notwendig (Tabelle 22-12). Bei Verdacht auf pseudomembranöse Kolitis ist eine umgehende endoskopische Abklärung (ggf. histologische Schnelldiagnose) und ggf. sofortige Einleitung einer empirischen Therapie (nach Abnahme von Material für Kultur und Toxinnachweis) erforderlich.

- Bei hämolytisch-urämischem Syndrom oder thrombotisch-thrombozytopenischer Purpura, bei blutig-wäßrigen Stühlen, bei Kindern unter 6 Jahren mit stationärer Behandlung wegen Durchfallerkrankung sowie bei endoskopisch nachgewiesener hämorrhagischer oder nekrotisierender Enterokolitis sollte zusätzlich eine gezielte Diagnostik hinsichtlich enterohämorrhagischer E. coli (EHEC) veranlaßt werden.

- Eine ausagekräftige Diagnostik enterotoxinogener E. coli (ETEC) ist aufwendig und mangels therapeutischer Konsequenzen nur bei schweren Verläufen (z. B. choleriforme Diarrhö) oder epidemiologischen Untersuchungen sinnvoll.

- Bei protrahiert oder chronisch verlaufenden Diarrhöen (besonders bei Kindern) sollte zusätzlich ei- 
ne gezielte Diagnostik hinsichtlich enteroaggregativer E. coli (EaggEC) veranlaßt werden.

- Untersuchungen zum Nachweis viraler Enteropathogene gehören mit Ausnahme der Rotavirusdiagnostik bei Kindern (Tabelle 22-12) und der Abklärung epidemiologisch relevanter Infektionen nicht $\mathrm{zu}$ den Routineuntersuchungen.

- Bei Verdacht auf importierte Durchfallerkrankung sollten stets auch parasitologische Stuhluntersuchungen durchgeführt werden. Parasitäre Erreger haben zwar nur einen relativ kleinen Anteil an der Genese der akuten Reisediarrhö, als Ursache chronischer oder chronisch rezidivierender gastrointestinaler Beschwerden nach Tropenreisen spielen sie jedoch eine wichtige Rolle. Zudem zeigen intestinale Parasitosen im Gegensatz zu den meisten bakterieller Enteritiden oft keinen zeitlich limitierten Verlauf und können $z$. T. noch nach langen Intervallen schwerwiegende Komplikationen verursachen (z. B. extraintestinale Amöbiasis). Schließlich erfordern sie eine spezifische Therapie, die eine definitive Diagnose voraussetzt.

- Durchfälle im Rahmen von Wurminfektionen (Strongyloidiasis, Trichuriasis, Fasciolopsiasis, Schistosomiasis u. a.) sind v. a. bei Kindern zu erwarten, die aus tropischen Entwicklungsländern stammen; z. T. besteht eine Dysenterie, häufig liegt eine Bluteosinophilie vor.

- Bei Durchfällen mit protrahiertem Verlauf und bei Immunkompromittierten sind zusätzlich gezielte Untersuchungen hinsichlich Kryptosporidien, Cyclospora cayetanensis und Mikrosporidien indiziert, die spezielle Methoden erfordern (s. Tabelle 22-12 und Teil A, Kap. 3).

Bei chronischen oder chronisch-rezidivierenden Durchfällen (Dauer $>3$ Wochen) sind zunächst mehrfach wiederholte Stuhluntersuchungen angezeigt unter besonderer Beachtung von Erregern, die protrahierte oder chronische Diarrhöen verursachen können ( $\mathrm{Ta}-$ belle 22-10). Zudem sind chronische systemische Infektionen mit Darmbeteiligung (Tabelle 22-13) und bei Immunkompromittierten zusätzliche opportunistische Infektionen (Abschn. 22.2.5) zu berücksichtigen. Bei negativen mikrobiologischen Befunden ist eine weitere gastroenterologische Abklärung einschließlich endoskopischer Untersuchungen (Koloskopie, Gastroduodenoskopie) mit intestinalen Biopsien erforderlich (Kap. 23).

\subsection{5}

\section{HIV-Infektion und Aids}

Der klinisch begründete Diagnoseverdacht ist meist offensichtlich beim Vorliegen von Aids-definierenden Erkrankungen der CDC/WHO-Klassifikation (Katego- rie C in Tabelle 22-14). Auch bei Symptomen und Erkrankungen der Kategorie B sowie bei persistierender Lymphadenopathie sollte heute stets an eine HIV-Infektion gedacht und die entsprechende Diagnostik veranlaßt werden.

Das Krankheitsbild der akuten HIV-Infektion, das in $10-60 \% 10$ Tage bis mehrere Wochen nach Infektion auftritt, manifestiert sich vorwiegend als mononukleoseartiges Krankheitsbild (s. Abschn. 22.2.3) mit Fieber, Allgemeinsymptomen, Pharyngitis, generalisierter Lymphadenopathie und variablen Exanthemen. Aufgrund der unspezifischen Symptomatik und der meist spontanen Remission erfolgt in der Mehrzahl keine HIV-Diagnostik oder nur bei protrahiertem Verlauf oder wenn neurologische Komplikationen (periphere Neuropathie, Radikulitis, Meningitis, Enzephalitis) hinzutreten.

Bei asymptomatischer HIV-Infektion wird die Diagnose am ehesten bei gezielten Untersuchungen aufgrund des epidemiologischen Hintergrundes (Zugehörigkeit zu Risikogruppen, Patienten mit anderen sexuell übertragbaren Erkrankungen; s. Abschn. 22.2.6), bei Blutspenden oder anderen Screeninguntersuchungen (z. B. Vorsorge- und arbeitsmedizinische Untersuchungen, obligatorischer HIV-Test im internationalen Reiseverkehr) gestellt.

\section{Diagnostik}

Die Diagnose der etablierten HIV-Infektion erfolgt vorwiegend serologisch durch den Nachweis spezifischer Antikörper gegen HIV-1/HIV-2 mittels ELISA als Suchtest und Immunoblot als Bestätigungstest (Teil A, Kap. 3, Tabelle 3-12). Diese Verfahren weisen allerdings eine diagnostische Lücke (Fensterperiode) von 2-12 Wochen (im Mittel 5 Wochen), in seltenen Fällen auch länger, auf. Vor der Serokonversion und oft auch während der akuten HIV-Infektion gelingt der direkte Virusnachweis nur mittels HIV-p24-Antigen-ELISA (frühestens nach 2 Wochen) oder besser mittels PCR (frühestens nach $10 \mathrm{Ta}$ gen), die derzeit verfügbaren kommerziellen Testsysteme erfassen HIV-2- und die meisten HIV-1-Nicht-B-Typen jedoch nicht oder unzureichend.

Ein wichtiger Laborparameter, der indirekt Aufschlüsse über den Krankheitsverlauf ermöglicht (Surrogatmarker), ist die absolute Zahl der $\mathrm{CD}_{4}$-Lymphozyten sowie der prozentuale Anteil der $\mathrm{CD}_{4}$-Zellen an der Gesamtmenge der Leukozyten sowie das Verhältnis von $\mathrm{CD}_{4}-\mathrm{zu}_{\mathrm{CD}}$-Zellen. Ebenso wichtig ist die Bestimmung der HI-Viruslast mittels quantitativer RT-PCR, die im Verlauf zur Beurteilung des Therapieerfolgs herangezogen wird. Die Nachweisgrenzen variieren je nach verwendetem Test und liegen z. Z. bei $<50$ Viruskopien/ml Serum. Bei Verdacht auf Resistenz gegen bestimmte antiretrovirale Medikamente kann eine genound phänotypische Resistenzbestimmung durchgeführt werden (Teil A, Kap. 3). 
Tabelle 22-14. CDC/WHO-Klassifikation (1993) der HIV-Infektion bei Jugendlichen und Erwachsenen

\begin{tabular}{|c|c|c|}
\hline Klinische Kategorie A & Klinische Kategorie B & Klinische Kategorie C \\
\hline $\begin{array}{l}\text { - Akute HIV-Erkrankung } \\
\text { - asymptomatische HIV-Infektion } \\
\text { - persistierende generalisierte } \\
\text { Lymphadenopathie (LAS) }\end{array}$ & $\begin{array}{l}\text { - Bazilläre Angiomatose } \\
\text { - Candidiasis oropharyngeal } \\
\text { - Candidiasis vaginal (persistierend oder } \\
\text { rezidivierend) } \\
\text { - Diarrhö länger als } 4 \text { Wochen } \\
\text { - Fieber }>38,5^{\circ} \mathrm{C} \text { länger als } 4 \text { Wochen } \\
\text { - Haarleukoplakie oral } \\
\text { - Herpes zoster in mehr als einem } \\
\text { Dermatom } \\
\text { - idiopathische thrombozytopenische } \\
\text { Purpura } \\
\text { - Listeriose } \\
\text { - periphere Neuropathie } \\
\text { - zervikale Dysplasie (mäßig bis schwer) } \\
\text { und/oder zervikales Carcinoma in situ }\end{array}$ & $\begin{array}{l}\text { Protozoeninfektionen: } \\
\text { - Isosporiasis, länger als } 4 \text { Wochen } \\
\text { - Kryptosporidose länger als } 4 \text { Wochen } \\
\text { - Pneumocystis-carinii-Pneumonie } \\
\text { - Toxoplasmaenzephalitis } \\
\text { Virusinfektionen: } \\
\text { - CMV-Retinitis } \\
\text { - CMV-Infektionen, generalisiert } \\
\text { - Herpes simplex, chronische mukokutane } \\
\text { Infektionen länger als } 4 \text { Wochen } \\
\text { - Herpes simplex, generalisiert } \\
\text { - HIV-Enzephalopathie } \\
\text { - progressive multifokale Leukenzephalopathie } \\
\text { (JC-Virus) } \\
\text { Pilzinfektionen: } \\
\text { - Candidiasis von Bronchien, Trachea, Lungen } \\
\text { - Candidaösophagitis } \\
\text { - Kokzidioidomykose } \\
\text { - Histoplasmose, disseminiert oder extrapul- } \\
\text { monal } \\
\text { - Kryptokokkose, extrapulmonal } \\
\text { Bakterieninfektionen: } \\
\text { - nichttuberkulöse Mykobakteriosen (dissemi- } \\
\text { niert oder extrapulmonal) } \\
\text { - rezidivierende Pneumonien } \\
\text { - rezidivierende Salmonellensepsis } \\
\text { - Tuberkulose } \\
\text { Malignome: } \\
\text { - Kaposi-Sarkom } \\
\text { - maligne Lymphome } \\
\text { Sonstiges: } \\
\text { - Wastingsyndrom (Gewichtsabnahme }>10 \% \text { ) } \\
\text { - Zervixkarzinom, invasiv }\end{array}$ \\
\hline $\begin{array}{l}\text { Laborkategorie } 1 \\
>500 \text { CD } 4+\text {-Lymphozyten/ } \mu \mathrm{l}\end{array}$ & $\begin{array}{l}\text { Laborkategorie } 2 \\
\text { 200-500 CD4+-Lymphozyten/ } \mu \mathrm{l}\end{array}$ & $\begin{array}{l}\text { Laborkategorie } 3 \\
>200 \text { CD } 4+\text {-Lymphozyten/ } \mu \mathrm{l}\end{array}$ \\
\hline
\end{tabular}

\subsubsection{1}

\section{Opportunistische Infektionen und Tumorerkrankungen}

Opportunistische Infektionen treten bei zunehmender Immundefizienz (meist $<200 \mathrm{CD} 4+$-Zellen/ $\mu \mathrm{l}$ ) auf und gelten meist als Aids-definierend (Kategorie $\mathrm{C}$ in Tabelle 22-14). Die Diagnostik der wichtigsten opportunistischen Infektionen wird im folgenden kurz dargestellt. Zur Diagnostik der bei HIV-Infektion gehäuft auftretenden Tumorerkrankungen (Kaposi-Sarkom, Non-Hodgkin-Lymphom, Zervixkarzinom) s. Kap. 21.

\section{Pneumocystis-carinii-Pneumonie (PcP)}

Die PcP ist die Infektion, die am häufigsten zur Definition des Vollbildes Aids führt. Der Immunstatus $\left(\mathrm{CD}_{4}+\right.$-Zellen meist $\left.<200 / \mu \mathrm{l}\right)$ und die Einnahme einer Primärprophylaxe sind zu berücksichtigen. Der Diagnoseverdacht ergibt sich bei trockenem Husten, Fieber und Belastungsdyspnoe. Der auskultatorische Befund ist meist uncharakteristisch. Der Krankheitsverlauf kann sowohl schleichend wie auch foudroyant sein. Komplikationen sind beatmungspflichtige respiratorische Insuffizienz, Pneumothorax ( $2 \%)$ und selten (am ehesten unter PcP-Prophylaxe mittels Pentamidininhalation) extrapulmonale Manifestationen (meist als abszeßartige Läsionen in Milz und Leber).

\section{Diagnostik}

Thoraxröntgen: bilaterale, interstitielle Infiltrate; arterielle Blutgasanalyse: pathologischer alveolär-arterieller Sauerstoffgradient; Labor: LDH und CRP meist erhöht.

Die Sicherung der Diagnose sowie der Nachweis möglicher bakterieller Begleiterreger erfolgt am zuverlässigsten mittels Bronchoskopie und bronchioalveolärer Lavage (spezielle Färbeverfahren s. Teil A, Kap. 3). Durch wiederholte Untersuchung eines provozierten Sputums gelingt der Erregenachweis in bis zu $60 \%$ der Fälle.

\section{Zerebrale Toxoplasmose}

Die Toxoplasmoseenzephalitis mit singulären oder multiplen intrazerebralen Abszessen ist die häufigste opportunistische Infektion des ZNS bei Aids-Patienten. Meist handelt es sich um Reaktivierung einer latenten Infektion. Klinische Manifestationen sind Kopfschmerzen, Fieber und je nach Lokalisation des bzw. der Entzündungsherde sehr variable neurologische Störungen 
(Wesensänderungen, Vigilanz- und kognitive Störungen, extrapyramidalmotorische Störungen, Ataxie, Krampfanfälle). Generalisierte Erkrankungen, Pneumonie, Myokarditis und Retinitis kommen ebenfalls vor.

\section{Diagnostik}

Eine zerebrale Toxoplasmose ist v. a. (aber nicht ausschließlich) zu erwarten bei Patienten

- mit $\mathrm{CD}_{4}+$-Lymphozytenzahl $<100 / \mu \mathrm{l}$,

- mit Nachweis von IgG-Antikörpern gegen Toxoplasma gondii (Durchseuchung s. Abschn. 22.2.3)

- und ohne primäre Chemoprophylaxe mit Wirksamkeit gegen Toxoplasmose.

Entscheidend für die Indikation zum Beginn einer empirischen Therapie ist die rasche Durchführung der bildgebenden Diagnostik. In der CCT (nativ und mit Kontrastmittelspätaufnahmen) und MRT gelingt in den meisten Fällen die Darstellung multifokaler, ringförmiger kontrastmittelanreichernder Strukturen mit perifokalem Ödem (Differentialdiagnose: primär zerebrales Non-Hodgkin-Lymphom; Abgrenzung zur Hirntoxoplasmose mittels PET noch zuverlässiger).

Der Liquorbefund ist uncharakteristisch bzw. unauffällig; Direktnachweis oder Isolierung (kulturell, Tierversuch) von Toxoplasmen im Liquor gelingen nur selten. Auch der Erregernachweis mittels PCR (aus Vollblut und Liquor) ist nicht ausreichend sensitiv, die Spezifität möglicherweise durch die in der Regel latente Infektion beeinträchtigt. Die Serologie (s. Abschn. 22.2.3) ist außer für die Feststellung der latenten Infektion (Durchseuchung) ohne diagnostische Bedeutung.

Bei fehlendem oder unzureichendem therapeutischem Ansprechen ist eine Abszeßpunktion angezeigt (Untersuchung des Punktats auf Toxoplasmen mittels Immunhistologie und ggf. PCR), insbesondere zur Diagnose anderer Ursachen.

\section{Zytomegalieviruserkrankungen}

Bei Aids-Patienten ist die Retinitis die häufigste Manifestation, gefolgt von Ösophagitis, Gastroenteritis, Kolitis, Cholangitis, Hepatitis, Pankreatitis und Polyradikulomyelitis. Seltener kann es auch bei HIV-Infizierten zu einer CMV-Pneumonitis oder -Enzephalitis kommen. Vor Einführung der antiretroviralen Kombinationstherapie waren bis zu 25\% der Patienten mit Aids von einer $\mathrm{CMV}$-induzierten Erkrankung betroffen (Manifestationsgipfel bei $<100 \mathrm{CD}_{4}$-Zellen).

Der klinische Verdacht ergibt sich je nach Lokalisation aufgrund von

- Sehstörungen und Gesichtsfeldausfällen bei Retinitis,

- Dysphagie und retrosternalen Schmerzen bei Ösophagitis,
- Diarrhöen und abdominellen Schmerzen bei Enterokolitis, Cholangitis und Pankreatitis,

- Dyspnoe, Fieber und unproduktivem Husten bei Pneumonitis,

- Schmerzen und Sensibilitätsstörungen der unteren Extremitäten, schlaffe Paresen, Blasen- und Enddarmstörungen bei Polyradikulomyelitis,

- neurologischen Defiziten und mnestischen Störungen bei Enzephalitis.

\section{Diagnostik}

Bei der Retinitis erfolgt die Diagnose und Indikation zur empirischen Therapie in der Regel klinisch: am Augenhintergrund sind meist peripher gelegene, weißliche Exsudationen und Blutungen sichtbar. Unbehandelt werden diese Herde größer und können schließlich auch die Makula erfassen. Die Abgrenzung gegenüber den sehr häufigen, in der Regel asymptomatischen Cotton-wool-Herden bei HIV-Patienten kann schwierig sein. Diese erscheinen klein, weiß, mit undeutlicher Abgrenzung und ohne Exsudate oder Blutungen.

Bei Ösophagitis, Gastroenteritis und Kolitis sind endoskopisch typischerweise multiple Erosionen und Ulzera zu sehen. Die Diagnose erfolgt bioptisch aufgrund des typischen histologischen Bildes (Eulenaugenzellen) und CMV-Nachweis mittels Immunhistologie oder In-situ-Hybridisierung.

Die CMV-Pneumonitis zeigt radiologisch uncharakteristische interstitielle Infiltrate. Die Diagnose erfolgt ebenfalls am besten bioptisch (s. oben); der CMV Nachweis (kulturell, PCR) in Sputum oder BAL ist wegen der häufig latenten Infektion und asymptomatischen Virusausscheidung nur beschränkt aussagekräftig.

Bei Polyradikulomyelitis, nicht jedoch bei der CMV-Enzephalitis, findet sich häufig eine mäßiggradige Liquorpleozytose mit Eiweißvermehrung. In der MRT zeigen sich bei Polyradikulomyelitis typischerweise diffuse Signalverstärkungen im Bereich der Cauda equina und der Oberfläche des Conus; bei der CMV Enzephalitis meist periventrikulär. Der CMV-Nachweis im Liquor mittels PCR weist bei beiden Manifestationen eine hohe diagnostische Sensitivität und Spezifität auf.

\section{Nichttuberkulöse Mykobakteriosen}

Nichttuberkulöse Mykobakteriosen (s. Abschn. 22.3.17) werden bei HIV-Infizierten vorwiegend durch Keime aus dem "Mycobacterium avium intracellulare complex“ (MAC) hervorgerufen und treten v. a. bei $\mathrm{CD}_{4}$-Zellzahlen unter 10o/ $\mu \mathrm{l}$ als meist disseminierte Infektion auf, bei der nahezu alle Organe beteilgt sein können. Die Symptome sind variabel und oft wenig charakteristisch: Schwäche, Fieber, Nachtschweiß, Husten, Durchfälle und Anämie. Als Zeichen einer Leberbeteiligung besteht häufig eine Erhöhung der alkalischen Phosphatase. Auch 
chronisches oder rezidivierendes Fieber unklarer Genese und/oder ein sog. Waisting-Syndom (Gewichtsabnahme bis zur Kachexie) können im Vordergrund stehen.

\section{Diagnostik}

In den bildgebenden Verfahren (Thoraxröntgen, Sonographie, CT-Untersuchungen) können vergrößerte Lymphknoten (besonders abdominell) nachweisbar sein. Die Erreger lassen sich bei disseminierter Infektion aus Blut mit Hilfe spezieller Kulturverfahren (Teil A, Kap. 3) isolieren. Der histologische und/oder kulturelle Erregernachweis gelingt nicht selten auch aus Knochenmark, Biopsien verschiedener Organe (z. B. Leber, Lunge, Lymphknoten) sowie häufig auch in Dünndarm-Biopsaten, oft ohne daß endoskopisch faßbare Veränderungen vorliegen, $z$. T. auch ohne gastrointestinale Symptomatik.

\section{Candidiasis}

Schon bei mäßiger Erniedrigung der $\mathrm{CD}_{4}+$-Zellzahl kann es zu oralem Soor kommen. Die Soorösophagitis als Aids-definierende Erkrankung tritt meist erst bei einer Helferzellzahl unter 10o/ $\mu$ l auf. Symptome sind Geschmackstörungen und Brennen im Mund bei oraler Manifestation sowie Dysphagie, retrosternale Schmerzen und Appetitlosigkeit bei Ösophagitis.

\section{Diagnostik}

Siehe auch Abschn. 22.5.1.

- Untersuchung: Inspektion des Mund-Rachen-Bereichs ergibt weiße, abstreichbare Beläge;

- endoskopische Verfahren (Gastroskopie): makroskopisch Soor im Ösophagus (weißliche Beläge, z. T. auch Ulzera);

- Erregernachweis im Abstrich und kulturelle Anzucht auf üblichen Nährmedien.

\section{Progressive multifokale Leukenzephalopathie (PML)}

Erreger dieser demyelinisierenden Erkrankung des zentralen Nervensystems ist das JC-Virus aus der Familie der Papova-Viren. Je nach Studien beträgt die Häufigkeit zwischen 5 und $10 \%$ der Aids-Patienten. Mögliche Symptome sind Ataxie, motorische Ausfälle, mnestische und sprachliche Störungen.

\section{Diagnostik}

In CCT und MRT zeigen sich typischerweise multifokale, asymmetrische, nicht kontrastmittelanreichernde, nicht raumfordernde Läsionen, die auf das Marklager beschränkt bleiben. Ähnliche Befunde können allerdings auch HIV-Enzephalopathie und CMV-Enzephalitis aufweisen. Der Erregernachweis mittels PCR im Liquor gelingt nur bei einem Teil der Fälle.

\section{Kryptokokkenmeningitis}

Die Infektion mit Cryptococcus neoformans erfolgt aerogen durch Keime aus Vogelkot. Die pulmonale Manifestation verläuft meist klinisch inapparent, erst durch Dissemination kommt es zur Meningoenzephalitis. Die klinische Verdachtsdiagnose ergibt sich bei Kopfschmerzen, Fieber, Meningismus, Wesensveränderungen und Bewußtseinsstörungen bis zum Koma.

\section{Diagnostik}

Eine Liquorpleozytose liegt nur bei knapp der Hälfte der Patienten vor. Der Kryptokokken-Antigen-Nachweis aus Blut und Liquor (Teil A, Kap. 3) zeigt eine hohe Sensitivität. Der Erregernachweis ist entweder direkt mikroskopisch im Liquor (Tuschepräparat) oder kulturell aus Liquor und Blut möglich (Teil A, Kap. 3). Vor allem bei Rezidiven ist eine Resistenztestung angezeigt (gelegentlich Resistenz gegen Imidazole, sehr selten gegen Amphotericin B).

\section{Bazilläre Angiomatose}

Bisher fast ausschließlich bei Aids-Patienten beobachtete Erkrankung durch Bartonella henselae (s. Abschn. 22.2.3.4 Katzenkratzkrankheit), seltener auch durch Bartonella quintana (s. auch Abschn. 22.3.22 Rickettsiosen). Übertragung unklar, wahrscheinlich u. a. auch durch Kratzer und Bisse von Katzen sowie möglicherweise über Ektoparasiten (Flöhe, Zecken, Kleiderläuse).

Der Verdacht ergibt sich bei kutanen und subkutanen Gefäßknoten (Endothelproliferation); an der Haut meist als rote Papeln variabler Größe (Differentialdiagnose: Kaposi-Sarkom) und/oder beim Befall innerer Organe (Leber u. a.) z. T. mit Bildung multipler blutgefüllter Zysten (bazilläre Peliosis hepatis). Bakteriämische und disseminierte Formen manifestieren sich am ehesten als Fieber unklarer Genese.

\section{Diagnostik}

Bioptischer Nachweis der meist zahlreich in den Gefäßknoten enthaltenen Bakterien (Versilberung, z. B. nach Warthin-Starry) und/oder mittels PCR. Eine kulturelle Anzucht ist schwierig (Teil A, Kap. 3), die Aussagekraft der serologischen Diagnostik (Abschn. 22.2.3) ist bei Immunkompromittierten eingeschränkt.

\section{Kryptosporidiose}

Cryptosporidium parvum (zoonotisch verbreiteter Einzeller, Übertragung durch Wasser, Nahrungsmittel und Schmierinfektion) führt bei Immunkompetenten zu akuten selbstlimitierten Durchfallerkrankungen mit gelegentlich schwererem oder protrahiertem Verlauf. Bei Immundefizienten (insbesondere Aids) kann es zu schwersten chronischen Panenteritiden ohne Selbstheilungstendenz mit breiig-wäßrigen, nichtblutigen Durchfällen, Malabsorption und Kachexie kommen. Weitere Manifestationen sind Cholangitis, Cholezysti- 
tis und Pankreatitis sowie selten auch ein Befall des Respirationstraktes (Bronchitis, Sinusitis, Pneumonien).

\section{Diagnostik}

Die relativ umweltresistenten Oozysten können im Stuhl mit Spezialfärbungen (Teil A, Kap. 3) und mittels Koproantigen-ELISA nachgewiesen werden oder histologisch in Biopsien (alle Stadien) aus dem Intestinaltrakt oder (selten) anderen Organen.

\section{Mikrosporidiosen}

Bislang sind über zehn verschiedene Mikrosporidien-Arten als Erreger von intestinalen, okulären, renalen, hepatischen, pulmonalen und generalisierten Infektionen beim Menschen gefunden worden, die vorwiegend bei Immunkompromittierten mit lebensbedrohlichen Erkrankungen einhergehen können. Am häufigsten ist die intestinale Mikrosporidiose (insbesondere bei Aids mit fortgeschrittener Immundefizienz; CD4-Zellen meist $<50 / \mu \mathrm{l}$ ); vorwiegend durch eine chronische Infektion mit Enterocytozoon bieneusi (seltener Encephalitozoon intestinalis), die zu schweren chronischen Durchfällen mit Malabsorption sowie zu Cholangitiden führen kann (ähnlich der Kryptosporidiose). Seltener sind ein Befall anderer Organe oder generalisierte Infektionen (Encephalitozoon cuniculi, E. hellem, E. intestinalis) oder eine Keratokonjunktivitis (Encephalitozoon hellem, Nosema und andere Arten).

\section{Diagnostik}

Diese beruht auf dem Mikrosporidiennachweis in Biopsien der befallenen Organe; bei intestinalen Infektionen am besten in Dünndarmbiopsien (Duodenum, Ileum). Die Stuhluntersuchung (spezielle Färbungen s. Teil A, Kap. 3) kann als Suchmethode eingesetzt werden; lichtoptisch nur vorläufige Artzuordnung, definitive Identifikation und Artbestimmung elektronenmikroskopisch oder mittels PCR.

\subsection{6}

\section{Sexuell übertragbare Erkrankungen}

Außer den sog. klassischen Geschlechtskrankheiten können zahlreiche weitere Pathogene sexuell übertragen werden (Tabelle 22-15). Der klinische Verdacht hinsichtlich einer sexuell übertragenen Infektion ergibt sich am ehesten bei

- Haut- oder Schleimhautveränderungen im Genitalbereich,

- Beschwerden im Urogenitalbereich wie Schmerzen, Dysurie, Ausfluß aus Harnröhre oder Vagina,

- anamnestisch bekannten, ungeschützten Sexualkontakten, insbesondere zu Partnern mit hoher Promiskuität.
Es ist jedoch zu beachten, daß selbst bei klassischen venerischen Erkrankungen Symptome und Befunde von Seiten der Genitalorgane völlig fehlen können.

\subsubsection{1}

\section{Gonorrhö}

Das klinische Spektrum reicht von asymptomatischen Infektionen (wesentliche Quellen der Verbreitung) über die akute Gonorrhö bis zu chronischen Erkrankungen.

Bei Männern steht im Vordergrund die akute schmerzhafte Urethritis mit purulentem Sekret, die meist schon 2-5 Tage post infectionem auftritt sowie akute und chronische Epididymitis und Prostatitis mit Schmerzen.

Bei Frauen treten akute und chronische Zervizitis, Urethritis und Bartholinitis mit Ausfluß, Schmerzen und lokalen Entzündungserscheinungen auf. Komplikationen sind akute und chronische Endometritis und Salpingitis sowie akute Perihepatitis mit Schmerzen im rechten Oberbauch (z. T. mit Fieber und Allgemeinsymptomen).

Orale bzw. anale Übertragung können zu Pharyngitis oder Proktitis führen.

Gelegentlich kommt es zu einer generalisierten Infektion (Gonokokkensepsis) mit Fieber, Polyarthralgien und haemorrhagischen oder nekrotischen Hautinfiltraten. Seltenere Manifestationen sind Monarthritis, Meningitis und Endokarditis sowie Gonoblenorrhö und Neugeborenenblenorrhö durch perinatale Übertragung.

\section{Diagnostik}

Bei der akuten Gonorrhö gelingt der Nachweis von Neisseria gonorrhoeae oft bereits in Abstrichen (Gramund Methylenblaufärbung) von Urethra, Prostataexprimat oder Rektum bzw. Zervix und Sekreten von Krypten und paraurethralen bzw. Bartholini-Drüsengängen. Typisch ist die Anordnung in Diplokokken, die nach Phagozytose innerhalb des Zellplasmas der neutrophilen Granulozyten liegen. Bei Frauen, extragenitalen Manifestationen, Komplikationen und fraglicher Resistenz hat der Erregernachweis stets auch kulturell zu erfolgen (sofort nach Materialabnahme beimpfen, ansonsten Verwendung von Transportnährböden) einschließlich Resistenzbestimmung (Teil A, Kap. 3). Zudem ist ein Nachweis auch mittels molekularbiologischer Methoden (Ligasekettenreaktion u.a) möglich.

Häufig bestehen gleichzeitig andere sexuell übertragbare Infektionen (besonders Chlamydien, Trichomonaden und Lues), die diagnostisch berücksichtigt werden müssen (Tabelle 22-15). 
Tabelle 22-15. Sexuell übertragbare Erkrankungen: Erreger und Diagnostik

\begin{tabular}{|c|c|c|}
\hline Erreger & Erkrankung & Diagnostik \\
\hline \multicolumn{3}{|c|}{$\begin{array}{l}\text { Erreger, die genitale Läsionen verursachen können } \\
\text { Viren }\end{array}$} \\
\hline - Herpes-simplex-Virus & Herpes genitalis & Abschn. 22.4.1 \\
\hline - Humane Papillomaviren & $\begin{array}{l}\text { Genitale Warzen, genitoanale } \\
\text { Malignome }\end{array}$ & Klinisch, bioptisch \\
\hline - Molluscum-contagiosum-Virus & Molluscum contagiosum & Klinisch \\
\hline \multicolumn{3}{|l|}{ Bakterien } \\
\hline $\begin{array}{l}\text { - Chlamydia-trachomatis-Seroty- } \\
\text { pen D-K }\end{array}$ & Nichtgonorrhoische Urethritis & Abschn. 22.2.6 \\
\hline - C.-trachomatis-Serotypen L1-3 & Lymphogranuloma venereum & Abschn. 22.2.6 \\
\hline - Ureaplasma urealyticum & Nichtgonorrhoische Urethritis & Abschn. 22.2.6 \\
\hline - Mycoplasma hominis & Nichtgonorrhoische Urethritis & Abschn. 22.2.6 \\
\hline - Haemophilus ducreyi & Ulcus molle & Abschn. 22.2 .6 \\
\hline $\begin{array}{l}\text { - Treponema pallidum } \\
\text { - Gardnerella vaginalis }\end{array}$ & $\begin{array}{l}\text { Lues } \\
\text { Bakterielle Vaginosis }\end{array}$ & $\begin{array}{l}\text { Abschn. } 22.2 .6 \\
\text { Klinisch, Abstrich }\end{array}$ \\
\hline $\begin{array}{l}\text { - Calymmatobacterium granulo- } \\
\text { matis }\end{array}$ & $\begin{array}{l}\text { Granuloma inguinale (Dono- } \\
\text { vanosis) }\end{array}$ & Abschn. 22.2.6 \\
\hline \multicolumn{3}{|l|}{ Pilze } \\
\hline \\
\hline $\begin{array}{l}\text { Parasiten } \\
\text { - Trichomonas vaginalis }\end{array}$ & Genitale Trichomoniasis & Abschn. 22.2.6 \\
\hline \multicolumn{3}{|l|}{ Arthropoden } \\
\hline - Sacrcoptes scabiei & $\begin{array}{l}\text { Pediculosis p } \\
\text { Scabies }\end{array}$ & Auflichtlupe, Geschabsel \\
\hline \multicolumn{3}{|c|}{$\begin{array}{l}\text { Erreger, die in der Regel keine genitalen Läsionen verursachen } \\
\text { Viren }\end{array}$} \\
\hline - Hepatitisviren & Hepatitis A-D & Kap. 23 \\
\hline - Zytomegalovirus & $\begin{array}{l}\text { Zytomegalie bei Neugebore- } \\
\text { nen und Immunkompromit- } \\
\text { tierten }\end{array}$ & Abschn. 22.2.3 und 22.2.5 \\
\hline - HIV & Aids & Abschn. 22.2 .5 \\
\hline - HHV-8 & Kaposi Sarkom & Bioptisch (Kap. 21) \\
\hline - HTLV-1 & $\begin{array}{l}\text { Tropische spastische Parapare- } \\
\text { se, T-Zell Leukämie, Lym- } \\
\text { phom }\end{array}$ & Kap. 21 \\
\hline \multicolumn{3}{|l|}{ Bakterien } \\
\hline - Shigella spp. & Shigellose & Abschn. 22.2.4 \\
\hline - Campylobacter spp. & Campylobacterenteritis & Abschn. 22.2.4 \\
\hline - Salmonella spp. & Salmonellose & Abschn. 22.2.4 \\
\hline - B-Streptokokken & Neonatale Sepsis/Meningitis & Abschn. 22.2.1 und 22.2.2 \\
\hline \multicolumn{3}{|l|}{ Parasiten } \\
\hline - Giardia lamblia & Giardiasis & Abschn. 22.6.6 \\
\hline - Cryptosporidium parvum & Kryptosporidiose & Abschn. 22.2.5 \\
\hline - Entamoeba histolytica & Amöbiasis & Abschn. 22.6.5 \\
\hline - Enterobius vermicularis & Enterobiasis & Abschn. 22.6.13 \\
\hline - Strongyloides stercoralis & Strongyloidiasis & Abschn. 22.6.13 \\
\hline - Trichuris trichiura & Trichuriasis & Abschn. 22.6.13 \\
\hline
\end{tabular}

\subsubsection{2}

\section{Genitale Chlamydieninfektionen}

Infektionen durch Chlamydia trachomatis (Abschn. 22.3.24) sind sehr häufig (z. T. asymptomatisch) und können sich manifestieren als nichtgonorrhoische Urethritis, Proktitis, Epididymitis, Prostatitis, mucopurulente Zervizitis und Salpingitis. Typisch ist die postgonorrhoische Urethritis, die sich 2-3 Wochen nach Behandlung der Gonorrhö mit Amoxicillin oder Cephalosporinen entwickelt und mit serösem oder purulentem Ausfluß und Dysurie einhergeht.

Das vorwiegend in den Tropen vorkommende Lym- phogranuloma venereum (LGV) wird durch die C. trachomatis Serotypen L1-3 verursacht und führt zu chronisch infiltrativen, z. T. ulzerierenden Entzündungen an Haut und Schleimhäuten im genitoanorektalen Bereich mit häufiger Lymphknotenbeteiligung. Komplikationen sind Fistelbildungen und genitale Elephanthiasis.

\section{Diagnostik}

Erregernachweis aus Abstrichen, Prostataexprimat, Punktaten oder Biopsien mittels LCR oder PCR, Isolierung mittels Zellkultur (Teil A, Abschn. 3.3.1); Antigennachweis in zellreichen Abstrichen mittels direkter Im- 
munfluoreszenz oder in der Immunhistologie. IgG-Antikörper weisen die Exposition nach, IgM und IgA eine frische Infektion oder Reinfektion.

\subsubsection{3}

\section{Genitale Mykoplasmeninfektionen}

Ureaplasma urealyticum und Mycoplasma hominis sind fakultativ pathogen (häufig auch bei Gesunden im Urogenitaltrakt und Nasen-Rachen-Raum). Beide Mykoplasmenarten können jedoch Urethritis (15-20\% der nichtgonorrhoischen Urethritiden), Prostatitis und selten auch Pyelonephritiden verursachen und sind wahrscheinliche Ursache oder Mitursache einer bakteriellen Vaginose und aufsteigender genitaler Infektionen bei Frauen (Endometritis, Salpingitis, Adnexitis, Pelveoperitonitis, postabortales und postpartales Fieber).

\section{Diagnostik}

Die Erreger können kulturell (Teil A, Abschn. 3.2.2) aus Abstrichen, Prostataexprimat, Punktaten und Biopsien (sofortige Verimpfung oder Verwendung spezieller Transportmedien) sowie durch Antigennachweis (z. B. direkte Immunfluoreszenz) und mittels PCR nachgewiesen werden. Während der Nachweis aus primär sterilem Material diagnostisch ist, muß der Nachweis aus häufig besiedelten Schleimhäuten kritisch gewertet werden (ggf. Quantifizierung).

\subsubsection{4}

\section{Lues (Syphilis)}

Die Manifestationen der Infektion mit Treponema pallidum sind sehr unterschiedlich und reichen von der asymptomatischen Infektion (Latenz) bis zu schweren Organerkrankungen:

- Primärstadium (Lues I) bei sexueller Übertagung mit Primäraffekt (schmerzloses Ulkus) an der Eintrittspforte und regionärer Lymphadenopathie (Bubonen);

- Sekundärstadium (Lues II) mit hämatogener Generalisierung, sehr variabler Haut- und Schleimhautbeteiligung (makulopapulöse Exantheme, Plaques, Condylomata lata etc.) und gelegentlichen Organmanifestationen (Meningitis, Hepatitis, Nephritis u. a.);

- Tertiärstadium (Lues III) mit Syphiliden und Gummabildung;

- latente Syphilis, asymptomatische Neurosyphilis und Spätmanifestationen (Metalues und Neurolues) am Gefäßsystem (Aortitis, Aneurysmabildung) und ZNS (Tabes dorsalis, progressive Paralyse);

- konnatale Lues (Übertragung von der Mutter auf das Kind)

\section{Diagnostik}

Der direkte Erregernachweis sollte v. a. aus dem Primäraffekt sowie aus Haut- oder Schleimhautläsionen (und Lymphknotenaspiraten) bei Lues II und bei früher konnataler Lues versucht werden. Dies gelingt mittels Dunkelfeld-Mikroskopie, sensitiver jedoch mittels direkter Immunfluoreszenz und PCR (auch aus Liquor bei Verdacht auf Neurosyphilis). Zudem ist auch ein histologischer Nachweis (Silberfärbung, Immunfluoreszenz) aus Biopsaten von Organmanifestationen verschiedener Stadien möglich.

Ansonsten wird die Diagnose ganz überwiegend serologisch gestellt. Zur Verfügung stehen Tests, die spezifisch gegen Treponemen gerichtete Antikörper bestimmen (spezifische Treponemenantikörpertests, z. B. TPHA, FTA-abs) und nichttreponemenspezifische Reagintests, die Antikörper gegen Lipide beschädigter Wirtszellen und lipoidartige Treponemenantigene erfassen (z. B. Cardiolipin-Test, VDRL). Als Screeningtest wird heute bevorzugt der TPHA eingesetzt und als Bestätigungstest der IgG-IFT-abs (Teil A, Kap. 3, Tabelle 3-9). Dabei ist zu beachten, daß diese bei frischen Infektionen noch negativ sein können (ggf. Wiederholung nach 2-3 Wochen). Hinweise für floride Infektion, Behandlungserfolg und konnatale Lues geben IgM-Antikörpertests (z. B. 19S-IgM-IFT), Reagintests und KBR (Teil A, Kap. 3, Tabelle 3-9).

Bei Verdacht bzw. zum Ausschluß einer Neurolues (die zum Zeitpunkt der Untersuchung asymptomatisch sein kann) ist die gleichzeitige Antikörperbestimmung in Liquor und Serum (Bestimmung des Liquor-SerumIndex s. Teil A, Abschn. 3.6.3) erforderlich. Indikationen für die Untersuchung von Liquor sind:

- alle Spätstadien,

- neurologische, ophthalmologische und/oder das Hörorgan betreffende Symptome und pathologische Befunde,

- andere klinische Hinweise für aktive Infektion (z. B. Aortitis, Gummen, Iritis),

- HIV-Infektion,

- Nichttreponemenspezifische Aktivitätsmarker (Reagintests) mit einem Titer von $>1: 32$ und Infektionsdauer $>1$ Jahr bzw. unbekannte Dauer,

- wenn eine Behandlung mit anderen Medikamenten als Penicillin erforderlich bzw. geplant ist.

Typische Liquorbefunde der Neurosyphilis sind:

- mäßiggradige Pleozytose $(10-400 / \mu \mathrm{l})$,

- erhöhte Eiweißkonzentration $(0,46-2 \mathrm{~g} / \mathrm{l})$,

- Liquor-Serum-Index $>3,0$,

- (positive PCR).

Bei Nachweis einer sexuell übertragenen Lues müssen andere sexuell übertragbare Infektionen ausgeschlossen werden (venerische Infektionen, HIV, Hepatitis B). 


\subsubsection{5}

\section{Ulcus molle}

Haemophilus ducreyi (weltweit verbreitet, besonders in Entwicklungsländern) wird fast ausschließlich sexuell übertragen und dringt über kleine Schleimhaut- oder Hautverletzungen ein. Nach 2-3 Tagen entstehen eine oder mehrere Papeln, die sich pustulös umwandeln und nach 4-7 Tagen in ein schmerzhaftes, weiches und nicht induriertes Ulkus (weicher Schanker, Chancroid) mit scharf begrenztem Rand und entzündlich infiltrierter Umgebung übergehen. Bei einem Teil der Patienten $(<50 \%)$ entwickelt sich eine regionale Lymphadenitis (Bubo) mit Rötung, Schmerzen und z. T. auch Einschmelzung und Fistelung. Allgemeinsymptome und leichtes Fieber sind möglich.

\section{Diagnostik}

Gramfärbung (stäbchenförmige gramnegative Bakterien) und kulturelle Isolierung inklusive Resistenztestung aus Abstrichen, Punktaten oder Biopsien des Ulkusrandes (besonders bakterienreich) und ggf. auch Lymphknotenaspirat auf Selektivnährboden. Auch ein Nachweis mittels PCR ist möglich. Auf evtl. gleichzeitige Lues und LGV (Chlamydien) ist zu achten.

\subsubsection{6}

\section{Granuloma inguinale}

Das Granuloma inguinale (Donovanosis) wird durch das bislang nicht kultivierbare Calymmatobacterium granulomatis ausgelöst und führt zu gering kontagiösen, indolenten, progressiv wachsenden Geschwüren und Gewebsindurationen, v. a. in den Lymphknoten der Leistenbeugen (fast nur bei Männern vorkommend, vorwiegend in den Tropen verbreitet).

Etwa 30 Tage nach Sexualkontakt bildet sich eine $\mathrm{Pa}$ pel, die ulzeriert und auf dem Grund rotes Granulationsgewebe enthält. Superinfektionen der Ulzera mit anderen Bakterien sind häufig. Pseudobubonen bilden sich in der Leistenregion durch Induration des Gewebes über den Lymphknoten. Mehrere nahe beieinander liegende Ulzera können konfluieren.

\section{Diagnostik}

Im Abstrichmaterial oder in Biopsien können Donovan-Körper als Akkumulation der Bakterien innerhalb und ausserhalb der neutrophilen Granulozyten nachgewiesen werden. Am besten sind die haufenförmig zusammenliegenden Bakterien im Plasma der Makrophagen und Granulozyten von Giemsa- und gramgefärbten Abklatschpräparaten des Ulkus nachzuweisen.
22.2.6.7

Trichomoniasis

Trichomonas vaginalis ist weltweit verbreitet und ein häufiger Keim des unteren Genitaltraktes. Außer einer milden Urethritis sind Männer meist asymptomatisch (gelegentlich Komplikation: Prostatitis). Bei Frauen entwickelt sich jedoch häufig eine Kolpitis mit Ausfluß, Juckreiz und Schmerzen.

\section{Diagnostik}

Unter dem Mikroskop sind die Trichomonaden im frisch abgenommenen und sofort untersuchten Nativpräparat von vaginalem oder urethralem Ausfluß als bewegliche Flagellaten leicht zu erkennen (besser als in gefärbten Abstrichen). Sie können noch sensitiver mittels direkter Immunfluoreszenz oder kulturell aus Abstrichen (Urethra, Vaginalabstrich, Prostataexprimat) nachgewiesen werden.

\subsection{7}

\section{Fieber unbekannter Ursache (FUO)}

Dies ist definiert als Fieber von mindestens 3 Wochen Dauer, dessen Ursache nach mindestens einer Woche diagnostischer Bemühungen nicht definiert werden konnte. Neben diesem klassischen FUO („fever of unknown origin") bezeichnet man heute auch andere fieberhafte Zustände als Fieber unklarer Ursache:

- nosokomiales Fieber unklarer Ursache: im Krankenhaus neu aufgetretenes Fieber, das nach 3 Tagen differentialdiagnostischer Untersuchungen persistiert und noch nicht aufgeklärt werden konnte,

- neutropenisches Fieber unklarer Ursache: Fieber bei Neutropenie ohne klinischen Fokus und ohne Erregernachweis, das nach 3 Tagen trotz Behandlung persistiert.

Die Aufklärungsrate (20-25\%) des klassischen FUO hat sich in den letzten 3 Jahrzehnten scheinbar nicht verbessert, sondern verringert, da viele febrile Erkrankungen inzwischen vor Ablauf von 3 Wochen einerseits diagnostiziert, andererseits durch relativ ungezielte antimikrobielle Therapie erfolgreich behandelt werden.

Infektionen können heute nur noch zu etwa $25 \%$, maligne Erkrankungen nur noch etwa $\mathrm{zu}$ 10-15\% als Ursache des klassischen FUO diagnostiziert werden. Bei etwa $40 \%$ der Patienten liegen subakute bis chronische entzündliche Erkrankungen mit vermuteter Autoimmunpathogenese bzw. ohne Erregernachweis vor (z. B. Sarkoidose, Thyreoiditis, M. Crohn, Arteriitis temporalis, M. Still, allergische Alveolitis). Zudem muß an die Möglichkeit von vorgetäuschtem bzw. artifiziellem Fieber gedacht werden. 


\section{Diagnostisches Vorgehen}

- Definitionsgemäß ist eine Basisdiagnostik bereits durchgeführt worden, $d$. h. sorgfältige Anamnese und klinische Untersuchung, Routinelabor (s. unten), EKG, abdominelle Sonographie und Thoraxröntgenuntersuchung. Zunächst ist zu überprüfen, ob die Basisdiagnostik ergänzt und wiederholt werden muß.

- Ausschluß von vorgetäuschtem oder artifiziellem Fieber: Messung mit elektrischem Thermometer, Messung in Anwesenheit medizinischen Personals sowie simultane Temperaturmessung von Urin und oraler/rektaler Temperaturen. Polymikrobielle Bakteriämien mit wechselnden Erregern sind verdächtig auf artifizielle Bakteriämie (Selbstinjektionen).

- Ausschluß von Medikamentenfieber: Soweit möglich Absetzen aller Medikamente, Temperaturen sollten innerhalb von $48 \mathrm{~h}$ nachlassen.

\section{Weiterführende Diagnostik}

Im Rahmen der erweiterten/ergänzten Basisdiagnostik sollte es möglich sein, häufige Infektionen (pulmonale, Harnwegs-, gastrointestinale, Wundinfektionen und Phlebitiden) oder andere häufige Ursachen von Fieber (Hyperthyreose) auszuschließen. Sind die Untersuchungen nicht richtungweisend und persistiert das Fieber 3 Wochen, ist formal die Diagnose Fieber unklarer Genese zu stellen. Die dann weiterführende Labor- und apparative Diagnostik muß soweit möglich individuell den anamnestischen Hinweisen oder körperlichen Befunden angepaßt werden und die Sensitivität/Spezifität der diagnostischen Methoden berücksichtigen. Zudem ist eine vollständige ophthalmologische Untersuchung notwendig sowie ggf. weitere Fachuntersuchungen (z. B. HNO, Urologie, Gynäkologie).

Der Tuberkulintest ist als gestufte Intrakutantestung nach Mendel-Mantoux (initial 1 TE bei Verdacht, ansonsten $10 \mathrm{TE}$ ) durchzuführen, Multi-Test Merieux zum Ausschluß einer Anergie.

\section{Labordiagnostik}

- Basisdiagnostik:

Blutbild einschließlich Differentialblutbild, BSG, CRP, Transaminasen, Lipase, Urinstatus, Retentionswerte, Elektrolyte, Serumeiweißelektrophorese, Akute-Phase-Proteine, Schilddrüsenhormone (inklusive TSH), Blutkulturen, Kulturen aus Mittelstrahlurin, Sputum, Stuhl und auffälligen Sekretionen; CMV-, EBV-, Lues-, Toxoplasmose-, HIV-Serologie, antinukleäre Antikörper und Rheumafaktor.

- Erweiterte Labordiagnostik: Mikroskopisches Differentialblutbild, ggf. weitere immunologische Untersuchungen: ds-DNS- und ENA-Antikörper, C-ANCA und P-ANCA, quantita- tive Immunglobuline (inklusive IgE und $\operatorname{Ig} D$ bei Verdacht auf Hyper-IgD-Syndrom), Antikörper gegen Peroxidase und Thyreoglobulin, Komplement $\mathrm{C}_{3}$ und $\mathrm{C}_{4}$, Lymphozytenphänotypisierung (nur indiziert bei gesicherten opportunistischen Infektionen, nachgewiesener HIV-Infektion oder auffälligen Veränderungen von Lymphozytenzahl oder -morphologie), Ferritin (bei Verdacht auf M. Still). Der Wert der IgG-Subklassen-Konzentrationsbestimmung ist gering, ebenso die Bedeutung der ACE-Messung zur Diagnosesicherung einer Sarkoidose. Bei jüngeren Erwachsenen mit anamnestischer Angina tonsillaris bzw. Pharyngitis: Antistreptolysintiter plus Rachenhinterwand-/Tonsillenabstrich auf A-Streptokokken.

BSG-Erhöhung auf $>50 \mathrm{~mm}$ in der 1 . Stunde bei älteren Patienten ( $>55$ Jahre) mit Fieber unklarer Genese sollte den Verdacht auf eine Arteriitis temporalis lenken und ggf. auch auch sonstige klinische Zeichen zur beidseitigen Biopsie führen.

Blutkulturen: 3 Blutkultursets (je mindestens $10 \mathrm{ml}$, Abstand 12-24 h) haben bei kontinuierlicher Bakteriämie in bis zu $95 \%$ ein positives Ergebnis. Warten auf Fieberanstieg zur Abnahme ist nicht notwendig. Negative Blutkulturen machen eine bakterielle Endokarditis unwahrscheinlich, schließen sie jedoch nicht aus, insbesondere bei Kunstklappenträgern, bei antibiotischer Vorbehandlung oder bei langsam bzw. nur unter bestimmten Bedingungen wachsenden Bakterien (z. B. Brucella, Haemophilus spp., Bartonella). Durch Mitteilung an das mikrobiologische Labor sollte veranlaßt werden, daß Blutkulturen länger und auch unter erhöhter $\mathrm{CO}_{2}$-Spannung inkubiert werden (Teil A, Abschn. 3.2.2). Bei dringendem Verdacht auf Endokarditis und negativen Kulturen sind serologische Untersuchungen hinsichtlich Q-Fieber und Bartonellosen angezeigt.

- Infektionsserologie:

Initiale Antikörperdiagnostik (außer Lues) wiederholen falls zunächst negativ (EBV, CMV, Toxoplasmose, HIV). Zusätzlich Antikörperdiagnostik für Brucellose, Q-Fieber, Borreliose, Bartonellose, Chlamydieninfektionen, Yersiniosen und Hepatitis C. Die Spezifität von Borrelien-Antikörpem sollte ggf. mittels Immunoblot geklärt werden. Bei fehlendem HIV-Antikörpernachweis muß bei begründetem Verdacht auf eine frische Infektion eine HIVDNS-Provirus-PCR durchgeführt werden; in ähnlicher Weise kann es sinnvoll sein, CMV-Antigen in Blutleukozyten, Rachenspülwasser und Urin bestimmen zu lassen. Wenig hilfreich sind serologische Untersuchungen auf Listerien-, Salmonellen-, Candida-, Aspergillus- und Plasmodienantikörper. Weitere Infektionsserologie nur gezielt nach Rücksprache mit infektiologischem Konsiliarius oder klinischem Mikrobiologen. Serum für einen späteren 
Nachweis eines ansteigenden Antikörpertiters (d. h. mindestens vierfacher Anstieg) sollte asserviert werden.

\section{Bildgebende Diagnostik}

- Sonographie:

Abdominelle Sonographie (Basisdiagnostik) ggf. wiederholen; Schilddrüsensonographie; Temporalarterien-Farbdopplersonographie (relativ hohe Spezifität bei geübten Untersuchern) bei klini-

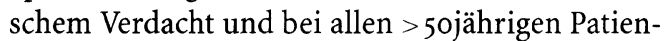
ten mit BSG-Beschleunigung. Echokardiographie: Screening-Methode zur Erkennung von Klappenvegetationen (mit einer Sensitivität von ca. $80 \%$ ); mit der transösophagealen Echokardiographie erhöhte Sensitivität zur Erkennung von Vegetationen (95\%).

- Computertomographie (CT):

Sensitiver als abdominelle Sonographie und Galliumszintigraphie bei der Identifizierung zerebraler, intraabdomineller und intrathorakaler Abszesse, zur Darstellung retroperitonealer, retrosternaler und mesenterialer Lymphknoten, und zur Darstellung von Läsionen in parenchymatösen Organen. Sie ist bei der Darstellung kalzifizierender Läsionen der MRT-Untersuchung und beim Nachweis einer Sinusitis der konventionellen Röntgendiagnostik überlegen.

- Magnetresonanztomographie (MRT): Höhere Sensitivität als CT für ZNS-Läsionen und zum Nachweis von Abszessen. Sensitive Methode zur Diagnose einer Osteomyelitis.

- Szintigraphie:

Szintigraphische Methoden (Indium ${ }^{111}$-markierte Leukozyten oder polyklonale Immunglobuline, Gallium $^{67}$-, Technetium ${ }^{99 \mathrm{~m}}$-markierte antigranulozytäre Antikörper) haben eine hohe Rate falschpositiver und falsch-negativer Ergebnisse und gewährleisten keine ausreichende Lokalisierung bzw. anatomische Zuordnung. CT-Untersuchungen werden daher bevorzugt bzw. zumindest in Kombination eingesetzt. Biopsien sollten nicht auf der alleinigen Grundlage einer Szintigraphie erfolgen.

- Röntgenkontrastdarstellungen:

Dünndarmdoppelkontrastdarstellungen sind lediglich bei entsprechendem Verdacht auf entzündliche Darmerkrankung indiziert. Die Koloskopie ist dem Kolonkontrasteinlauf in der Sensitivität überlegen und kann durch Biopsien zur definitiven Diagnose führen.

\section{Biopsien}

Sorgfältige Planung ist notwendig: Bei dringendem Infektionsverdacht, aber auch dann, wenn z. B. eine Tuberkulose ausgeschlossen werden soll, sind die Biopsate zu teilen und in jeweils adäquaten Transportmedien für alle erforderlichen histopathologischen und mikrobiologischen Untersuchungen einzusenden bzw. zu überbringen. Ein Teil des Gewebeblocks sollte, wenn möglich, aufbewahrt werden für zukünftige Untersuchungen.

- Lymphknoten:

Vergrößerte Lymphknoten im Rahmen eines Fie-

bers unklarer Genese müssen biopsiert oder exstirpiert werden. Eventuell kann eine Feinnadelaspiration mit Zytologie bereits wertvolle Hinweise auf die Genese geben; allerdings sind Ziehl-Neelsenund Warthin-Starry-Färbung an zytologischen Präparaten nicht ausreichend sensitiv. Die diagnostische Treffsicherheit sowohl für die histologische Begutachtung als auch die zytologische Begutachtung sind abhängig von der Erfahrung des Untersuchers. Bei fehlender Diagnose aus der Biopsie ist eine Lymphknotenexstirpation mit histologischer und, bei geringer Wahrscheinlichkeit für ein Malignom, mikrobiologischer Aufarbeitung anzuschließen. Neben der Histologie sind Mikroskopie und Kultur auf Mykobakterien, Warthin-Starry-Färbung, aerobe und anaerobe Kultur sowie Pilzkulturen angezeigt.

- Haut:

Alle auffälligen Hautareale sollten photodokumentiert und (bei negativer Luesserologie und Fehlen einer eitrigen Sekretion) mittels Stanzbiopsie histologisch untersucht werden. Bei Verdacht auf Tuberkulose oder atypische Mykobakteriose Färbung und Kultur auf Mykobakterien; Pilzkulturen besonders bei Verdacht auf Sporotrichose; bei Verdacht auf Hautleishmaniose zusätzlich Tupfpräparat anfertigen (s. Abschn. 22.6.2).

- Weitere mögliche Organe (je nach hinweisenden Befunden): Temporalarterien, Pleura, Lunge, Niere, Muskel, Nerven, Darm, Feinnadelaspirationszytologie der Schilddrüse, Nasenschleimhaut (bei Verdacht auf M. Wegener), Lippen (bei Verdacht auf SjögrenSyndrom).

- Knochenmark:

Die diagnostische Sensitivität liegt bei $15 \%$, die Spezifität ist jedoch höher als bei Leberbiopsien. Hämatologische, infektiöse oder granulomatöse Erkrankungen werden am häufigsten diagnostiziert. Bei immunkompetenten Patienten besteht nur eine geringe Sensitivität für die Diagnose einer disseminierten Mykobakterieninfektion (<5\%).

- Leber:

Eine Biopsie ist insbesondere dann sinnvoll, wenn eine Hepatomegalie vorliegt, klinische oder laborchemische Befunde auf eine Leberbeteiligung hinweisen oder eine disseminierte Tuberkulose oder Pilzinfektion vorliegen könnte; $15-30 \%$ der Leberbiopsien sind in diesem Fall diagnostisch. Sollte ei- 
ne Diagnose auch aus der Leberbiopsie nicht gestellt werden, bleibt die Ursache des Fiebers häufig unklar. Bei lokalisierten Veränderungen in der bildgebenden Diagnostik sollte eine gezielte Biopsie erfolgen. Bisweilen ist dafür eine Laparoskopie notwendig. Routineuntersuchungen: Kultur auf bakterielle Erreger (aerob und anaerob), Mykobakterien und Pilze, Mikroskopie auf Bakterien, Mykobakterien, Pilze und andere Erreger (Dieterle's Silber-Imprägnierung, Warthin-Starry-Färbung); molekular-biologische Diagnostik (z. B. Tuberkulose-PCR, Bartonellen-PCR) in Abhängigkeit von der Verdachtsdiagnose und den Erfahrungen des jeweiligen Labors. Die Sensitivität der histologischen Diagnostik ist abhängig von der Erfahrung des bearbeitenden Pathologen. Gegebenenfalls sollte ein Stanzzylinder in Formalin asserviert und bei unklaren Befunden zu einem Referenzpathologen gesandt werden.

\section{Laparotomie und Laparoskopie}

Eine explorative Laparotomie ist selten indiziert. Heute werden früher mittels Laparotomie diagnostizierte Erkrankungen häufig durch bildgebende Verfahren (CT, MRT) erkannt. Eine Laparoskopie ist zu erwägen, wenn sich bei Patienten mit Fieber unklarer Genese und abdominellen Symptomen in der sonstigen Diagnostik (einschließlich transkutaner Leberbiopsie) kein wegweisender Befund ergeben hat. Insbesondere tuberkulöse Peritonitis, nekrotisierende Vaskulitis oder peritoneale Karzinose mögen in manchen Fällen nur so zu diagnostizieren sein.

\subsection{8}

\section{Importierte Infektionskrankheiten}

Die häufigsten Erkrankungen während wie nach Auslandsreisen sind gastrointestinale Infektionen gefolgt von Infektionen der oberen Atemwege und im HNOBereich. Bei Reisen unter einfachen Bedingungen oder längerfristigen Aufenthalten in tropischen Entwicklungsländern sind auch intestinale Parasitosen (Giardiasis, Amöbiasis, intestinale Wurminfektionen) nicht selten. Hepatitis A ist die häufigste durch eine Impfung vermeidbare Importerkrankung bei Reisenden. Insgesamt handelt es sich somit vorwiegend um Infektionskrankheiten mit ubiquitärer Verbreitung, die zwar in Tropen und Subtropen meist wesentlich häufiger vorkommen (tropentypische Erkrankungen), jedoch keine eigentlichen Tropenkrankheiten sind.

Die wichtigste tropenspezifische Erkrankung ist die Malaria, insbesondere bei Aufenthalten in Hochendemiegebieten und fehlender oder unzureichender Prophylaxe. Andere tropenspezifische Erkrankungen sind mit Ausnahme von Dengue-Fieber und einigen anderen Arbovirusinfektionen bei Reisenden relativ selten oder mit speziellen Expositionsrisiken verbunden.
Dennoch können sie erhebliche diagnostische Probleme bereiten.

\section{Anamnestische Hinweise}

Diese sind oft richtungsweisend sowohl für den initialen Krankheitsverdacht hinsichtlich importierter Infektionskrankheiten wie für Differentialdiagnostik und weiteres Vorgehen. Zusätzlich zu den sonst üblichen anamnestischen Angaben müssen detaillierte Angaben und Daten zu folgenden Fragen erhoben werden:

- Reiseanamnese bzw. Herkunftsland,

- spezielle Expositionen und Risiken (Tabelle 22-16),

- ggf. durchgeführte Vorbeugemaßnahmen (Impfungen, Chemoprophylaxe).

Tabelle 22-16. Expositionsrisiken und importierte Infektionen

\begin{tabular}{|c|c|}
\hline Expositionsrisiko & Infektionskrankheiten \\
\hline $\begin{array}{l}\text { Unsichere Nah- } \\
\text { rungsmittel (roh, } \\
\text { ungenügend er- } \\
\text { hitzt oder nicht } \\
\text { frisch verzehrt) }\end{array}$ & $\begin{array}{l}\text { Infektiöse Enteritis (s. Abschn. 22.2.4), } \\
\text { Amöbiasis, Askariasis, Echinokokkose } \\
\text { Giardiasis, Hepatitis A, Hepatitis E, Po- } \\
\text { liomyelitis, Trichuriasis, Toxocariasis, } \\
\text { Typhus abdominalis, Zystizerkose u. a. }\end{array}$ \\
\hline \multicolumn{2}{|c|}{ Spezielle Nahrungsmittel: } \\
\hline Fleisch & $\begin{array}{l}\text { Campylobacter, EHECa, Salmonellosen, } \\
\text { Taeniasis, Toxoplasmose, Trichinose }\end{array}$ \\
\hline - Fisch & $\begin{array}{l}\text { Anisakiasis, Capillariasis, Clonorchiasis, } \\
\text { Diphyllobothriasis, Gnathostomiasis, } \\
\text { Opisthorchiasis }\end{array}$ \\
\hline $\begin{array}{l}\text { - Krebse und } \\
\text { Krabben }\end{array}$ & $\begin{array}{l}\text { Angiostrongyliasis, intestinale Tremato- } \\
\text { deninfektionen, Paragonimiasis }\end{array}$ \\
\hline $\begin{array}{l}\text { - Milch, Milch- } \\
\text { produkte }\end{array}$ & $\begin{array}{l}\text { Brucellose, Kryptosporidiose, Listeriose, } \\
\text { Tuberkulose }\end{array}$ \\
\hline - Wasserpflanzen & $\begin{array}{l}\text { Fasciolopsiasis (z. B. Wassernüsse), Fas- } \\
\text { ciolose (z. B. Brunnenkresse) }\end{array}$ \\
\hline $\begin{array}{l}\text { Unsicheres Trink- } \\
\text { wasser }\end{array}$ & $\begin{array}{l}\text { Siehe Nahrungsmittel, Ancylostomiasis, } \\
\text { Dracunculiasis }\end{array}$ \\
\hline $\begin{array}{l}\text { Insektenstiche/-bisse } \\
\text { - Meist ohne Re- } \\
\text { aktion an der } \\
\text { Stich-/Bißstelle }\end{array}$ & $\begin{array}{l}\text { Arbovirosen, Babesiosen, Ehrlichiose, } \\
\text { Filariosen, Fleckfieber-Rickettsiosen, } \\
\text { Leishmaniosen, Malaria, Pest, Q-Fieber, } \\
\text { Rückfallfieber-Borreliosen, Tularämie }\end{array}$ \\
\hline $\begin{array}{l}\text { - Häufig mit Re- } \\
\text { aktion an der } \\
\text { Stich/Bißstelle }\end{array}$ & $\begin{array}{l}\text { Lyme-Borreliose, Trypanosomiasen } \\
\text { (Chagas-Krankheit, Schlafkrankheit), } \\
\text { Tsutsugamushi-Fieber, Zeckenbißfieber- } \\
\text { rickettsiosen }\end{array}$ \\
\hline Sexualkontakte & $\begin{array}{l}\text { Sexuell übertragbare Erkrankungen } \\
\text { (s. Abschn. 22.2.6) }\end{array}$ \\
\hline Barfußlaufen & $\begin{array}{l}\text { Hakenwurminfektion, kutane Larva mi- } \\
\text { grans, Strongyloidiasis, Tungiasis }\end{array}$ \\
\hline Süßwasserkontakt & Leptospirose, Schistosomiasis \\
\hline Tierkontakte & $\begin{array}{l}\text { Affenpocken, Argentinisches/bolivianisches } \\
\text { HF', Balantidiasis, Bartonellosen, Brucello- } \\
\text { sen, Ebolafieber, Erysipeloid, Hantavirusin- } \\
\text { fektionen, Krim-Kongo-Fieber, Kryptokok- } \\
\text { kose, Lassafieber, Leptospirose, lymphozy- } \\
\text { täre Choriomeningitis, Milzbrand, Orni- } \\
\text { those, Pasteurellose, Q-Fieber, Rattenbiß- } \\
\text { fieber, Rift-Tal-Fieber, Tollwut, Tularämie }\end{array}$ \\
\hline
\end{tabular}

a Enterohämorrhagische E. coli.

${ }^{\mathrm{b}} H F$ : hämorrhagisches Fieber. 
Bei vielen Erkrankungen ergeben sich hieraus bereits entscheidende Hinweise. Andererseits können bestimmte Infektionen allein schon geographisch oder aufgrund fehlender Exposition (z. B. Schistosomiasis bei fehlendem Süßwasserkontakt) ausgeschlossen werden.

\section{Diagnostisches Vorgehen}

Abstufung und Dringlichkeit des Vorgehens richten sich nach Aktualität und Schweregrad der Erkrankung sowie Lebensalter und eventuellen Grunderkrankungen des Patienten. Bei der Mehrzahl der Patienten lassen sich die Symptome einem oder mehreren Leitsymptomen zuordnen. Die häufigsten sind:

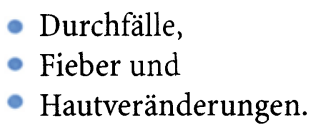

Bei allen wesentlichen nach Auslandsaufenthalt oder bei ausländischen Patienten auftretenden Erkrankungen, die Probleme bei der Diagnostik oder Behandlung bereiten, empfiehlt sich die konsiliarische Beratung mit dem Infektiologen, klinischen Mikrobiologen und Tropenmediziner sowie ggf. die Mit- oder Weiterbehandlung durch eine Einrichtung mit spezieller tropenmedizinischer Ausrichtung.

\section{Leitsymptom Fieber}

Fieber ist eine häufige, während und nach Tropenreisen auftretende Krankheitserscheinung und stellt bei Erkrankungen nach Rückkehr das zweithäufigste Leitsymptom dar (in ca. 15-25\% aller Fälle). Die Mehrzahl der importierten fieberhaften Erkrankungen zeigt einen akuten selbstlimitierten Verlauf. Ursächlich liegen meist Infektionen des Magen-Darm-Trakts oder Atemwegsinfektionen sowie andere ubiquitär verbreitete Infektionen zugrunde. Tropenspezifische Ursachen stellen mit Ausnahme von Malaria und Arbovirosen nur einen kleinen Anteil.

\section{Diagnostik}

Bei jeder fieberhaften Erkrankung nach Aufenthalt in Malariaendemiegebieten steht die rasche diagnostische Klärung einer Malaria wegen ihrer Häufigkeit, Dringlichkeit und potentiellen Gefährlichkeit im Vordergrund (s. Abschn. 22.6.1).

Daher gilt: Jedes Fieber nach Tropenaufenthalt ist malariaverdächtig (bis zum Beweis des Gegenteils). Die frühzeitige Diagnose ist entscheidend zur Vermeidung von Komplikationen und Todesfällen.

Nach Ausschluß einer Malaria richten sich die differentialdiagnostischen Überlegungen und das weitere Vorgehen nach der Anamnese, der Schwere des Krankheitsbildes, zusätzlichen Symptomen, klinischen Befunden und weiteren Untersuchungsbefunde (Laborbefunde, apparative Diagnostik).
Tabelle 22-17. Basisuntersuchungen bei Leitsymptom Fieber und Verdacht auf importierte Infektionskrankheit

Detaillierte Anamnese inkl. Expositionsrisiken

(Tabelle 22-16)

Vollständige klinische Untersuchung

Dicker Tropfen und Blutausstrich

Vollständiges Blutbild inkl. Differenzierung

Leberenzyme, LDH, CK, Retentionswerte, Glukose, Elektrolyte

BSG, CRP

- Blutkultur

Urinstatus, Urinkultur

Bakteriologische Stuhluntersuchung

Parasitologische Stuhluntersuchung

EKG

Röntgenaufnahme des Thorax

Abdominelle Sonographie

Neben der Malariadiagnostik sind weitere Basisuntersuchungen (Tabelle 22-17) erforderlich, die oft bereits wesentliche Hinweise auf das Vorliegen weiterer häufiger und dringlich therapiebedürftiger Infektionen oder bestimmter Infektionssyndrome und Organinfektionen ergeben:

- Auch bei unklaren fieberhaften Erkrankungen finden sich nicht selten eindeutig pathologische Urinbefunde oder radiologisch feststellbare Infiltrate der Lunge, auch ohne daß die typischen klinischen Symptome einer Harnwegsinfektion, Pneumonie oder Lungentuberkulose vorliegen.

- Mittels Blutkultur können Typhus abdominalis, Paratyphus, septische Infektionen und weitere bakterielle Infektionen (Brucellose, bakterielle Endokarditis, Miliartuberkulose, Listeriose, Melioidose) erfaßt werden. Dabei ist zu beachten, daß eine antibiotische Vorbehandlung die diagnostische Ausbeute erheblich beeinträchtigen kann. Eine Kultur aus Knochenmark kann in diesem Fall sensitiver sein.

- Zusätzlich sollten stets bakteriologische Urin- und Stuhluntersuchungen durchgeführt werden. Enteritiserreger wie Campylobacter jejuni und Salmonellen können (insbesondere bei Immunkompromittierten) auch fieberhafte Erkrankungen ohne Enteritis-Symptomatik verursachen.

- Sonographisch lassen sich neben Hepato- oder Splenomegalie v. a. Amöbenleberabszesse und pyogene Abszesse parenchymatöser Bauchorgane erfassen. Im Frühstadium von Amöbenleberabszessen kann die Darstellbarkeit eingeschränkt sein, so daß kurzfristige Wiederholungen angezeigt sind.

Wenn sich aus den Basisuntersuchungen weder eine Diagnose bzw. ein konkreter Diagnoseverdacht noch richtungsweisende Befunde ergeben, ist eine weitere Stufendiagnostik (Abb. 22-1) erforderlich, die auch seltenere Fieberursachen einschließt (Tabelle 22-18). Hierbei empfiehlt sich unter Berücksichtigung von Anamnese und weiteren Befunden eine schrittweise 


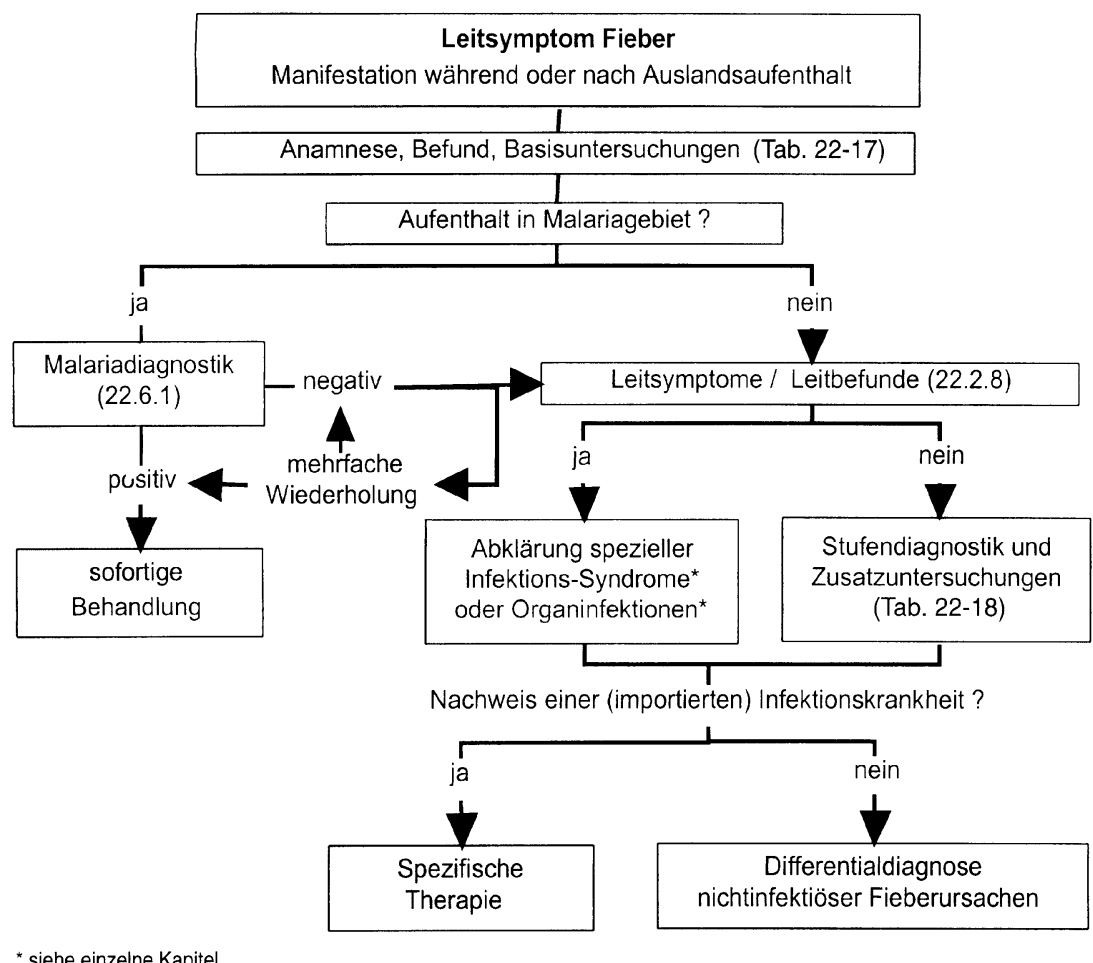

* siehe einzelne Kapitel

\begin{tabular}{|c|c|}
\hline Labor & $\begin{array}{l}\text { Mehrfache Wiederholung von dickem Tropfen und Blut- } \\
\text { ausstrich } \\
\text { Mehrfache Blutkulturen (inkl. Brucellosen, Melioidose, Yer- } \\
\text { siniosen) } \\
\text { - Wiederholte Urin-, Stuhl- und Sputumkulturen (inkl. Tbc) } \\
\text { Ergänzende Laboruntersuchungen (Pankreasenzyme, } \\
\text { Gerinnungsparameter, Elektrophorese u. a.) } \\
\text { ASL, Rheumafaktor, ANA, ANCA }\end{array}$ \\
\hline Serologie & 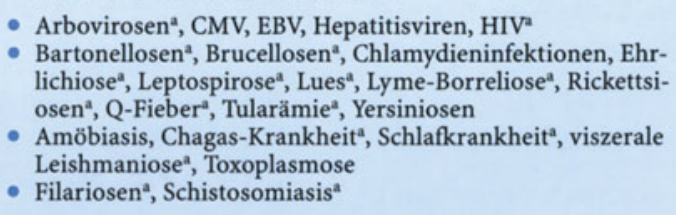 \\
\hline $\begin{array}{l}\text { Bildgebende } \\
\text { Diagnostik }\end{array}$ & $\begin{array}{l}\text { Wiederholung der abdominellen Sonographie } \\
\text { - Echokardiographie } \\
\text { - CT (Abdomen, Thorax, ggf. Schädel, Wirbelsäule) }\end{array}$ \\
\hline Punktionen & - Knochenmark (Zytologie, Histologie, Kulturen) \\
\hline Endoskópie & Rekto-/Sigmoidoskopie \\
\hline $\begin{array}{l}\text { Zusatzuntersuchungen } \\
\text { (nur bei gezielter Indikation) }\end{array}$ & $\begin{array}{l}\text { Weitere Laboruntersuchungen (s. Abschn. 22.2.7) } \\
\text { Weitere radiologische Untersuchungen (s. Abschn. 22.2.7) } \\
\text { MRT (s. Abschn. 22.2.7) } \\
\text { Szintigraphische Untersuchungen (s. Abschn. 22.2.7) } \\
\text { Weitere endoskopische Untersuchungen (z. B. Gastroduo- } \\
\text { denoskopie, Koloskopie, ERCP, Bronchoskopie; } \\
\text { s. Abschn. 22.2.7) } \\
\text { Invasive Untersuchungen (z. B. Leberbiopsie, weitere Or- } \\
\text { ganbiopsien, Laparaskopie, explorative Laparatomie, } \\
\text { s. Abschn. 22.2.7) }\end{array}$ \\
\hline
\end{tabular}

a Nur bei möglichem geographischem und/oder expositionellem Risiko.
Abb. 22-1. Vorgehen bei Fieber und Verdacht auf importierte Infektionskrankheit

Tabelle 22-18. Erweiterte Stufendiagnostik bei Leitsymptom Fieber und Verdacht auf importierte Infektionskrankheit (zusätzlich zur Basisuntersuchung s. Tabelle 22-17) 
Abklärung der in Frage kommenden importierten Infektionskrankheiten nach ihrer Wahrscheinlichkeit und Dringlichkeit. Zusätzlich müssen allerdings zahlreiche ubiquitäre Infektionen (s. Abschn. 22.2.7) und nichtinfektiöse Fieberursachen mitberücksichtigt werden.

Die serologische und ggf. auch kulturelle und molekularbiologische Diagnostik hinsichtlich der in bestimmten Regionen umfangreichen Palette von Arbovirosen (s. Abschn. 22.4.11) sollte in Absprache mit dem Virologen bzw. Tropenmediziner erfolgen. Sie ist indiziert bei Erkrankungen mit schwerem Verlauf oder Komplikationen (Enzephalitis, Hämorrhagien), bei begründetem Verdacht auf das Vorliegen seuchenhygienisch relevanter Infektionen (Gelbfieber, virale hämorrhagische Fieber) und bei epidemiologischen Fragestellungen. Bei unkompliziert und selbstlimitiert verlaufenden fieberhaften Importerkrankungen ist diese relativ aufwendige Diagnostik mangels therapeutischer oder seuchenhygienischer Konsequenzen nicht routinemäßig erforderlich.

\section{Leitsymptom Durchfälle}

Durchfälle und andere gastrointestinale Beschwerden sind die häufigsten Gesundheitsstörungen während
Tropenaufenthalten. Diarrhö ist auch das häufigste Leitsymptom importierter Infektionskrankheiten bei Tropenrückkehrern ( $<50 \%$ der Fälle). Meist handelt es sich um sogenannte Reisediarrhöen mit unkompliziertem und selbstlimitiertem Verlauf. Ursächlich liegt am häufigsten eine Infektion mit enterotoxinbildenden Escherichia coli (ETEC) zugrunde. Daneben kommt jedoch eine Vielzahl anderer Erreger in Frage (s. oben: Tabelle 22-10). Schwerere Verläufe mit behandlungsbedürftigen Flüssigkeits- und Elektrolytverlusten und/ oder Dysenterie wurden in verschiedenen Studien in 3$15 \%$ der Fälle beobachtet.

\section{Diagnostik}

Diese entspricht weitgehend der bei Verdacht auf infektiöse Enteritis (s. Abschn. 22.2.4). Neben den ubiquitär vorkommenden Durchfallerregern müssen je nach Aufenthaltsort v. a. verschiedene parasitäre Erreger (Amöben, Wurminfektionen) und bei profusen wäßrigen Durchfällen auch die Cholera mitberücksichtigt werden (Abb. 22.2). Zudem muß stets daran gedacht werden, daß Durchfälle und andere gastrointestinale Beschwerden auch im Rahmen systemischer Infektionen auftreten können (s. oben: Tabelle 22-13). So be-

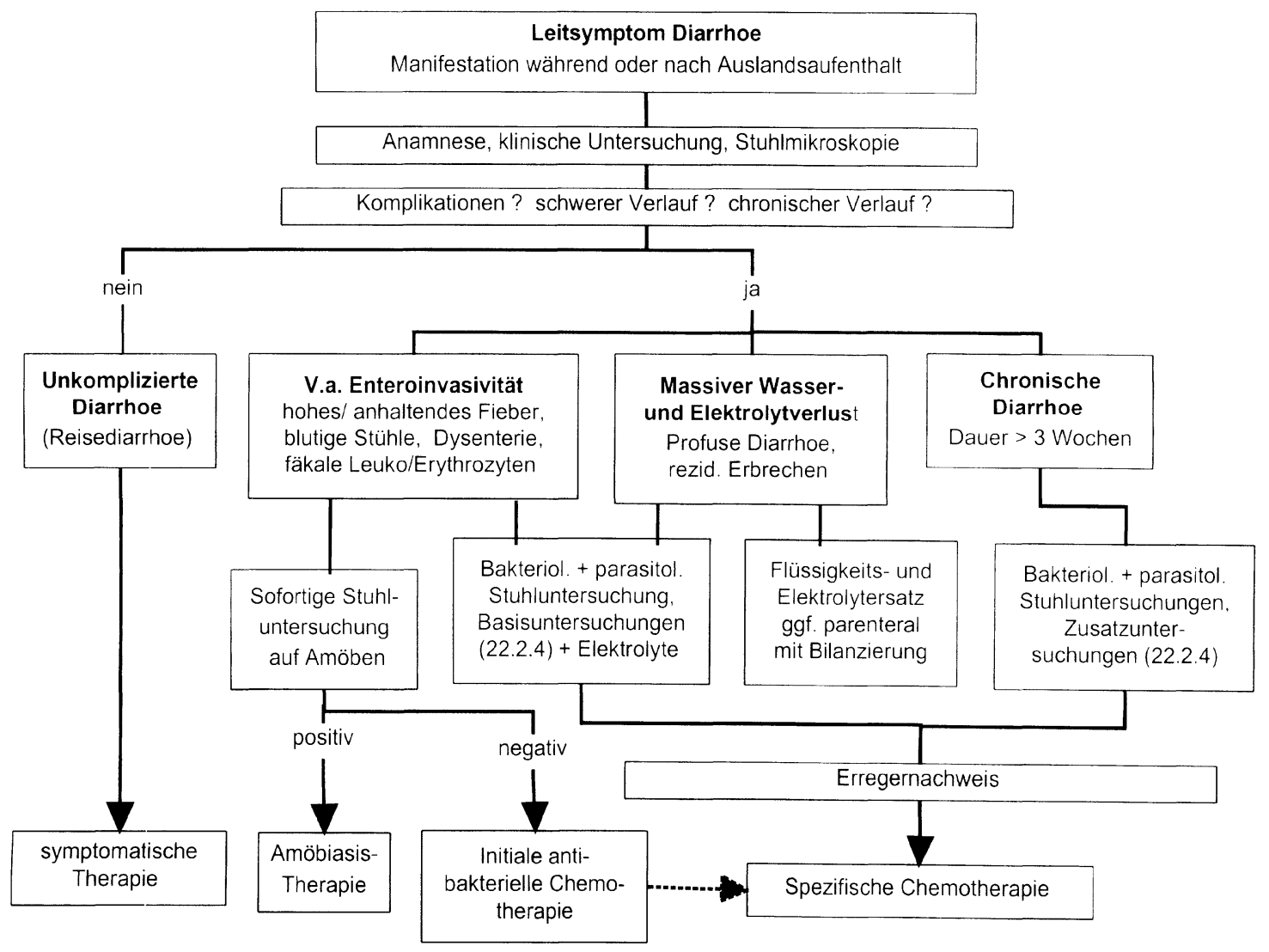

Abb. 22-2. Vorgehen bei Diarrhö und Verdacht auf importierte Infektionskrankheit 
richten bis zu $20 \%$ der Patienten mit Malaria tropica über Durchfälle und andere gastrointestinale Symptome wie Erbrechen und abdominelle Schmerzen. Bei Fieber und Durchfällen nach Aufenthalt in Malariagebieten ist daher immer eine Malaria auszuschließen (s. Abschn. 22.6.1).

\section{Leitsymptom Hautveränderungen}

Erkrankungen und Veränderungen der Haut sind ein häufiger Befund während und nach Fernreisen. Bei Tropenreisenden, die sich wegen einer Erkrankung nach Rückkehr in Behandlung begaben, stellten Hautveränderungen mit ca. $10 \%$ das dritthäufigste Leitsymptom dar.

\section{Diagnostisches Vorgehen}

Grundsätzlich sind bei Reisenden wie bei ausländischen Patienten zahlreiche infektiöse und nichtinfektiöse Dermatosen zu berücksichtigen. Auch an Hautmanifestationen im Rahmen generalisierter Infektionskrankheiten (Tabelle 22-19) und anderer Erkrankungen ist zu denken. Wichtig ist zudem stets eine genaue Arzneimittelanamnese, da Medikamente nicht selten Auslöser von Hautveränderungen sind (z. B. Malariachemoprophylaxe).

Tabelle 22-19. Fieber und Hautveränderungen bei Tropenrückkehrern

\begin{tabular}{|c|c|c|}
\hline Häufig & Gelegentlich & Selten \\
\hline $\begin{array}{l}\text { Pyodermien, } \\
\text { Erysipel } \\
\text { Dengue u. a. Ar- } \\
\text { bovirosen } \\
\text { Infektiöse Mo- } \\
\text { nonukleose } \\
\text { - Varizellen } \\
\text { - Lyme-Borreliose } \\
\text { - Zeckenbißfie- } \\
\text { ber-Rickettsiose } \\
\text { - Arzneimittelre- } \\
\text { aktionen } \\
\text { Röteln } \\
\text { - Masern } \\
\text { Scharlach }\end{array}$ & $\begin{array}{l}\text { Akute Schisto- } \\
\text { somiasis } \\
\text { Typhus abdomi- } \\
\text { nalis } \\
\text { - Zytomegalie } \\
\text { Akute HIV- } \\
\text { Infektion } \\
\text { Filariosen }\end{array}$ & $\begin{array}{l}\text { Erythema nodo- } \\
\text { sum bei Tbc, Le- } \\
\text { pra u. a. Infek- } \\
\text { tionen } \\
\text { - Trichinose } \\
\text { - Leptospirose } \\
\text { - Schlafkrankheit } \\
\text { - Chagas-Krank- } \\
\text { heit } \\
\text { - Brucellose } \\
\text { - Fleckfieber } \\
\text { - Rückfallfieber } \\
\text { - Milzbrand } \\
\text { - Systemmykosen } \\
\text { - Virale hämor- } \\
\text { rhagische Fieber }\end{array}$ \\
\hline
\end{tabular}

Bei Reisenden steht jedoch meist eine begrenzte Palette typischer Dermatosen im Vordergrund (Tabelle 2220), die in erster Linie von Aufenthaltsort, Reisestil und besonderen Expositionen bestimmt wird. Bei ausländischen Patienten und Immigranten muß zusätzlich mit Hauterkrankungen gerechnet werden, die bei Reisenden nur selten auftreten, aber in vielen tropischen Entwicklungsländern immer noch häufig sind wie Lepra, Buruli-Ulkus, Hauttuberkulose, venerische Infektionen, Filariosen und Dracunculiasis.
Tabelle 22-20. Infektiöse Hautveränderungen bei Tropenrückkehrern

\begin{tabular}{|c|c|}
\hline Tropentypische Dermatosen & Diagnostik \\
\hline $\begin{array}{l}\text { Häufiger: } \\
\text { Pyodermien (Ekthyma, Impetigo } \\
\text { u. a.) }\end{array}$ & Klinisch, Kultur \\
\hline Insektenstich-Dermatitis & $\begin{array}{l}\text { Klinisch-anamnestisch, } \\
\text { ggf. Biopsie }\end{array}$ \\
\hline Hautmykosen & $\begin{array}{l}\text { Kalilaugepräparat, Kultur, } \\
\text { ggf. Biopsie }\end{array}$ \\
\hline Kutane Larva migrans & Klinisch \\
\hline $\begin{array}{l}\text { Ektoparasitosen (Scabies, Tungia- } \\
\text { sis, Pediculosis, Phthiriasis, Puli- } \\
\text { culosis u. a.) }\end{array}$ & $\begin{array}{l}\text { Klinisch, Lupeninspek- } \\
\text { tion, Hautgeschabsel }\end{array}$ \\
\hline Hautleishmaniosen & $\begin{array}{l}\text { Abstriche, Hautbiopsie } \\
\text { (s. Abschn. 22.6.2) }\end{array}$ \\
\hline Myiasis & $\begin{array}{l}\text { Klinisch, Exstirpation, } \\
\text { ggf. operative Entfernung }\end{array}$ \\
\hline Sexuell übertragene Krankheiten & s. Abschn. 22.2.4 \\
\hline Fieber mit Exanthem & s. Tabelle 22-19 \\
\hline Kutane Herpes-simplex-Infektion & s. Abschn. 22.4 .1 \\
\hline $\begin{array}{l}\text { Septikämie mit Hauterscheinun- } \\
\text { gen }\end{array}$ & s. Abschn. 22.2.1 \\
\hline Seltener & \\
\hline Filariosen & $\begin{array}{l}\text { Serologie, Parasitologie } \\
\text { (s. Abschn. 22.6.4) }\end{array}$ \\
\hline $\begin{array}{l}\text { Buruli-Ulkus (Mycobacterium ul- } \\
\text { cerans) }\end{array}$ & $\begin{array}{l}\text { Klinisch, Abstrich, Biop- } \\
\text { sie, ggf. PCR }\end{array}$ \\
\hline Hauttuberkulose & $\begin{array}{l}\text { Klinisch, Abstrich, Biop- } \\
\text { sie, ggf. PCR }\end{array}$ \\
\hline Lepra & $\begin{array}{l}\text { Klinisch, Abstrich, Biop- } \\
\text { sie, ggf. PCR }\end{array}$ \\
\hline Dracunculiasis & Klinisch, parasitologisch \\
\hline
\end{tabular}

Das diagnostische Vorgehen (Abb. 22.3) richtet sich nach

- der Anamnese,

- der Morphologie der Hautveränderungen und

- dem Vorliegen weiterer Symptome und Befunde.

Bei ausländischen Patienten ist zu berücksichtigen, daß sich Hautveränderungen auf farbiger Haut anders darstellen und diagnostische Schwierigkeiten bereiten können. Erytheme und makulöse Exantheme sind auf stark pigmentierter Haut kaum sichtbar, während Schuppungen und Pigmentstörungen deutlicher zu sehen sind. Die dunkle Haut neigt zu ausgeprägten follikulären und mesenchymalen Reaktionen, so daß papulöse Hautveränderungen und Narbenbildung (Keloide) oft stark ausgeprägt sind. Zudem kann das Erscheinungsbild durch traditionelle Heilmethoden und Eigenbehandlungen beeinflußt sein.

\section{Diagnostik}

Bei einigen importierten Dermatosen kann die Diagnose bereits klinisch gestellt werden aufgrund der typischen Morphologie, z. B. bei unkomplizierten Pyodermien und kutaner Larva migrans (s. unten: Tabelle 22-28), oder aufgrund der Anamnese (z. B. Insektenstichreaktionen, Gifttierverletzungen) oder bei der therapeutischen Versorgung, z. B. Inzision bzw. Exzision bei Tungiasis oder subkutaner Myiasis. Ansonsten 
Abb. 22-3. Vorgehen bei Hautveränderungen und Verdacht auf importierte Infektionskrankheit

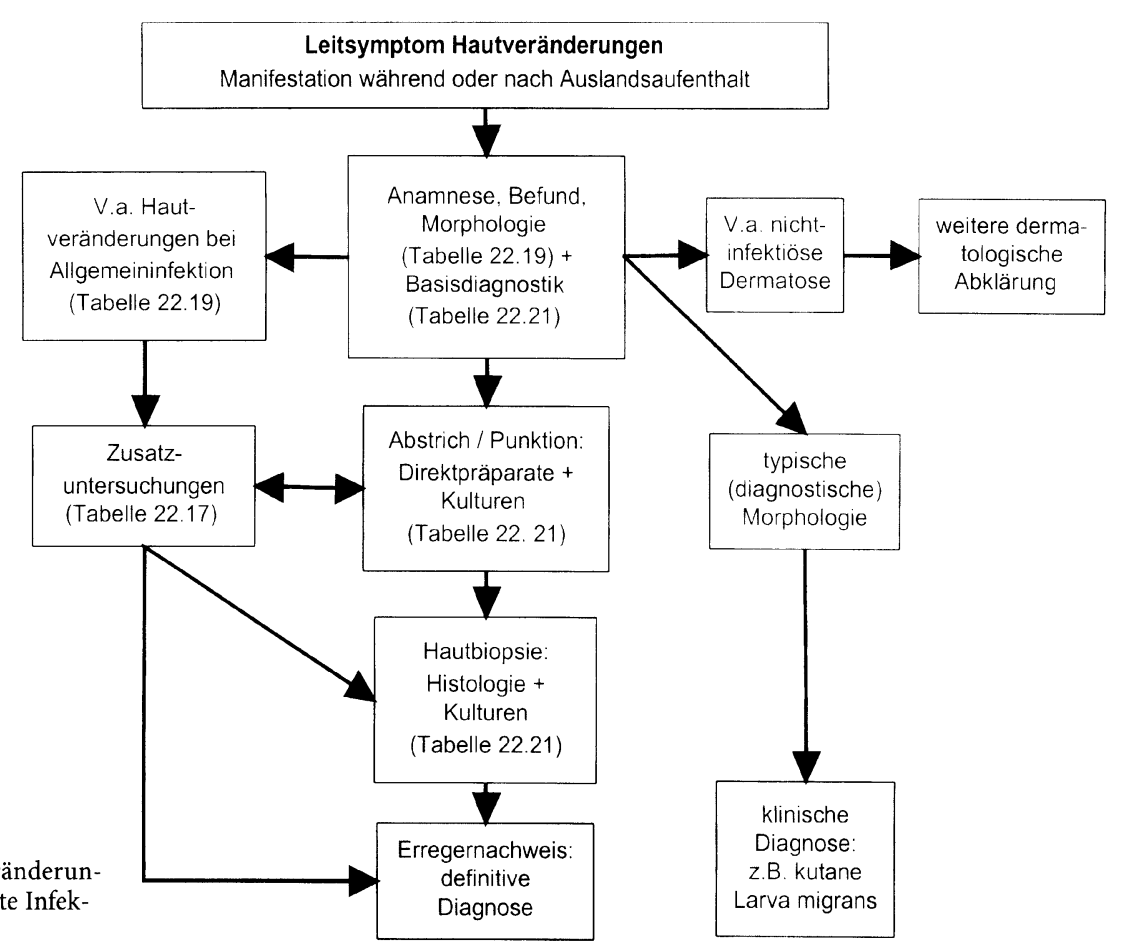

erfordert die definitive Diagnose gezielte mikrobiologische Untersuchungen zum Erregernachweis (Tabelle 22-21). Bei Pyodermien und anderen Hautinfektionen mit disseminiertem Befall und/oder Zeichen der Streuung (Lymphangiitis/adenitis, Fieber u. a. Allgemeinsymptome) sollten zudem die humoralen Entzündungsparameter und ggf. Blutkulturen untersucht werden. Bei Verdacht auf Hautmanifestationen im Rahmen generalisierter Infektionskrankheiten sind gezielte $\mathrm{Zu}$ satzuntersuchungen indiziert (s. oben: Tabelle 22-19).

Sollten Basisdiagnostik und Zusatzuntersuchungen nicht zu einer Diagnose führen, ist in der Regel eine Hautbiopsie mit histologischer und mikrobiologischer Aufarbeitung erforderlich sowie eine weitere dermatologische und tropenmedizinische Abklärung entsprechend den differentialdiagnostisch in Frage kommenden Krankheitsbildern (Tabelle 22-21). Bei HIV-Infizierten müssen zusätzlich opportunistische Hautinfektionen und Hauttumoren berücksichtigt werden (s. Abschn. 22.2.5), wobei bazilläre Angiomatose, eosinophile Follikulitis und Kaposi-Sarkom gehäuft bei HIV-Patienten aus tropischen Entwicklungsländern auftreten.
Tabelle 22-21. Diagnostik bei Verdacht auf importierte Hautinfektion

\begin{tabular}{|c|c|}
\hline Diagnostik & Bemerkungen \\
\hline Basisdiagnostik & $\begin{array}{l}\text { Gram- und Giemsapräparat (Ab- } \\
\text { strich, Punktat), Pilzpräparat } \\
\text { (KOH), bakteriologische Kulturen } \\
\text { (Eitererreger), ggf. Pilzkulturen }\end{array}$ \\
\hline \\
\hline a) Verdacht auf Scabies & $\begin{array}{l}\text { - Auflichtdermatoskopie, Hautge- } \\
\text { schabsel (Mikroskopie) }\end{array}$ \\
\hline $\begin{array}{l}\text { b) Verdacht auf Leishma- } \\
\text { niose }\end{array}$ & $\begin{array}{l}\text { - Abstrich (Giemsa), Biopsie (Hi- } \\
\text { stologie, Kultur, ggf. PCR) }\end{array}$ \\
\hline c) Verdacht auf Lepra & $\begin{array}{l}\text { - Skarifikation + Nasenabstrich } \\
(\mathrm{ZN})^{*} \text {, Hautbiopsie + ggf. Ner- } \\
\text { venbiopsie (Histologie, ggf. PCR) }\end{array}$ \\
\hline $\begin{array}{l}\text { d) Verdacht auf Hauttu- } \\
\text { berkulose }\end{array}$ & $\begin{array}{l}\text { - Abstrich }\left(\mathrm{ZN}^{*}\right)+\text { Biopsie (Histo- } \\
\text { logie, Kultur, ggf. PCR) }\end{array}$ \\
\hline $\begin{array}{l}\text { e) Verdacht auf Buruli- } \\
\text { Ulkus }\end{array}$ & $\begin{array}{l}\text { - Abstrich }\left(\mathrm{ZN}^{*}\right)+\text { Biopsie (Histo- } \\
\text { logie, Kultur, ggf. PCR) }\end{array}$ \\
\hline $\begin{array}{l}\text { f) Verdacht auf nichtve- } \\
\text { nerische Treponema- } \\
\text { tosen }\end{array}$ & $\begin{array}{l}\text { - Exsudat/Punktat (Dunkelfeld- } \\
\text { mikroskopie), Luesserologie }\end{array}$ \\
\hline $\begin{array}{l}\text { g) Verdacht auf subkuta- } \\
\text { ne Mykose }\end{array}$ & - Biopsie (Kultur, Histologie) \\
\hline $\begin{array}{l}\text { h) Verdacht auf System- } \\
\text { mykose }\end{array}$ & $\begin{array}{l}\text { - Biopsie (Kultur, Histologie), ggf. } \\
\text { Serologie (Tabelle 22-25) }\end{array}$ \\
\hline $\begin{array}{l}\text { Zusatzuntersuchungen } \\
\text { bei Verdacht auf Allge- } \\
\text { meininfektion }\end{array}$ & $\begin{array}{l}\text { - Basisuntersuchung (Tabelle 22-17) } \\
\text { - ggf. erweiterte Stufendiagnostik } \\
\text { (Tabelle 22-18) }\end{array}$ \\
\hline Biopsie & $\begin{array}{l}\text { - Histologie (inklusive Spezialfär- } \\
\text { bungen für Mykobakterien und } \\
\text { Pilze; ggf. Immunhistologie/ } \\
\text { DNS-Hybridisierung für HSV } \\
\text { und andere Viren) } \\
\text { - Kulturen (bakteriolog. + myko- } \\
\text { logisch; ggf. Leishmanien) }\end{array}$ \\
\hline
\end{tabular}




\section{3}

\section{Bakterielle Infektionskrankheiten}

Im folgenden ist die Diagnostik bei den wichtigsten bakteriellen Infektionskrankheiten aufgeführt soweit sie nicht bereits bei den verschiedenen Infektionssyndromen erwähnt wurde. Die Diagnostik bei selteneren bakteriellen Infektionskrankheiten ist in Tabelle 22-22 wiedergegeben.

\subsection{1}

\section{Scharlach}

Ausgehend von einer Pharyngotonsillitis (gelegentlich auch von Pyodermien oder Wundinfektionen) durch toxinogene Streptokokken der Gruppe A (selten andere Gruppen und hämolysierende Staphylokokken) kommt es bei Nichtimmunen (ohne toxinneutralisierende Antikörper) zur Scharlacherkrankung, die eine gewisse Immunität hinterläßt.
Die klinische Diagnose ist meist evident bei akuter hochfieberhafter Erkrankung, typischem kleinstflekkigem, z. T. follikulärem (sandpapierartig), zu einem diffusen Erythem konfluierendem, makulopapulösem Exanthem (auf Druck abblassend), das im Gesicht (mit perioraler Aussparung) und an den Leisten beginnt, sich v. a. an Hals, Nacken, Thorax und Innenseite der Arme ausbreitet und mit charakteristischer groblamellärer Schuppung (besonders an Handtellern und Fußsohlen) abheilt. Weitere Symptome sind Halsschmerzen, Erdbeerzunge (weißlich belegt mit vergrößerten geröteten Papillen) und nachfolgende Himbeerzunge (gerötet mit vergrößerten Papillen) sowie Kopf-, Glieder- und Bauchschmerzen, Übelkeit und Erbrechen. Komplikationen sind Lymphadenitis colli, Peritonsillarabszeß, Otitis media, Sinusitis, selten auch Pneumonie und Meningitis sowie rheumatische Nacherkrankungen (rheumatisches Fieber, Glomerulonephritis).

Tabelle 22-22. Diagnostik bei selteneren bakteriellen Infektionskrankheiten

\begin{tabular}{|c|c|c|c|}
\hline Krankheit (Erreger) & Obertragung & Klinik & Diagnostik \\
\hline $\begin{array}{l}\text { Carrión-Krankheit } \\
\text { (Bartonella bacilliformis) }\end{array}$ & $\begin{array}{l}\text { Durch Stechmücken (Phlebo- } \\
\text { tomen); verbreitet in Andentä- } \\
\text { lern von Peru, Ecuador und } \\
\text { Kolumbien }\end{array}$ & $\begin{array}{l}\text { - Oroya-Fieber mit hämolyti- } \\
\text { scher Anämie; Komplikatio- } \\
\text { nen: Meningitis, Salmonellen- } \\
\text { sepsis } \\
\text { - Verruga peruana: Gefäßkno- } \\
\text { ten der Haut (nach Monaten } \\
\text { bis Jahren) }\end{array}$ & $\begin{array}{l}\text { Erregernachweis (Giemsa-Fär- } \\
\text { bung) in Blutausstrich und Biop- } \\
\text { sien (Verruga); kulturell, PCR; } \\
\text { Serologie (bei Verruga meist ne- } \\
\text { gativ) }\end{array}$ \\
\hline $\begin{array}{l}\text { Erysipeloid } \\
\text { (Erysipelothrix rhusiopa- } \\
\text { thiae) }\end{array}$ & $\begin{array}{l}\text { Hautinokulation durch rohes } \\
\text { Fleisch + Fisch (Zoonose) }\end{array}$ & $\begin{array}{l}\text { Erysipelartige Dermatitis und } \\
\text { Zellulitis, meist ohne Fieber; } \\
\text { Komplikationen: Arthritis, En- } \\
\text { dokarditis }\end{array}$ & $\begin{array}{l}\text { Klinisch; kultureller Erreger- } \\
\text { nachweis in Abstrichen, Punkta- } \\
\text { ten + Blutkultur }\end{array}$ \\
\hline $\begin{array}{l}\text { Melioidose } \\
\text { (Burkholderia pseudomal- } \\
\text { lei) }\end{array}$ & $\begin{array}{l}\text { Meist durch Hautinokulation } \\
\text { (schlammige Böden, beson- } \\
\text { ders in Südostasien) }\end{array}$ & $\begin{array}{l}\text { Pneumonie, zudem septische } \\
\text { und abszedierende Verlaufsfor- } \\
\text { men (Haut, innere Organe) }\end{array}$ & $\begin{array}{l}\text { Erregernachweis (Grampräparat } \\
\text { und Kultur) aus Sputum, Ab- } \\
\text { szeßpunktat, Blut; Serologie } \\
\text { (IgM-Antikörper), PCR }\end{array}$ \\
\hline $\begin{array}{l}\text { Malleus (Rotz) } \\
\text { (Pseudomonas mallei) }\end{array}$ & $\begin{array}{l}\text { Haut-/Schleimhautinokulation } \\
\text { bei Tierkontakt (besonders } \\
\text { Pferde/Esel; Entwicklungslän- } \\
\text { der) }\end{array}$ & $\begin{array}{l}\text { Akuter oder chronischer Haut-I } \\
\text { Nasenrotz mit ulzerierenden } \\
\text { Entzündungen; Komplikationen: } \\
\text { Sepsis, Pneumonie }\end{array}$ & $\begin{array}{l}\text { Erregernachweis mittels Kultur/ } \\
\text { Tierversuch, Serologie }\end{array}$ \\
\hline $\begin{array}{l}\text { Pest } \\
\text { (Yersinia pestis) }\end{array}$ & $\begin{array}{l}\text { - Durch Flöhe (besonders } \\
\text { Rattenfloh) } \\
\text { - Tröpfcheninfektion (bei } \\
\text { Lungenpest) }\end{array}$ & $\begin{array}{l}\text { - Beulenpest: regionäre Lymph- } \\
\text { adenitis der Stichstelle, Sepsis, } \\
\text { sekundäre Lungenpest; } \\
\text { - primäre Lungenpest }\end{array}$ & $\begin{array}{l}\text { Direktnachweis (Gram/Giemsa- } \\
\text { Färbung) + Kultur aus Bubonen- } \\
\text { aspirat, Sputum und Blut; } \\
\text { Schnelldiagnose: direkte Im- } \\
\text { munfluoreszenz; (Serologie) }\end{array}$ \\
\hline $\begin{array}{l}\text { Rattenbißfieber } \\
\text { (Spirillum minus, } \\
\text { Streptobacillus monilifor- } \\
\text { mis) }\end{array}$ & $\begin{array}{l}\text { Durch Rattenbiß (bei } S \text {. moni- } \\
\text { liformis auch über kontami- } \\
\text { nierte Nahrungsmittel) }\end{array}$ & $\begin{array}{l}\text { Fieberhafte Erkrankungen (So- } \\
\text { doku, Haverhill fever) mit häufi- } \\
\text { gem Exanthem. Komplikation: } \\
\text { Endokarditis }\end{array}$ & $\begin{array}{l}\text { Nachweis von } S \text {. minus im Blut- } \\
\text { ausstrich (Dunkelfeld, Giemsa- } \\
\text { Färbung) + Tierversuch; bei } S \text {. } \\
\text { moniliformis Kultur + Tierver- } \\
\text { such }\end{array}$ \\
\hline $\begin{array}{l}\text { Rückfallfieber } \\
\text { (Borrelia recurrentis und } \\
\text { andere Arten) }\end{array}$ & $\begin{array}{l}\text { - Durch Kleiderläuse (B. re- } \\
\text { currentis), } \\
\text { - durch Zecken (Borrelia dut- } \\
\text { toni u. a.) }\end{array}$ & $\begin{array}{l}\text { Hochfieberhafte Erkrankung } \\
\text { Komplikationen: Meningoenze- } \\
\text { phalitis, Myokarditis, Hämor- } \\
\text { rhagien (besonders bei Läuse- } \\
\text { rückfallfieber) }\end{array}$ & $\begin{array}{l}\text { Nachweis im Blutausstrich und } \\
\text { dicken Tropfen (Giemsafär- } \\
\text { bung), Isolierung (Tierversuch) } \\
\text { möglich }\end{array}$ \\
\hline $\begin{array}{l}\text { Tularämie } \\
\text { (Francisella tularensis) }\end{array}$ & $\begin{array}{l}\text { Zeckenbiß, Hautinokulation } \\
\text { (infiziertes Fleisch), Tierbiß; } \\
\text { gelegentlich Inhalation + Inge- } \\
\text { stion }\end{array}$ & $\begin{array}{l}\text { Ulzerierende Primärläsion + re- } \\
\text { gionäre Lymphadenitis; okulo- } \\
\text { glanduläres Syndrom; gelegent- } \\
\text { lich Pneumonie, Enteritis, Sepsis }\end{array}$ & $\begin{array}{l}\text { Serologisch (signifikanter Titer- } \\
\text { anstieg), Erregerisolierung (Kul- } \\
\text { tur, Tierversuch) meist schwie- } \\
\text { rig }\end{array}$ \\
\hline
\end{tabular}




\section{Diagnostik}

Klinisch, Erregernachweis und Antigenschnelltests im Rachen- und Tonsillenabstrich.

\subsection{2}

\section{Toxinschocksyndrom (TSS)}

Verursacht durch Resorption verschiedener durch bestimmte Staphylococcus-aureus-Stämme gebildete Exotoxine, meist Toxic-shock-syndrome-Toxin 1 (TSST-1), seltener Enterotoxin B und C. In über $90 \%$ als menstruelles TSS bei pathologischer Besiedlung der menstruellen Vagina (gehäuft bei Tamponbenützung), seltener als nichtmenstruelles TSS ausgehend von oberflächlichen oder invasiven (Wundinfektionen, Abszesse, Osteomyelitis, Pneumonie) S.-aureus-Infektionen sowie postpartal; nur ausnahmsweise bei systemischen Infektionen (Sepsis, Endokarditis).

Abhängig vom Ausmaß der Toxinämie kommt es akut zu Fieber, Erbrechen, Durchfällen, Hypotonie bis zum protrahierten Schock und kapillären Lecksyndrom mit multiplen Organschädigungen (ARDS, Nieren-/Leberinsuffizienz, kardialer und ZNS-Beteiligung), Gerinnungsstörungen bis zur Verbrauchskoagulopathie sowie zu einem diffusen, kleinfleckigen Exanthem (bis zur Erythrodermie) mit charakteristischer groblamellärer Desquamation während der Rekonvaleszenz.

\section{Diagnostik}

Klinisches Bild, Nachweis von S. aureus mit TSST-1und/oder Enterotoxin-B/C-Bildung, TSST-1-Antikörper (signifikanter Titeranstieg), immunologischer TSST-1-Nachweis (oft negativ).

\subsection{3}

\section{Diphtherie}

Die Diphtherie ist eine akute Lokalinfektion durch toxinbildende Stämme von Corynebacterium diphtheriae meist als membranöse Pharyngitis (z. T. mit Laryngitis) selten als Haut- oder Wunddiphtherie. Gefahr der akuten Atemwegsobstruktion (Krupp-Syndrom), toxische Myokarditis und Neuritis z.T. mit Lähmungen durch Resorption von Diphtherietoxin (Exotoxin lysogener Stämme).

Der Krankheitsverdacht ergibt sich v. a. aufgrund der typischen grauweißen, membranartigen Beläge von Rachen und Tonsillen, die anhaften und beim $\mathrm{Ab}$ heben meist bluten. Zudem besteht variables Fieber sowie eine Lymphadenopathie und $z$. T. eine diffuse Schwellung im Halsbereich. Haut- und Wunddiphtherie zeigen meist schmutzig-grau belegte Ulzera.

\section{Diagnostik}

Klinische Verdachtsdiagnose und kulturelle Isolierung (Teil A, Abschn. 3.2.2) aus Abstrichen von den Pseudo- membranen (besonders unter der Membran) sowie Rachen und Nase. Ein orientierender Schnellnachweis ist möglich mittels Neisser-Färbung, direkter Immunfluoreszenz und PCR.

\subsection{4}

\section{Milzbrand (Anthrax)}

Erreger Bacillus anthracis, Zoonose, z. T. Berufsinfektion, in einigen Entwicklungsländern noch häufig (Import über Tierprodukte möglich); vorwiegend als Hautmilzbrand mit Gefahr septischer Ausbreitung, primärer Lungen- oder Darmmilzbrand selten. Schlechte Prognose der disseminierten Formen.

Der klinische Verdacht ergibt sich meist aufgrund einer in der Regel singulär (bevorugt im Gesicht, Hals, Nacken oder Armen) auftretenden schmerzlosen Papel (Inokulationsstelle), die sich nach wenigen Tagen in ein oder mehrere, an der Basis blutende Vesikel (hämorrhagische Pustel) umwandelt und schließlich ulzeriert (4-6 cm großer Eschar). Fieber und Allgemeinsymptome bestehen nur bei einem Teil der Patienten; regionale Lymphadenopathie und periläsionales Ödem können sehr ausgeprägt und schmerzhaft sein.

Die disseminierte Infektion verläuft unter dem Bild einer Sepsis (s. Abschn. 22.2.1), häufig besteht eine hämorrhagische Diathese.

\section{Diagnostik}

Klinisches Bild; orientierender Direktnachweis (Grampräparat) der großen, bekapselten grampositiven Bakterien im Abstrich von Bläschenflüssigkeit und Ulkusgrund; die definitive Diagnose beruht auf der kulturellen Isolierung (Abstrich, Blutkultur).

\subsection{5}

Tetanus

Clostridium tetani ist ubiquitär verbreitet. Es erfolgt meist eine nichtinvasive Lokalinfektion mit Toxinproduktion (Tetanospasmin) unter anaeroben Bedingungen besonders in verschmutzten bzw. nekrotischen Wunden, Verbrennungen und Hautinfektionen; z. T. nur Bagatellverletzungen. Gehäuft in Entwicklungsländern, bei schlechter Hygiene (Tetanus neonatorum) und i.v.-Drogenabusus.

Die irreversible synaptische Toxinbindung mit Fortfall der Hemmung der Motoneuronen (Tetanospasmin hemmt die Freisetzung der inhibitorischen Neurotransmitter GABA und Glyzin) führt zu schmerzhaften tonischen Krampfanfällen (häufig durch externe Stimuli getriggert), Muskelschwäche und -rigidität, typischerweise im Bereich der Massetermuskeln beginnend (Trismus, Risus sardonicus); Gefahr von Aspiration und respiratorischer Insuffizienz sind die Folgen. 


\section{Diagnostik}

Typisches klinisches Bild (Tetanie), Identifikation des möglichen Infektionsherdes. Laborwerte tragen wenig zur Diagnose bei; häufig besteht eine mäßige Leukozytose; der Liquordruck ist $z$. T. erhöht, die Liquorbefunde jedoch normal. Gelegentlich können die grampositiven Tetanusbakterien in Wundaspiraten nachgewiesen werden. Eine kulturelle Anzucht gelingt oft nicht und ist andererseits auch von Wunden möglich wenn kein Tetanus vorliegt. Differentialdiagnostisch ist an eine Strichnin-Vergiftung zu denken (ggf. Strichninbestimmung im Blut).

\subsection{6}

\section{Botulismus}

Intoxikation durch Aufnahme präformierter Toxine (Typ A, B, E, selten F und G) über Nahrungsmittel nach Kontamination mit Clostridium botulinum und dessen Wachstum unter anaeroben Bedingungen (meist hausgemachte Wurstwaren und Konserven). Gelegentlich auch als Säuglingsbotulismus bei Fehlbesiedlung des unreifen Intestinaltrakts mit Überwuchern von toxinbildenden $C$. botulinum, selten als Wundbotulismus. Toxinbedingte Inaktivierung oder Freisetzungshemmung von Azetylcholin an neuromuskulären Synapsen mit Ausbildung rasch progressiver, bilateraler (aber nicht symmetrischer), meist deszendierenden Muskellähmungen. Beginn typischerweise an der von Hirnnerven innervierten Muskulatur mit Gesichtsmuskelschwäche, Augenmuskellähmungen (Doppelbilder, Ptosis), Dysphagie, Dysarthrie, Mundtrockenheit und Müdigkeit. Es besteht die Gefahr der Bulbärparalyse und Atemlähmung.

\section{Diagnostik}

Die Verdachtsdiagnose muß anhand des klinischen Bildes gestellt werden. Die Routinelaboruntersuchungen geben keine diagnostischen Hinweise. Im Elektromyogramm fällt meist ein stufenförmiger Anstieg der Muskelaktionspotentiale bei hochfrequenter elektrischer Stimulation auf; die Nervenleitgeschwindigkeit ist normal.

Entscheidend ist der Toxinnachweis (Mäuseschutzversuch, ELISA) in Patientenblut, Stuhl, Magenspülflüssigkeit und Resten des inkriminierten Nahrungsmittels. Bei Säuglings- und Wundbotulismus ist auch die anaerobe kulturelle Isolierung (und Toxinnachweis) aus Stuhl bzw. Wundabstrich möglich (s. Teil A, Abschn. 3.2.2).

\subsection{7}

\section{Gasbrand}

Bei Kontamination von Wunden mit verschiedenen im Boden und z. T. im Darm verbreiteten Clostridien (Clostridium perfringens, C. novyi, C. septicum, C. histolyti- cum u. a.) und anaeroben Verhältnissen (hyp-/anoxisches und devitalisiertes Gewebe, geschlossene Wunden, Fremdkörper) entstehende gangränöse, gasbildende Infektion mit rascher Ausbreitung auf gesundes Gewebe (besonders Muskulatur), z. T. auch postoperativ (z. B. nach Amputation ischämischer Gliedmaßen). Gelegentlich kommt es zur relativ benignen Clostridienzellulitis der Haut oder Subkutis ohne Beteiligung tieferer Strukturen.

\section{Diagnostik}

Klinisches Bild, Krepitation (auch bei anderen Infektionen möglich), Nachweis von Gaseinschlüssen bei der bildgebenden Diagnostik (Röntgenaufnahmen, Sonographie, CT, MRT); Abstrich (große grampositive Stäbchen) und anaerobe Kultur.

\subsection{8}

\section{Listeriose}

Infektionen mit Listeria monocytogenes (zoonotisch verbreitet, Übertragung durch kontaminierte Nahrungsmittel) verlaufen meist a- oder oligosymptomatisch (grippal), können jedoch auch schwerwiegende Erkrankungen verursachen. Vermehrt gefährdet sind Personen mit reduzierter Abwehr wie Tumorpatienten, Diabetiker, Alkoholiker und Patienten mit angeborenen oder erworbenen Immundefekten. Die wichtigsten Erkrankungen sind:

- Meningitis (s. Abschn. 22.2.2).

- Sepsis, bevorzugt bei Abwehrschwäche (s. Abschn. 22.2.1).

- Infektionen in der Schwangerschaft (bei der Mutter meist als grippale Infektion oder asymptomatisch) können zu einer diaplazentaren Infektion des Feten führen mit Abort, Totgeburt oder konnataler Listeriose (Frühform der Neugeborenenlisteriose) mit häufiger Frühgeburt, mekoniumhaltigem Fruchtwasser, schweren septischen Verläufen z. T. mit Pneumonie, Atemnotsyndrom, Hauterscheinungen und/oder disseminierten Mikroabszessen (Granulomatosis infantisepticum).

- Perinatal erworbene Neugeborenenlisteriose (Spätinfektion) bei vaginaler/rektaler Besiedlung der Mutter oder nosokomialer Infektion meist als Meningitis verlaufend.

- Seltene Organlisteriosen: Konjunktivitis, okuloglanduläres Syndrom, Endophthalmitis, Pharyngitis, Tonsillitis, zervikale Lymphadenitis z. T. mit mononukleoseartigem Syndrom (s. Abschn. 22.2.3) und gelegentlich Einschmelzung und Perforation nach außen, papulöse oder pustulöse Dermatitis (gehäuft bei Schlachthofarbeitern), Endokarditis (besonders bei vorgeschädigten oder künstlichen Herzklappen), Hepatitis und Arthritis. 


\section{Diagnostik}

Die definitive Diagnose beruht auf der kulturellen Isolierung aus Blut (möglichst mehrfache Blutkulturen), Liquor (Grampräparat meist negativ) oder Abstrichen bzw. Punktaten oder Biopsien sonstiger Organlokalisationen. Bei Schwangeren zusätzlich Abstriche von Zervix oder Vaginalsekret; bei konnataler Listeriose zudem aus Mekonium und Plazentaabstrichen. Die Serodiagnostik ist wenig aussagekräftig.

\subsection{9}

\section{Typhus und Paratyphus abdominalis}

Der Krankheitsverdacht ergibt sich bei Fieberkontinua (meist $39-41^{\circ} \mathrm{C}$ ) mit anfangs treppenförmigem Anstieg, Kopfschmerzen, Inappetenz, Benommenheit, Übelkeit z. T. mit Erbrechen und trockenem Husten. In den ersten 1-2 Krankheitswochen bestehen oft Obstipation und abdominelle Schmerzen, gelegentlich aber auch schon frühzeitig Durchfälle. Über $80 \%$ der Erkrankungen in Deutschland werden aus dem Ausland (besonders Entwicklungsländer) importiert; Inkubationszeit 1-3 Wochen.

Komplikationen (meist erst in der 3. Krankheitswoche) sind Darmperforation, intestinale Blutung, toxisch bedingte Kreislaufdepression sowie metastatische Absiedelung in andere Organe mit Auftreten von Osteomyelitis, Spondylitis, Pneumonie und Meningitis. Etwa 3\% der Patienten werden Dauerausscheider.

Der körperliche Untersuchungsbefund zeigt eine Hepatosplenomegalie, eine relative Bradykardie, ein gespanntes Abdomen und gelegentlich einen pathologischen Auskultationsbefund der Lunge. Bei 1/3 der Patienten findet sich ein typischer, diskreter Hautausschlag am Rumpf, sog. Roseolen. Laborchemisch ist eine Leukopenie und insbesondere das Fehlen von Eosinophilen im Differentialblutbild charakteristisch.

\section{Diagnostik}

Isolierung von Salmonella typhi und Paratyphus-Salmonellen (S. paratyphi A, S. schottmuelleri, S. hirschfeldii) aus der Blutkultur; ggf. auch aus Knochenmark (höhere Ausbeute in antibiotisch anbehandelten Fällen). Stuhlkulturen sind meist erst ab der 2. Woche positiv. Die diagnostische Wertigkeit der Serologie (Widal-Reaktion u. a.) ist begrenzt, da sie erst in der 2.3. Krankheitswoche positiv wird und ein Titeranstieg bei frühzeitiger Antibiotikatherapie ausbleiben kann. Mehrfache Kontrolle der Stuhlkulturen nach Behandlung (Dauerausscheider).

\subsubsection{0}

\section{Pertussis}

Bordetella pertussis wird durch Tröpfcheninfektion verbreitet und ist besonders für Neugeborene hochkonta- giös. Das Krankheitsbild ist variabel und reicht von abortiven Formen bis zu schwersten Hustenparoxysmen (Keuchhusten) mit bedrohlichem Verlauf (vorwiegend bei Neugeborenen und Säuglingen). Komplikationen: Apnoeanfälle, Aspiration, Bronchopneumonie und Otitis (meist Sekundärinfektionen durch Haemophilus influenzae, Pneumokokken u. a.), Krampfanfälle, Enzephalopathie (z. T. neurologische Dauerschäden).

Bei Jugendlichen und Erwachsenen (mit fehlender oder partieller Immunität) kann Pertussis unter dem Bild einer akuten oder portrahierten Bronchitis verlaufen (Infektionsgefahr für Neugeborene und junge Säuglinge, die durch die Impfung noch nicht zuverlässig geschützt sind).

\section{Diagnostik}

Klinisch, Erregerisolierung (sofortige Verimpfung, Hustenplatte) aus Nasopharyngealabstrich (Teil A, Abschn. 3.2.2); Schnelltests (direkte Immunfluoreszenz, PCR), Serologie nur retrospektiv.

\subsubsection{1}

\section{Yersiniosen}

Yersinia enterocolitica und Y. pseudotuberculosis (Anthropozoonosen) werden übertragen durch kontaminiertes Wasser und Nahrungsmittel, direkt von Mensch $\mathrm{zu}$ Mensch (Schmierinfektion) und durch Tierkontakt sowie gelegentlich durch Blutkonserven (Vermehrung bei niedrigen Temperaturen) von bakteriämischen Spendern oder nach Kontamination.

Fakultativ pathogen, gelegentlich auch in der Darmflora Gesunder. Mögliche Ursache von akuten und chronischen Enteritiden (s. Abschn. 22.2.4), mesenterialer Lymphadenitis (Pseudoappendizitis), reaktiver Arthritis (meist bei HLA-B27), Erythema nodosum und gelegentlich septischen Krankheitsbildern (bevorzugt bei schweren Grunderkrankungen und Abwehrschwäche sowie bei Thalassämie, Hämochromatose u. a. Erkrankungen mit Eisenüberladung) z. T. mit septischen Absiedlungen (Leber-/Milzabszesse).

\section{Diagnostik}

Kulturelle Isolierung (Teil A, Abschn. 3.2.2) aus Stuhl, Blut u. a. Materialien. Serologie (Teil A, Kap. 3, Tabelle 3-9).

\subsubsection{2}

\section{Brucellosen}

Systemische Infektion durch Brucella abortus, B. melitensis oder B. suis (zoonotisch verbreitet), die eine Vielzahl von Organen befallen kann. Entsprechend vielgestaltig ist das klinische Bild. Nach einer Inkubationszeit von 2-8 Wochen treten unspezifische Prodromalerscheinungen auf wie Abgeschlagenheit, Kopf- und Glie- 
derschmerzen, Nachtschweiß, Appetitlosigkeit und Fieber. Typische Manifestationsorte sind

- Gastrointestinaltrakt: Hepatosplenomegalie, granulomatöse Hepatitis,

- Skelettsystem: Arthritis, Spondylitis, Osteomyelitis,

- Zentralnervensystem: Meningitis, Enzephalitis, intrazerebraler Abszeß,

- kardiovaskuläres System: Endokarditis, Myokarditis,

- Respirationstrakt: Bronchitis, Pneumonie, Lungenabszesse.

Unbehandelt können sich chronische Verlaufsformen entwickeln. Anamnestische Angaben zu beruflicher Exposition, Ernährungsweise (z. B. unpasteurisierte Milchprodukte) und Auslandsaufenthalten geben oft wichtige Hinweise. Dagegen sind der klinische Untersuchungsbefund und laborchemische Untersuchungen eher uncharakteristisch. Lediglich Anämie, Leukopenie und Thrombozytopenie sind häufiger zu finden.

\section{Diagnostik}

Im akuten Stadium ist der kulturelle Erregernachweis entscheidend. Brucellen lassen sich insbesondere aus Blutkulturen und aus Knochenmark nachweisen. Hierzu müssen vor Beginn einer antibiotischen Therapie wiederholt Blutkulturen entnommen werden, die unter besonderen Bedingungen (Teil A, Abschn. 3.2.2) bebrütet werden sollten. Daher ist der Verdacht auf Brucellose dem mikrobiologischen Labor mitzuteilen. Sehr sensitiv und spezifisch ist der serologische Nachweis von Antikörpern mittels Gruber-Widal-Reaktion, KBR und andere Verfahren (Teil A, Kap. 3, Tabelle 3z9z). Zu Beginn der Erkrankung können diese jedoch noch fehlen (ggf. Wiederholung nach 1-2 Wochen).

\subsubsection{3}

\section{Legionellosen}

Legionella pneumophila und andere Arten mit ubiquitärer Verbreitung im Wasser und Boden (aerogene Infektion, z. T. über Aerosole, z. B. bei Klimaanlagen, Duschen und Bodenstaub z. B. bei Baggerarbeiten) können sporadische und gelegentlich (klein-)epidemische Erkrankungen mit schweren Pneumonien (Legionärskrankheit) und hoher Letalität (bis $20 \%$ ) verursachen. Gehäuft bei Abwehrschwäche (schwere Grunderkrankungen, Immunkompromittierte, Alkoholiker), in höherem Alter und bei Rauchern; z. T. auch leichtere grippale Erkrankungen (Pontiac-Fieber).

Der Krankheitsverdacht ergibt sich sowohl bei ambulant wie nosokomial erworbener Pneumonie mit akutem fieberhaftem Beginn, trockenem Husten und Dyspnoe. Häufig bestehen ausgeprägte Myalgien, Kopfschmerzen und Benommenheit. Der Auskultationsbefund ist variabel, radiologisch zeigen sich flekkige oder interstitielle Infiltrate in einem oder mehre- ren Lungenlappen mit Ausbreitungstendenz. In schwereren Fällen bestehen meist Zeichen einer Leber(Transaminasenerhöhung) und Nierenbeteiligung (Proteinurie, Hämaturie) sowie eine Hyponatriämie.

\section{Diagnostik}

Im meist nichtpurulenten Sputum sind in der Gramfärbung Granulozyten aber keine Bakterien nachweisbar. Die Erregerisolierung (Spezialnährböden) ist möglich aus Sputum, BAL, Lungenbiopsien, Pleurapunktat und Blut. Serologisch (IFT u. a. Verfahren) zeigt sich eine Serokonversion oder ein signifikanter Titeranstieg oft erst im Verlauf. Bedeutsam sind daher Methoden für die Schnelldiagnostik:

1. mikroskopisch (direkte Immunfluoreszenz), PCR und DNS-in-situ-Hybridisierung aus Rachenabstrich, Sputum, BAL oder Lungenbiopsie,

2. Nachweis zirkulierender Antigene (ELISA) im Urin und auch im Serum.

\subsubsection{4}

Leptospirosen

Weltweit verbreitete Infektion mit Leptospira interrogans (verschiedene Serovare), in Mitteleuropa selten gewordene Anthropozoonosen, von grippalen Bildern (Serovare: Leptospira canicola, L. pomona, L. grippotyphosa u. a.) bis zum prognostisch nach wie vor ernsten M. Weil (meist L. icterohaemorrhagiae) reichend.

Typischerweise biphasischer Verlauf mit initialem Fieber, Konjunktivitis, z. T. ausgeprägten Myalgien (besonders Wadenmuskulatur), Zephalgien und uncharakteristischen Exanthemen; Organmanifestationen meist nach vorübergehender Entfieberung als $\mathrm{Ne}$ phritis, Hepatitis, seröse Meningitis u. a. Bei M. Weil ausgeprägtes hepatorenales Syndrom mit hämorrhagischer Diathese möglich.

\section{Diagnostik}

Direktnachweis (Dunkelfeld, Phasenkontrast), Erregerisolierung (Spezialmedizin, Tierversuch) und PCR aus Blut, Liquor (während 1. Phase) und Urin (später). Serologie (ab 8.-10. Tag, Titeranstieg).

\subsubsection{5}

\section{Lyme-Borreliose}

Der zoonotisch verbreitete Erreger Borrelia burgdorfe$r i$ sensu lato (B. burgdorferi sensu strictu, B. afzelii, $B$. garinii) wird durch Zecken der Gattung Ixodes übertragen. Die klinischen Manifestationen sind sehr variabel. In etwa der Hälfte der Fälle kommt es 3-30 Tage nach der Übertragung (Zeckenbisse werden oft nicht bemerkt) an der Bißstelle zu dem sich ringförmig ausdehnenden Erythema migrans (Rötung von minde- 
stens $5 \mathrm{~cm}$ Durchmesser) meist mit typischer zentraler Abblassung. Zum Teil entwickelt sich gleichzeitig oder anschließend ein akutes fieberhaftes Krankheitsbild mit Kopfschmerzen, Myalgien, Arthralgien und gelegentlich multiplen Erythemen; Komplikationen sind akute Meningitis (Abschn. 22.2.2), Myokarditis (s. Kap. 18), Ophthalmitis, Hepatitis und Myositis.

Nach Wochen bis Monaten, gelegentlich sogar erst nach Jahren, können, auch ohne anamnestisch eruierbare Akuterkrankung, Spätmanifestationen an den Gelenken (rezidivierende Arthritiden besonders der großen Gelenke), der Haut (Lymphadenosis benigna cutis, Acrodermatitis chronica atrophicans) und am Nervensystem als Meningopolyneuritis (z. B. Bannwarth-Syndrom), Enzephalomyelitis (Parästhesien, spastische Paraparese, neurogene Blasenfunktionsstörungen u. a.) oder periphere Neuropathien auftreten.

\section{Diagnostik}

Klinisch (besonders bei Erythema migrans da Serologie häufig negativ); Antikörpernachweis (IgG- und IgM-Antikörper im ELISA und/oder IFT, Bestätigungstest: Immunoblot) in Serum und ggf. Liquor (LiquorSerum-Index ). Der direkte Erregernachweis ist kulturell (Spezialmedien, s. Teil A, Abschn. 3.2.2) und mittels PCR möglich aus Hautbiopsien, Blut, Liquor und Gelenkpunktaten.

\subsubsection{6}

Tuberkulose - Siehe Kap. 19.

\subsubsection{7}

\section{Nichttuberkulöse Mykobakteriosen}

Lokale (Haut, Abszesse), pulmonale (z. T. tuberkuloseartig) und disseminierte Erkrankungen (Tabelle 22-23) durch nichttuberkulöse Mykobakterien (fakultativ pathogene Saprophyten), auch als atypische Mykobakterien oder als MOTT („mycobacteria other than M. tuberculosis") bezeichnet, gehäuft bei Immunkompromittierten (z. B. Aids), besonders Mycobacterium-avium-Komplex (s. Abschn. 22.2.5); wahrscheinlich häufig latente Infektion.

\section{Diagnostik}

orientierender Nachweis von Mykobakterien (ZiehlNeelsen-/Auraminfärbung) in Abstrichen (Sputum, Bronchiallavage, Abszeßpunktat) und Biopsien (Haut, Lunge, Knochenmark, Lymphknoten, Leber, Darm u. a. Organe); nach Möglichkeit sollte stets eine kulturelle Isolierung (Teil A, Abschn. 3.2.2.) versucht werden, da diese Voraussetung für genaue Typisierung und Sensibilitätstestung (sehr variable Empfindlichkeit, häufig Primärresistenzen) ist. Nachweis und Typisierung sind auch mittels PCR möglich. Wegen der ubiquitären Verbreitung und der Möglichkeit einer asym-
Tabelle 22-23. Nichttuberkulöse Mykobakteriosen: Erreger und Lokalisation

\begin{tabular}{|c|c|}
\hline Mycobacterium spp. & Lokalisation \\
\hline $\begin{array}{l}\text { M.-avium-Komplex } \\
\text { (s. Abschn. 22.2.5) }\end{array}$ & $\begin{array}{l}\text { Lunge, Lymphknoten, disseminierte } \\
\text { Infektion }\end{array}$ \\
\hline M. kansasii & Lunge, disseminierte Infektion \\
\hline $\begin{array}{l}\text { M. fortuitum/ } \\
\text { M. chelonae }\end{array}$ & Haut, Lunge, disseminierte Infektion \\
\hline M. abscessus & Haut, Wundinfektion \\
\hline M. marinum & $\begin{array}{l}\text { Schwimmbadgranulome, disseminier- } \\
\text { te Infektion }\end{array}$ \\
\hline M. ulcerans & Buruli-Ulkus \\
\hline M. gordonae & Haut, Lunge, disseminierte Infektion \\
\hline M. scrofulaceum & $\begin{array}{l}\text { Lymphknoten, Lunge, disseminierte } \\
\text { Infektion }\end{array}$ \\
\hline M. heamophilum & Haut, Gewebe, Lymphknoten \\
\hline M. szulgai/M. xenopi & Lunge \\
\hline $\begin{array}{l}\text { M. malmoense/ } \\
\text { M. simiae }\end{array}$ & $\begin{array}{l}\text { Lunge, Lymphknoten, disseminierte } \\
\text { Infektion }\end{array}$ \\
\hline
\end{tabular}

ptomatischen Besiedlung von Schleimhäuten ist jedoch eine kritische Bewertung angezeigt (Korrelation zu klinischem Befund, Erregernachweis im Gewebe und in der Kultur), insbesondere bei der Untersuchung von nicht primär sterilen Materialien.

\subsubsection{8}

Lepra

Mycobacterium leprae verursacht in Abhängigkeit von der Abwehrlage des Patienten verschiedene Erkrankungsformen:

- Tuberkuloide Lepra: erregerarme meist hypopigmentierte, anästhetische Hautmanifestationen und chronische periphere Neuritiden mit Sensibilitätsstörungen, Paresen, Muskelatrophien und Kontrakturen.

- Lepromatöse Lepra: granulomatöse erregerreiche Infiltrationen der Haut und tiefere Strukturen (v. a. Gesicht und Extremitäten) mit Entstehung schwerer Mutilationen;

- Mischformen (dimorphe/Borderline-Lepra) und indeterminierte Frühformen.

- Leprareaktionen:

- Reaktionen vom Typ 1 („,reversal reaction“) bei Borderline-Lepra mit akut entzündlichen Veränderungen im Bereich von Hautläsionen und Nerven (Erythem, Schwellung, Schmerzen, z. T. Fieber) und Gefahr irreversibler Nervenschädigungen.

- Reaktionen vom Typ 2 (Erythema nodosum leprosum) bei multibazillärer Lepra mit Fieber, Aufschießen multipler schmerzhafter nodulärer Hautläsionen, Synovitis und Iridozyklitis (Gefahr bleibender Augenschäden). 


\section{Diagnostik}

Erregernachweis (modifizierte Ziehl-Neelsen-Färbung) in Haut-/Nasenabstrichen und Biopsien; oft typische Histologie besonders in Nervenbiopsien (z. B. N. ulnaris) und auch beim Fehlen von Erregern (tuberkuloide Lepra). Nachweis mittels PCR (gelingt auch bei erregerarmer, z. B. tuberkuloider Lepra). Positiver Lepromin-Hauttest bei tuberkuloider Lepra.

\subsubsection{9}

\section{Aktinomykose}

Actinomyces israeli und selten andere Arten (Kommensalen im Oropharynx und Gastrointestinaltrakt) verursachen meist eine zervikofasziale Aktinomykose mit chronisch-infiltrativen Entzündungen im Halsbereich und Fistelneigung; seltener thorakale, abdominale und disseminierte Formen mit chronisch-granulomatösen Entzündungsherden.

\section{Diagnostik}

Erregernachweis im befallenen Gewebe (typische Drusen), kulturelle Isolierung (Teil A, Abschn. 3.2.2) und Typisierung.

\subsubsection{0}

\section{Nokardiose}

Nocardia asteroides (schwach säurefest) und andere Nocardia-Arten sind ubiquitäre Saprophyten (N. brasiliensis in Blumenerde tropischer Zimmerpflanzen) und verursachen v. a. bei Immunkompromittierten akute und chronische ( $\mathrm{z}$. T. kavernöse) Pneumonien mit häufiger hämatogener Streuung (z. B. Hirnabszesse).

\section{Diagnostik}

Erregernachweis (Grampräparat, keine Drusenbildung) in Sputum, Bronchiallavage, Lungenbiopsien und Abszeßpunktaten; kulturelle Isolierung (Teil A, Abschn. 3.2.2), langsames Wachstum, Differenzierung schwierig.

\subsubsection{1}

\section{Whipple-Krankheit}

Tropheryma whippelii, ein bislang nicht kultivierbares grampositives Stäbchenbakterium (genetisch zu den Aktinomyzeten gehörend) ist der Erreger der seltenen Whipple-Krankheit, bevorzugtes Auftreten bei weißen Männern in Europa und USA (möglicherweise genetische Prädisposition mit spezifischem Immundefekt).

Beginn meist mit rezidivierenden Arthralgien, Lymphadenopathie und Polyserositis (Arthritis, Pleuritis, Perikarditis); im weiteren Verlauf Diarrhöen, abdominelle Schmerzen, Steatorrhö, Malabsorption und Gewichtsverlust, später häufige ZNS-Beteiligung und
Endokarditis. Unbehandelt ernste Prognose, insbesondere bei ZNS-Beteiligung.

\section{Diagnostik}

Nachweis der Bakterien in Biopsaten von Dünndarm und anderen befallenen Organen mittels PCR und (weniger sensitiv) Histologie (PAS-positive Stäbchen in Epithelzellen und Makrophagen); zur Diagnose einer ZNS-Beteiligung eignen sich Magnetresonanztomographie (auch PET) und Liquoruntersuchung mittels PCR.

\subsubsection{2}

\section{Rickettsiosen}

Die Rickettsiosen werden nach klinischen, epidemiologischen und mikrobiologischen Gesichtspunkten in 4 Gruppen eingeteilt:

- Fleckfiebergruppe („typhus group“) mit klassischem Fleckfieber (Erreger: Rickettsia prowazekii; Übertragung durch Kleiderläuse) und murinem Fleckfieber (R. typhi; Übertragung durch Flöhe).

- Zeckenbißfiebergruppe („spotted fever group“) mit Felsengebirgsfieber (R. rickettsii, Übertragung durch Zecken), den Zeckenbißfiebern in Südeuropa, Afrika, Indien, Sibirien und Australien (R. conorii u. a.; Übertragung durch Zecken) und Rikkettsienpocken ( $R$. akari; Übertragung durch Milben).

- Tsutsugamushifieber (R. tsutsugamushi; Übertragung durch Milben).

- Q-Fieber, dessen Erreger (Coxiella burneti) taxonomisch nicht zu den Rickettsien im engeren Sinn gehört.

Der Erreger des Wolhynischen Fiebers Bartonella quintana wird heute nicht mehr zu den Rickettsien gerechnet (s. bazilläre Angiomatose, Abschn. 22.2.5)

Das Q-Fieber ist die einzige in Deutschland vorkommende Rickettsiose. Importierte Fälle von Zekkenbißfieber (meist R.-conorii-Zeckenbißfieber; Synonym: Boutonneuse-Fieber), insbesondere aus Südund Ostafrika (v. a. bei Safaritouristen), aber auch aus dem Mittelmeergebiet, sind nicht selten. Gelegentlich werden auch Fälle von Tsutsugamushi-Fieber, Felsengebirgsfieber, murinem Fleckfieber und Q-Fieber importiert, während das klassische Fleckfieber auf die arme Hochlandbevölkerung fokaler Endemiegebiete Afrikas (v. a. Äthiopien) und Lateinamerikas beschränkt ist. Epidemien kommen nur beim klassischen Fleckfieber und regional begrenzt auch beim QFieber vor

\section{Klinischer Krankheitsverdacht}

Alle Rickettsiosen sind akute Erkrankungen mit meist kontinuierlichem, etwa 2 Wochen andauerndem Fie- 
ber, das - außer beim Q-Fieber - häufig mit einem Exanthem einhergeht (besonders ausgeprägt und $\mathrm{z}$. T. hämorrhagisch beim klassischen Fleckfieber und Felsengebirgsfieber). Bei der Fleckfieber- und Zeckenbißfiebergruppe steht eine generalisierte Vaskulitis mit variabler Organbeteiligung (ZNS, Myokarditis) im Vordergrund. Bei den Zeckenbißfiebern, Rickettsienpokken und Tsutsugamushi-Fieber ist häufig eine Primärläsion (Eschar) an der Infektionsstelle vorhanden, typischerweise in Form einer schwärzlich überkrusteten Nekrose („tâche noire“). Spätrezidive des klassischen Fleckfiebers können sich noch nach langer Zeit manifestieren (Brill-Zinsser-Erkrankung).

Das Q-Fieber verläuft meist unter dem Bild einer (sog. atypischen) interstitiellen Pneumonie (trockener Husten, geringer Auskultationsbefund trotz z. T. ausgedehnter fleckförmiger Infiltrate), gelegentlich treten chronische Verläufe in Form einer Endokarditis oder granulomatösen Hepatitis auf.

\section{Diagnostik}

Die Diagnose wird in der Regel serologisch gesichert (IFT, ELISA, KBR; IgM-Antikörper, signifikanter Titeranstieg), möglichst unter Verwendung art- oder gruppenspezifischer Rickettsienantigene (Teil A, Kap. 3 Tabelle 3-z9z); die Proteus OX-2-, OX-19- und OX-K-Heteroagglutinationstests (Weil-Felix) sind unzuverlässig. Bei akuten C.-burneti-Infektionen sind hohe bzw. ansteigende Antikörperspiegel gegen Phase-II-Antigen nachweisbar, bei chronischen Q-Fiebererkrankungen Antikörper gegen Phase-I-Antigen.

Die Erregerisolierung (Zellkultur, Hühnerembryo, Tierversuch) ist schwierig; Rickettsien können mittels direkter Immunfluoreszenz auch im Eschar nachgewiesen werden. Ein Nachweis mittels PCR aus Blut und anderen Materialien ist bei den meisten Rickettsien und C. burneti ebenfalls möglich.

\subsubsection{3}

\section{Ehrlichiosen}

Erkrankungen durch kleine gramnegative, molekulargenetisch den Rickettsien nahestehende Bakterien mit intrazellulärer Vermehrung. Am häufigsten als humane monozytäre Ehrlichiose (HME) durch Ehrlichia chaffeensis (Übertragung durch Zecken, Reservoir verschiedene Hirscharten). Selten als humane granulozytäre Ehrlichiose (HGE) durch eine mit E. phagocytophila und E. equi nahe verwandte Ehrlichia-Art; Übertragung wahrscheinlich ebenfalls durch Zecken, bislang nur im Nordosten der USA beobachtet. Die SennetsuEhrlichiose (Erreger: E. sennetsu) scheint auf Japan begrenzt (Übertragungsmodus und Reservoir unklar).

Alle Ehrlichiosen verlaufen mit Fieber, z. T. mit Schüttelfrösten, Kopfschmerzen, Myalgien und gelegentlichem Exanthem. Bei HME und HGE besteht meist eine Leukopenie und Thrombopenie; Komplikationen sind Meningoenzephalitis, respiratorische Insuffizienz, Nierenversagen sowie gastrointestinale und pulmonale Blutungen. Bei Sennetsu-Ehrlichiose liegt meist eine generalisierte Lymphadenopathie (besonders zervikal und retroaurikulär) und eine Lymphozytose mit vermehrten atypischen Lymphozyten vor sowie z. T. eine Hepatosplenomegalie (mononukleoseartiges Krankheitsbild, s. Abschn. 22.2.3).

\section{Diagnostik}

Serologie (signifikanter Titeranstieg), Erregernachweis aus Blut mittels PCR; der Nachweis der Erreger im gefärbten Blutausstrich als intrazytoplasmatische Einschlüsse (Morulae) in Leukozyten gelingt häufig nicht, Isolierung mittels Zellkultur (schwierig) oder Tierversuch (bei E. sennetsu).

\subsubsection{4}

\section{Chlamydieninfektionen}

22.3.24.1

\section{Infektionen durch Chlamydia trachomatis}

Unterschiedliche Serovare von C. trachomatis (A-L) sind die Ursache verschiedener Erkrankungen, die sich 5 verschiedenen Kategorien zuordnen lassen:

1) klassisches Trachom,

2) Konjuntivitiden bei Kindern und Erwachsenen,

3) urogenitale Erkrankungen bei Erwachsenen (s. Abschn. 22.2.6) einschließlich

4) Lymphogranuloma venereum (s. Abschn. 22.2.6)

5) perinatal erworbene Neugeboreneninfektionen (Neugeborenenpneumonitis und Neugeborenenkonjunktivitis).

Komplikationen (bei Serotypen D-K): Reiter-Syndrom (s. Kap. 27), Perihepatitis (bei Salpingitis/Zervizitis).

\section{Diagnostik}

Nachweis mittels Isolierung (Zellkultur) und/oder immunzytologisch (direkte Immunfluoreszenz, Immunperoxidase) aus Abstrichen bzw. Punktaten; PCR, Ligasekettenreaktion. Serodiagnostik: bei Neugeborenen (IgM-Antikörper) und bei Lymphogranuloma venereum (s. Abschn. 22.2.6) meist hohe Antikörpertiter, ansonsten geringe Aussagekraft (hohe Durchseuchung).

\subsubsection{2 \\ Psittakose (Ornithose)}

Der Erreger Chlamydia psittaci (verschiedene Serotypen) wird durch Staub- und Tröpfcheninfektion von Vögeln (Papageien, Wellensittiche, aber auch einheimische Vogelarten) übertragen, selten von Mensch zu Mensch; z. T. Berufskrankheit (Geflügelzucht, Vogelhändler). 
Variables Krankheitsbild von grippeartigen Erscheinungen mit häufig pulmonaler Beteiligung (meist als sog. atypische Pneumonie) bis zu bedrohlichen Verläufen mit schwerer, z. T. hämorrhagischer Pneumonie, ZNS-Beteiligung, akuter Peri-, Myo- und Endokarditis.

\section{Diagnostik}

Meist serologisch (KBR, IFT u. a. Testverfahren; signifikanter Titeranstieg bzw. hohe Titer); Isolierung (Zellkultur) schwierig, PCR.

\subsubsection{3}

\section{Infektionen durch Chlamydia pneumoniae}

Weltweit verbreiteter Erreger von sporadisch und z. T. epidemisch auftretenden, akuten Erkrankungen des oberen (Pharyngitis) und unteren (Bronchitis, Pneumonitis) Respirationstrakts sowie bei Otitis; wohl häufig asymptomatische Infektion (hohe Durchseuchung); bei älteren Patienten mit chronischen Grunderkrankungen und bei Kleinkindern in Entwicklungsländern gelegentlich auch schwer verlaufende Pneumonien; z. T. protrahierter Verlauf (chronischer Husten über 12 Monate). Es gibt Hinweise für eine Assoziation zwischen $C$. pneumoniae und der Entstehung von Arteriosklerose bzw. koronarer Herzerkrankung (seroepidemiologische Untersuchungen, Nachweis von C. pneumoniae in Atheromen, Reduktion der Reinfarktrate nach antibiotischer Behandlung). Ob tatsächlich ein Kausalzusammenhang und damit ein möglicher Interventionsbedarf besteht, ist derzeit jedoch unklar.

\section{Diagnostik}

Serologisch (IFT u. a. Tests, IgM-Antikörper, signifikanter IgG/IgA-Antikörperanstieg), Isolierung mittels Zellkultur, PCR.

\subsubsection{5}

\section{Mykoplasmeninfektionen}

Mycoplama hominis und Ureaplasma urealyticum sind Erreger von vorwiegend sexuell übertragenen Infektionen des Urogenitaltrakts (s. Abschn. 22.2.6).

Mycoplasma pneumoniae kann akute, meist gutartig verlaufende Erkrankungen des oberen (Bronchiolitis, Laryngitis, Pharyngitis, Otitis) und unteren Respirationstraktes (sog. atypische Pneumonie bevorzugt bei Kindern und jungen Erwachsenen) hervorrufen. Die Mykoplasmenpneumonie beginnt relativ plötzlich mit hohen Temperaturen ohne Schüttelfrost (Kontinua um $39^{\circ} \mathrm{C}$ ). Es stellt sich schnell ein quälender, unproduktiver Reizhusten ein, der pertussisähnlich bis zum Erbrechen führen kann. Dieser Reizhusten kann die eigentliche pneumonische Infiltration lange überdauern. Häufig wird über Kopf- und Ohrenschmerzen geklagt. Perkutorisch läßt sich meist eine sehr diskrete Dämp- fung feststellen, während die Auskultation meist unauffällig ist.

Röntgenologisch überrascht dann nicht selten die Massivität der Infiltration, die segmentär, lobär oder diffus fleckig und bilateral auftreten kann.

Neben der Pneumonie können Mykoplasmen auch eine Otitis und eine Meningoenzephalitis verursachen (s. Abschn. 22.2.2).

Komplikationen sind immunologisch bedingte Hämolysen, die selten $(<1 \%)$ bedrohliche (transfusionspflichtige) Ausmaße annehmen. Unklare Hämolysen sollten differentialdiagnostisch immer an eine Mykoplasmeninfektion denken lassen. Pleura- und Perikardergüsse kommen ebenso wie diffuse Myokarditiden vor.

\section{Diagnostik}

Die Laborbefunde sind wenig ergiebig. Mit der um den 6. Krankheitstag einsetzenden Kälteagglutininbildung steigt die BSG stark an Die Leukozyten können auf extreme Werte, z. T. bis zu $60000 / \mu l$ ansteigen und im Differentialblutbild einen leukämoiden Charakter annehmen. Die Transaminasen können, wie bei allen Pneumonien, erhöht sein, sind aber diagnostisch wenig hilfreich. In der Mehrzahl der Fälle sind Kälteagglutinine nachweisbar.

Der Erregernachweis aus Bronchialsekret ist kulturell (Teil A, Abschn. 3.2.2) und mittels PCR möglich. Die Antikörperantwort (signifikanter Anstieg) ist oft erst spät (z. T. jenseits der 3. Krankheitswoche) aussagekräftig.

\section{4 \\ Virusinfektionen}

22.4.1

\section{Herpes simplex}

Herpes-simplex-Viren (HSV) führen zu latenten Infektionen mit hoher Durchseuchung. Primärinfektion mit Herpes-simplex-Virus Typ 1 (HSV-1 oder humanes Herpesvirus Typ $1=\mathrm{HHV}-1)$ und Typ 2 (HSV -2 oder HHV-2) verläuft asymptomatisch oder als Gingivostomatitis (Stomatitis aphthosa), Pharyngitis, Keratokonjunktivitis, kutane Infektion (z. B. Herpesparonychie), Vulvovaginitis, Balanitis, Urethritis und/oder Anoproktitis. Nach der Primärinfektion meist Ursache rezidivierender mukokutaner Herpesläsionen labial-oral (meist HSV-1) und genitoanal (meist HSV-2).

Seltenere, aber z. T. gravierende Manifestationen sind rekurrierende oder progrediente Keratokonjunktivitis, disseminierte mukokutane Infektion bei atopischem Ekzem (Ekzema herpeticatum), perinatale Infektion (Herpes neonatorum, HSV -2) mit lokalisiertem (mukokutan, Stomatitis, Keratitis) oder generalisiertem (Hepatitis, Enzephalitis, Pneumonitis) Verlauf so- 
wie eine sporadische, akute hämorrhagisch nekrotisierende Enzephalitis (HSV-1) mit hoher Letalität (s. Abschn. 22.2.2) und eine meist benigne lymphozytäre Meningitis (HSV-2), z. T. mit rezidivierendem Verlauf (Mollaret-Meningitis).

Bei Immunkompromittierten (z. B. angeborene Immundefizienz, Hämoblastosen, Transplantationspatienten, HIV-Infektion, iatrogene Immunsuppression) treten gehäuft disseminierte kutane und mukokutane Infektionen auf sowie schwerwiegende Organinfektionen (Ösophagitis, Pneumonie und generalisierte Infektionen mit Beteiligung von Leber u. a. Organen).

\section{Diagnostik}

Isolierung (Zellkultur) sowie Nachweis mittels Immunhistologie/zytologie, DNS-in-situ-Hybridisierung und/ oder PCR aus Abstrichen, Biopsien, Liquor und Blut (besonders bei Immunkompromittierten). Durch den Nachweis von HSV-DNS im Liquor mittels PCR ist eine rasche und sensitive Diagnose der HSV-Enzephalitis möglich (s. Abschn. 22.2.2). Herpesläsionen zeigen histo/zytopathologisch typische vielkernige Riesenzellen und eosinophile Kerneinschlußkörperchen. Der Nachweis von Antikörpern (IgM-Antikörper, Titerverlauf) im Serum bzw. Liquor ist wegen hoher Durchseuchung nur von begrenzter Aussagekraft (sinnvoll am ehesten bei Primärinfektionen).

\subsection{2}

\section{Varizellen und Zoster}

Primärinfektion mit dem Varizella-Zoster-Virus (VZV) als meist benigne Varizellen (Windpocken), lokale Komplikationen: Sekundärinfektion (meist Staphylococcus aureus), korneale Läsionen. Systemische Komplikationen (Pneumonitis, Meningoenzephalitis, Hepatitis, hämorrhagische Varizellen) gehäuft bei Immunkompromittierten, Neugeborenen (perinatale Infektion der Mutter) und Erwachsenen. Selten Embryopathien bei mütterlichen Varizellen im 1. Trimenon. Nach Primärinfektion Viruslatenz in sensorischen Ganglien, durch Reaktivierung Herpes zoster (Gürtelrose) bei Patienten mit Malignomen (besonders M. Hodgkin), Immunsuppression sowie spontan besonders in höherem Alter. Lokale Komplikationen bei Zoster ophthalmicus und Zoster oticus. Bei Immunkompromittierten sind kutane Disseminierung (z. T. mit nekrotisierenden Läsionen) und viszerale Generalisierung (Hepatitis, Pneumonitis, Enzephalitis) möglich.

\section{Diagnostik}

Klinisches Bild; Virusisolierung (Zellkultur), Immunhistolgie/zytologie und PCR aus Bläscheninhalt, Biopsien sowie Blut und Urin (bei Immunkompromittierten), histo-/zytopathologisches Bild ähnlich wie bei
Herpes-simplex-Virusinfektion (vielkernige Riesenzellen); Serologie (IgM-Antikörper).

\subsection{3}

Masern

Der Diagnoseverdacht ergibt sich bei typischem klinischem Bild mit hohem Fieber, katarrhalischen Symptomen (Schnupfen, trockener Husten), Konjunktivitis, Enanthem an der Wangenschleimhaut (Koplik-Flekken: weißliche Stippchen mit rötlichem Hof), und nachfolgendem typischem Masernexanthem (makulopapulös, feinfleckig und konfluierend) beginnend am Kopf (hinter den Ohren) und nach kaudal fortschreitend. Komplikationen: Otitis, Pseudokrupp, Bronchopneumonie, akute postinfektiöse Enzephalitis (Mortalität $12-15 \%$, Defektheilungsrate bis $50 \%$ ); sehr selten subakute sklerosierende Panenzephalitis (SSPE) mit progredientem Verlauf.

\section{Diagnostik}

Klinisches Bild; mäßiggradige Leukopenie, gelegentlich Thrombozytopenie. Die Serodiagnostik ist aussagekräftig (IgM-Antikörper), bei SSPE hohe IgG-Antikörperspiegel im Serum und Liquor. Das Masernvirus kann auch aus Rachenspülwasser, Blut und Liquor mittels Zellkultur isoliert (oft schwierig) oder mittels PCR nachgewiesen werden (Teil A, Abschn. 3.5.3).

\subsection{4}

Röteln

Postnatal erworbene Infektionen verlaufen mild oder asymptomatisch. Typische Krankheitszeichen sind das feinfleckig makulöse, meist nicht konfluierende Rötelnexanthem mit Beginn am Kopf und Ausbreitung auf Brust und Peripherie sowie die mäßig schmerzhafte, bevorzugt nuchale Lymphadenopathie. Arthralgien und Thrombozytopenie können auftreten, eine Enzephalitis ist sehr selten. Bedeutung haben die Röteln vorwiegend durch die zu Abort und schweren Entwicklungsstörungen des Kindes (Taubheit, Katarakt, mentale Retardierung u. a.) führende Rötelnembryopathie bei Erstinfektion der Mutter (auch asymptomatisch) während der Schwangerschaft (insbesondere im 1. Trimenon).

\section{Diagnostik}

Klinik; die Diagnose kann serologisch bestätigt werden (IgM-Antikörper); bei konnataler Infektion ist die Diagnose serologisch (IgM-Antikörper) und durch den Virusnachweis mittels PCR oder auch kulturell in Fruchtwasser oder kindlichem Blut möglich. 


\subsection{5}

\section{Parvovirusinfektion}

Das humane Parvovirus B19 ist der Erreger des Erythema infectiosum (Ringelröteln), einer meist leicht und z. T. afebril verlaufenden Erkrankung (bevorzugt bei Kindern) mit typischem Exanthem, das als rötlich-livides, schmetterlingsförmiges Erythem auf den Wangen (periorale Aussparung) beginnt, sich feinfleckig am Stamm ausbreitet und dann zu typischen girlandenförmigen Erythemen besonders an den Extremitätenstreckseiten konfluiert. Weitere, oft unabhängig von einem Erythema infectiosum auftretende Manifestationen sind Arthritiden (besonders bei jüngeren Frauen) bevorzugt an den Finger- und Handgelenken mit z. T. protrahiertem Verlauf sowie eine Störung der Erythropoese, die bei vorbestehender Anämie bzw. bei Patienten mit hämolytischer Anämie schwere aplastische Krisen auslösen kann (gelegentlich auch Ursache persistierender aplastischer Anämie bei Immunkompromittierten). Während der Schwangerschaft können Infektionen der Mutter (auch asymptomatische) zur featlen Infektion mit Hydrops fetalis und intrauterinem Fruchttod führen.

\section{Diagnostik}

Klinisches Bild und Serologie (IgM-Antwort, ggf. IgGTiteranstieg); bei Immunkompromittierten und fetaler Infektion bevorzugt durch Virusnachweis mittels PCR, In-situ-Hybridisierung und direkter Immunfluoreszenz aus Blut (auch Fetalblut), Knochenmark und/oder Fruchtwasser.

\subsection{6}

Mumps

Die klinische Verdachtsdiagnose ist meist naheliegend bei typischem Krankheitsbild mit schmerzhafter Parotisschwellung, die meist einseitig beginnt und nach 12 Tagen auch die andere Speicheldrüse betrifft; zudem variables Fieber. Schwieriger ist der Diagnoseverdacht bei Orchitis, Oophoritis, Pankreatitis, Meningitis oder Meningoenzephalitis (s. Abschn. 22.2.2), insbesondere wenn diese nicht als Komplikation während oder im Anschluß an eine Mumpsparotitis auftreten.

\section{Diagnostik}

Klinisch; häufig besteht eine Erhöhung der Serumamylasewerte (meist normale Lipase, außer bei Pankreatitis). Serodiagnostik (IgM-Antikörper). Ein Virusnachweis ist möglich (Kultur, PCR), gehört jedoch nicht zur Routinendiagnostik.

\subsection{7}

Poliomyelitis

Ein Diagnoseverdacht ergibt sich bei jeder schlaffen Lähmung ohne sensorische Defizite (besonders an den unteren Extremitäten, meist beidseits aber nicht symmetrisch), v. a. wenn sie sich während oder nach einer fieberhaften Erkrankung manifestiert. Heute handelt es sich fast ausschließlich um importierte Erkrankungen oder um eine vakzineassoziierte paralytische Poliomyelitis (VAPP) nach Schluckimpfung mit Lebendvakzine (OPV) beim Erkrankten oder bei Kontaktpersonen. Komplikationen sind Atemlähmung und Beteiligung der Hirnnerven.

\section{Diagnostik}

Bei begründetem Verdacht sollte stets ein Virusnachweis (Kultur und PCR) aus Stuhl, Rachensekret/-spülwasser und/oder Liquor versucht werden, dies gilt auch für VAPP-Verdachtsfälle. Virusnachweis und Typisierung sind epidemiologisch und ggf. auch entschädigungsrechtlich (Impfschaden) bedeutsam. Die Serologie (Serokonversion, signifikanter Antikörperanstieg) ist nur von untergeordneter Bedeutung.

\subsection{8}

Influenza

Die Erkrankung beginnt mit plötzlich einsetzenden Kopf-, Gelenk- und Gliederschmerzen (lumbosakral, dorsal, Schultergürtel) und innerhalb weniger Stunden steil ansteigendem Fieber (Kontinua). Das Allgemeinbefinden ist stark beeinträchtig mit Schwäche, Inappetenz, Übelkeit, Schwindel und Kollapsneigung. Im Verlauf besteht oft ein quälender trockener Husten und Halsschmerzen. Bei der körperlichen Untersuchung fallen gedunsenes Gesicht, livide Haut- und Lippenverfärbung, Konjunktivalinjektion, Lidrandkrusten, verschwollene Periorbitalbereiche, bläulichrote Schwellung des Rachenrings, und rautenförmiges geflecktes, manchmal auch hämorrhagisches Enanthem des weichen Gaumens auf, das mit flammender Rötung auf Gaumenbögen und Uvula übergreifen kann. Das Integument ist vermehrt gerötet, gelegentlich besteht ein flüchtiges kleinfleckiges Exanthem, z. T. auch meningeale Reizerscheinungen ohne Pleozytose und häufig Herpesrezidive im Gesichtsbereich.

Komplikationen sind Laryngotracheobronchitis (Pseudokrupp besonders bei Kleinkindern), Bronchiolitis, interstitielle Pneumonie, foudroyant verlaufende hämorrhagische Pneumonie und Myokarditis.

\section{Diagnostik}

Bei begründetem Verdacht sollte der Virusnachweis stets versucht werden, wenn epidemiologische Relevanz besteht (Erkrankungen außerhalb bekannter Epidemien) oder bei Komplikationen: Virusanzucht und PCR aus Gurgelwasser, Nasensekret oder Bronchialsekret (bzw. BAL 
bei schwerer Pneumonie) innerhalb der ersten 3 Krankheitstage. Nachweis eines deutlichen Titeranstiegs spezifischer Antikörper (z. B. Hämagglutinationshemmtest-HHT) in gepaarten Seren von mindestens 7-10 Tagen Abstand.

\subsection{9}

\section{Tollwut}

Der Diagnoseverdacht ergibt sich am ehesten bei einer Enzephalitis, die mit Erregungszuständen und/oder dem relativ typischen Symptom einer Hydrophobie einhergeht. Allerdings sind diese Symptome keineswegs bei allen Patienten vorhanden, sondern es finden sich häufig lediglich die sonstigen Symptome einer Enzephalitis (s. Abschn. 2.2.2) mit Vigilanzstörungen, Benommenheit bis zur Bewußtlosigkeit und neurologischen Herdsymptomen. Oft ist eine entsprechende Exposition (Tierbiß etc.) in der Vorgeschichte zu eruieren. Die Prognose ist außer bei den extrem seltenen Erkrankungen von Geimpften immer infaust.

\section{Diagnostik}

Der Virusnachweis ist intra vitam möglich mittels Antigennachweis (direkte Immunfluoreszenz u. a. Verfahren), PCR und Virusanzucht aus Korenalabstrichen, Speichel und Liquor sowie postmortal aus Gehirngewebe (Histologie: Negri-Körperchen).

\subsubsection{0}

\section{Hantavirusinfektionen}

Die Übertragung von Hantaviren erfolgt durch Einatmung infektiöser Aerosole von Nagerexkrementen oder durch Bißverletzung. Je nach Virustyp sind verschiedene Erkrankungen möglich:

- Nephropathia epidemica (Serotyp Puumala u. a.) mit fieberhafter Allgemeinerkrankung und Nephritis 4-10 Tage nach Krankheitsbeginn (Oligurie, Proteinurie, Anstieg der Retentionswerte) und meist folgenloser Ausheilung.
- Hämorrhagisches Fieber mit renalem Syndrom (Serotyp Dobrava, Hantaan oder Seoul) mit zusätzlichen Blutungskomplikationen wie bei viralen hämorrhagischen Fiebern (s. Abschn. 22.4.11) und Letalität bis $5 \%$.

- „Hantavirus pulmonary syndrome“ (Serotyp „four corners" u. a.) mit schweren Verlauf (Letalität bis $50 \%)$. Nach initialem Fieber, Myalgien und Abgeschlagenheit kommt es zur raschen Ausbildung einer pulmonalen Insuffizienz (ARDS).

\section{Diagnostik}

Die Diagnose wird vorwiegend durch den Nachweis spezifischer IgG- und IgM-Antikörper bestätigt (s. Teil A, Kap. 3 Tabelle 3-12). Antikörper sind in der Regel bereits beim Auftreten der klinischen Symptome nachweisbar. IgM-Antikörper persistieren nur kurz, IgG-Antikörper hingegen über viele Jahre. Der kulturelle Virusnachweis ist schwierig; eine Nachweis mittels PCR aus Blut und Lungenbiopsien ist möglich (Teil A, Kap. 3, Tabelle 3-7).

\subsubsection{1}

\section{Dengue-Fieber und andere Arbovirosen}

Dengue-Fieber ist die häufigste tropenspezifische Viruserkrankung, die nach Deutschland importiert wird (Schätzung: ca. 3000 Fälle pro Jahr) und verläuft als fieberhafte Allgemeinerkrankung mit ausgeprägten Myalgien und Arthralgien. Vor allem bei Kindern in Südostasien kann es zu hämorrhagischem Dengue-Fieber (DHF) oder Dengue-Schocksyndrom (DSS) mit massiven Spontanblutungen bzw. Kreislaufzusammenbruch und hoher Letalität kommen.

Daneben gibt es zahlreiche weitere durch Arthropoden übertragene Viruserkrankungen (Arbovirosen) in Tropen und Subtropen, die als Dengue-artige Erkrankungen (z. T. mit schweren langanhaltenden Arthralgien), als Enzephalitis oder als virale hämorrhagische Fieber verlaufen können (Tabelle 22-24).

Tabelle 22.24 Die wichtigsten tropischen Virusinfektionen

\begin{tabular}{llll}
$\begin{array}{l}\text { Fieberhafte Allge- } \\
\text { meinerkrankungen }\end{array}$ & $\begin{array}{l}\text { mit besonders ausgeprägten } \\
\text { Arthralgien }\end{array}$ & Virus-Enzephalitiden & $\begin{array}{l}\text { virale hämorrhagische Fieber } \\
\text { (VHF) }\end{array}$ \\
\hline - Dengue-Fieber & - Ross-River-Virusinfektion & - Japanische Enzephalitis & - Dengue-hämorrhagisches Fieber \\
- West-Nil-Fieber & - Chikungunya & - Pferdeenzephalitiden (östl., westl., & - Gelbfieber \\
- Pappataci-Fieber & - Sindbis-Fieber & venzolan. EE) & - Rifttalfieber \\
- Rift-Tal-Fieber & - O'nyong-nyong & - Europäische Zweckenenzephalitis & - Hantavirusinfektion (HFRS) \\
& & (FSME, TBE) - Lassafieber & - Ebolafieber \\
& & - Colorado-Zeckenbißfieber & - Marburg-Virusinfektion \\
& & - West-Nil-Fieber & - Kongo-Krim-HF* \\
& & - Murray-Tal-Enzephalitis & - Argentinisches HF* \\
& & & - Bolivianisches HF* \\
& & & Kyasanur-Wald-Krankheit
\end{tabular}

${ }^{*} \mathrm{HF}=$ hämorrhagisches Fieber 
Der Krankheitsverdacht ergibt sich bei

- akuter hochfieberhafter Erkrankung mit Myalgien, Kopfschmerzen und variablem Exanthem; z. T. ausgeprägte Muskel-, Knochen- und Gelenkschmerzen sowie gelegentlich Petechien, Schleimhautblutungen, ZNS-Beteiligung und Myokarditis (DHF und DSS sind bei Reisenden sehr selten),

- Beginn der Erkrankung innerhalb von 2 Wochen nach Verlassen des Verbreitungsgebietes.

\section{Diagnostik}

Die Verdachtsdiagnose ergibt sich aus Anamnese (Aufenthalt im Endemiegebiet), klinischem Bild und hinweisenden Laborparametern (Thrombopenie, Neutropenie bei relativer Lymphozytose, wiederholt negative Diagnostik hinsichtlich Malaria s. Abschn. 22.6.1). Bei unkomplizierten Erkrankungen kann mangels Konsequenzen auf eine spezifische Diagnostik verzichtet werden. Bei schweren Erkrankungen, insbesondere bei Verlauf als Enzephalitis oder hämorrhagisches Fieber, sind gezielte serologische (Teil A, Kap. 3, Tabelle 3-10) und virologische (Virusisolierung mittels Zellkultur, PCR) Untersuchungen unter Berücksichtigung aller differentialdiagnostisch und epidemiologisch in Frage kommender Erkrankungen erforderlich (Rücksprache mit tropenmedizinischer Einrichtung bzw. tropenmedizinisch erfahrenem Virologen).

\subsubsection{2}

\section{Virale hämorrhagische Fieber (VHF)}

Akute fieberhafte Erkrankungen mit z. T. schweren Hämorrhagien und hoher Letalität. Ursachen können neben Gelbfieber und hämorrhagischem Dengue-Fieber verschiedene in Afrika sporadisch oder endemisch vorkommende Viruserkrankungen (Lassa-, Ebola-, Marburg- und Rift-Tal-Fieber) sein sowie das Krim-KongoFieber, die südamerikanischen hämorrhagischen Fieber, die klassische Hantaan-Erkrankung (s. 22.4.10) und weitere seltenere Virusinfektionen (Tabelle 22-24). Der Diagnoseverdacht ergibt sich bei

- akuten fieberhaften Erkrankungen mit schweren Hämorrhagien an Haut, Schleimhäuten und inneren Organen,

- Erkrankung innerhalb von 3 Wochen nach Einreise aus Verbreitungsgebieten,

- Ausschluß anderer akuter fieberhafter Erkrankungen, die mit Hämorrhagien einhergehen können (z. B. Malaria, Typhus abdominalis, Rickettsiosen, Sepsis, Meningitis, hämolytisch-urämisches Syndrom, Toxinschocksyndrom, Leptospirosen, Pest).

\section{Diagnostik}

Virusisolierung (Zellkultur, PCR) aus Blut, Urin, Rachenspülwasser und Organbiopsien bzw. Autopsiematerial; Schnelltests: Antigennachweis mittels direkter
Immunfluoreszenz (Teil A, Abschn. 3.6.3) und Elekronenmikroskopie (bei Marburg- und Ebolavirus); Serologie (IgM-Antikörper, signifikanter Titeranstieg, s. Teil A, Abschn. 3.6.2). Für Auswahl und Art der Untersuchungen sowie für vorschriftsmäßige Sicherheitsverpackung und Überbringung des Untersuchungsmaterials ist eine Rücksprache (vor Materialabnahme) mit dem Untersuchungslabor unerläßlich. Bereits bei begründetem Verdacht sind die entsprechenden Infektionsschutzmaßnahmen konsequent durchzuführen wie Isolierung des Patienten, Behandlung unter Barrieremaßnahmen, Desinfektion aller Ausscheidungen und am Patienten verwendeten Materialien, Vorsichtsmaßnahmen bei der Bearbeitung aller Patientenproben (möglichst Inaktivierung, z. B. mit Triton X-100) und Beachtung der Meldepflicht bereits bei Verdacht.

\section{5 \\ Mykosen innerer Organe \\ 22.5.1 \\ Candidiasis \\ Neben Infektionen von Haut und Schleimhäuten kön- nen Hefen der Gattung Candida (Candida albicans u. a.) schwerwiegende disseminierte Infektionen oder Erkrankungen innerer Organe verursachen. Betroffen sind fast ausschließlich Patienten \\ - mit schweren Abwehrstörungen (z. B. Hämoblasto- sen, Aids, Malignome, Chemotherapie), \\ - nach spontanen (Ulkus), operativen oder traumati- schen Perforationen des Intestinaltrakts (besonders Ösophagus) und thoraxchirurgischen Eingriffen, \\ - mit intravasalen oder intraluminalen Fremdkör- pern (Katheter, Herzklappen), \\ - Peritonealdialyse, \\ - i.v.-Drogenabusus, \\ - nach schweren Verbrennungen.}

Eine Therapie mit Kortikosteroiden oder mit Breitbandantibiotika wirkt begünstigend.

Bei disseminierter Candidiasis (Candidasepsis) besteht meist hohes Fieber. Bei schwerer Neutropenie kommt es häufig zu rascher Progredienz mit septischer Metastasierung in multiple Organe (z. B. Lunge, Niere, Gehirn). Bei subakutem Verlauf (z. B. Dauerernährung über Venenkatheter) kann eine Endophthalmitis (wattebauschartige Läsionen in Retina und Glaskörper) entstehen sowie papulöse oder pustulöse Hautabsiedlungen.

Die Symptome der Candidaendokarditis entsprechen denen der bakteriellen Endokarditis. Splenomegalie, Petechien und Mikroembolisationen sind häufig. Die Candidaperitonitis nach Abdominaleingriffen oder bei kontinuierlicher Peritonealdialyse manifestiert sich mit Fieber und abdominellen Schmerzen. Das Dialysat ist meist trüb und enthält Hefezellen und 
Pseudohyphen. Bei Aids-Patienten tritt neben oberflächlichen Candidainfektionen sehr häufig eine Candidaösophagitis auf (s. Abschn. 22.2.5).

\section{Diagnostik}

Der Nachweis einer systemischen Infektion erfolgt kulturell aus Blut, Liquor, Punktaten, Biopsien (auch histologisch) und Kathetern. In Schleimhautabstrichen und im Dialysat ist ein orientierender Direktnachweis im Grampräparat sinnvoll. Bei disseminierten Infektionen lassen sich meist zirkulierende Antigene (Teil A, Abschn. 3.6.3) nachweisen (Schnelltest), auch ein Nachweis mittels PCR im Blut und normalerweise sterilen Geweben ist möglich. Der Antikörpernachweis ist nur begrenzt aussagekräftig (signifikanter Anstieg).

\subsection{2}

\section{Aspergillose}

Die Inhalation der ubiquitär verbreiteten Schimmelpilze der Gattung Aspergillus (meist A. fumigatus) führt meist nur bei vorbestehender Schädigung zur Kolonisation von Alveolen, Bronchien oder Nasennebenhöhlen. Dies kann eine allergische Bronchialaspergillose (s. Kap. 19) oder allergische Sinusitis (Kap. 30) auslösen. In Hohlräumen (Lungenzysten, Kavernen, Nasennebenhöhlen) können sich große Pilzballen (Aspergillome) ohne Gewebeinvasion bilden. Bei fibrosierenden Lungenerkrankungen (Sarkoidose, Silikose, Tuberkulose, Histoplasmose) kann eine chronisch nekrotisierende Lungenaspergillose mit Husten, Auswurf und Hämoptysen entstehen. Zur invasiven Aspergillose mit akuter Bronchopneumonie und/oder hämatogener Disseminierung (besonders in Hirn, Niere und Kno- chen) kommt es nur bei Immunkompromittierten (besonders bei schwerer Neutropenie).

\section{Diagnostik}

Aspergillome der Lunge zeigen radiologisch meist das typische Bild einer beweglichen intrakavitären Masse; Pilzbälle in den Nasennebenhöhlen sind in der CT oder MRT nachweisbar. Der Nachweis von Aspergillen in Sputum oder BAL beweist nur die Kolonisation. Bei neutropenischen Patienten ist er jedoch prädiktiv für eine invasive pulmonale Aspergillose. Entscheidend ist der Nachweis von Aspergillushyphen im Biopsat (Bronchoskopie, ggf. auch andere Organe). Bei disseminierter Aspergillose sind Blutkulturen nicht immer positiv, zudem sind falsch-positive Kulturen und auch falsch-positive PCR-Ergebnisse durch Kontamination nicht selten. Antikörper sind bei den meisten Aspergillosepatienten nachweisbar, allerdings auch bei Gesunden, und sie können bei Immunkompromittierten fehlen. Der Nachweis zirkulierender Antigene ist spezifisch jedoch nicht sehr sensitiv.

\subsection{3}

\section{Sonstige Systemmykosen}

Neben den wichtigsten einheimischen Mykosen innerer Organe (Candidiasis, Kryptokokkose - s. Abschn. 22.2.5 - und Aspergillose) kommen zahlreiche weitere Pilze als Erreger opportunistischer Infektionen in Frage (Mucormykosen, Penicillinose, Infektionen durch Sporothrix, Fusarium, Trichosporon, Geotrichum, Rhodotorula u. a.). Für Diagnoseverdacht und Lokalisation ist neben den klinischen Befunden meist die bildgebende Diagnostik wegweisend. Disseminierte Infektionen (besonders bei schwerer Neutropenie)

Tabelle 22-25. Die wichtigsten exotischen Systemmykosen

\begin{tabular}{|c|c|c|c|c|}
\hline $\begin{array}{l}\text { Krankheit } \\
\text { (Erreger) }\end{array}$ & Verbreitung & Krankheitsbild & Untersuchungsmaterial & Diagnostik \\
\hline $\begin{array}{l}\text { Histoplasmose } \\
\text { (Histoplasma capsula- } \\
\text { tum) }\end{array}$ & $\begin{array}{l}\text { Nord/Südamerika } \\
\text { sporadisch weltweit }\end{array}$ & $\begin{array}{l}\text { Akute und chronische Pneu- } \\
\text { monie, disseminierte Form }\end{array}$ & $\begin{array}{l}\text { Sputum, BAL, Knochen- } \\
\text { mark, Blut, Biopsate } \\
\text { (Lunge, andere Organe) }\end{array}$ & $\begin{array}{l}\text { Histologisch, kultu- } \\
\text { rell, serologisch }\end{array}$ \\
\hline $\begin{array}{l}\text { Afrikanische } \\
\text { Histoplasmose } \\
\text { (H. duboisii) }\end{array}$ & $\begin{array}{l}\text { West- und Zentrala- } \\
\text { frika }\end{array}$ & $\begin{array}{l}\text { Wie Histoplasmose, zudem } \\
\text { granulomatöse Dermatitis, } \\
\text { Osteomyelitis }\end{array}$ & $\begin{array}{l}\text { Wie Histoplasmose, zu- } \\
\text { dem Hautbiopsate, Biop- } \\
\text { sate und Operationsmate- } \\
\text { rial vom Knochen }\end{array}$ & $\begin{array}{l}\text { Histologisch, kultu- } \\
\text { rell }\end{array}$ \\
\hline $\begin{array}{l}\text { Kokzidioidomykose } \\
\text { (Coccidioides immitis) }\end{array}$ & $\begin{array}{l}\text { Süd- und Nordame- } \\
\text { rika }\end{array}$ & $\begin{array}{l}\text { Akute Pneumonie; dissemi- } \\
\text { nierte Form (Sepsis) mit me- } \\
\text { tastatischen Organläsionen } \\
\text { (Haut, Knochen u. a.) }\end{array}$ & $\begin{array}{l}\text { Sputum, BAL; Blut, Li- } \\
\text { quor, Biopsate (Lunge, } \\
\text { Haut, Knochen u. a. Orga- } \\
\text { ne) }\end{array}$ & $\begin{array}{l}\text { Zytologisch, histolo- } \\
\text { gisch, kulturell, se- } \\
\text { rologisch }\end{array}$ \\
\hline $\begin{array}{l}\text { Blastomykose } \\
\text { (Blastomyces dermatiti- } \\
\text { dis) }\end{array}$ & $\begin{array}{l}\text { Nord- und Mittel- } \\
\text { amerika }\end{array}$ & $\begin{array}{l}\text { Chronische Pneumonie, gra- } \\
\text { nulomatöse Dermatitis, } \\
\text { Osteomyelitis }\end{array}$ & $\begin{array}{l}\text { Sputum, BAL, Hautabstri- } \\
\text { che, Biopsate (Haut, Lun- } \\
\text { ge, Knochen) }\end{array}$ & $\begin{array}{l}\text { Histologisch, kultu- } \\
\text { rell, (serologisch) }\end{array}$ \\
\hline $\begin{array}{l}\text { Parakokzidioidomykose } \\
\text { (Paracoccidioides brasi- } \\
\text { liensis) }\end{array}$ & $\begin{array}{l}\text { Süd- und Nordame- } \\
\text { rika }\end{array}$ & $\begin{array}{l}\text { Ulzerierende Haut- und } \\
\text { Schleimhautgranulome, } \\
\text { Lymphadenitis, disseminier- } \\
\text { te Form (noduläre Läsionen } \\
\text { in Lunge u. a. Organen) }\end{array}$ & $\begin{array}{l}\text { Haut- und Schleimhaut- } \\
\text { abstriche, Biopsate (Haut, } \\
\text { Schleimhäut, Lymphkno- } \\
\text { ten, Lunge u. a. Organe) }\end{array}$ & $\begin{array}{l}\text { Zytologisch, histolo- } \\
\text { gisch, kulturell, se- } \\
\text { rologisch }\end{array}$ \\
\hline
\end{tabular}


manifestieren sich vorwiegend unter dem Bild einer Sepsis (s. Abschn. 22.2.1) oder Fieber unbekannter Ursache (s. Abschn. 22.2.7).

Ein orientierender Nachweis gelingt oft bereits zytologisch (z. B. Calcofluor-Färbung) bzw. histologisch (zusätzliche Silberfärbung empfehlenswert) in Abstrichen, Eiter, Sputum, BAL und Biopsien oder Operationsmaterial befallener Organe (z. B. Lunge, Haut, subkutane Läsionen, Schleimhäute, Nasennebenhöhlen, Orbita, Knochen, Hirnabszesse, Meningen).

Für die Diagnosesicherung inklusive genauer Artbestimmung und ggf. Resistenztestung sollte jedoch stets eine kulturelle Isolierung (Teil A, Abschn. 3.2.3) versucht werden. Bei disseminierten Infektionen ist der Nachweis mittels Blutkultur (inkl. Lysiszentrifugationstechnik und Kultur auf festen Medien) und soweit etabliert auch mittels PCR empfehlenswert.

Die wichtigsten exotischen Mykosen sind Histoplasmose, Kokzidioidomykose, Parakokzidioidomykose und Blastomykose (Diagnostik s. Tabelle 22-25). Daneben sind chronische subkutane Mykosen (Eumyzetom, Chromomykose, Rhinosporidiose u. a.) in den Tropen verbreitet (gleichzeitige zytologische, histologische und kulturelle Diagnostik von Abstrichen und Biopsien).

\section{6}

\section{Parasitosen}

Im folgenden ist die Diagnostik der wichtigsten Parasitosen aufgeführt, soweit sie nicht bereits bei den verschiedenen Infektionssyndromen erwähnt wurde. Die Diagnostik bei selteneren Protozoeninfektionen ist in
Tabelle 22-26, die der wichtigsten intestinalen Wurminfektionen in Tabelle 22-27 und die bei seltenerer Wurminfektionen in Tabelle 22-28 zusammengefaßt.

\subsection{1}

Malaria

Der Krankheitsverdacht ergibt sich

- bei jedem Patienten mit unklarem Fieber nach Aufenthalt in Malariagebieten; eine Malaria tropica manifestiert sich in der Regel innerhalb von 3 Monaten nach Rückkehr (Mindestinkubationszeit 5 Tage);

- bei rezidivierendem Fieber alle 48 (gelegentlich auch 24) h bzw. $72 \mathrm{~h}$ nach Aufenthalt in Malariagebieten bis Jahre vor Erkrankungsbeginn (Verdacht auf Malaria tertiana bzw. Malaria quartana).

Ausnahmen: Sehr selten wird eine Malaria auch ohne Aufenthalt in einem Endemiegebiet erworben, z. B. durch eingeschleppte infektiöse Moskitos (meist in der Nähe internationaler Flughäfen), kontaminierte Kanülen, Transfusion, Transplantation, Laborexposition oder konnatal. Bei Patienten, die aus Malariaendemiegebieten stammen, kann auch eine Malaria tropica noch Jahre nach Verlassen des Endemiegebietes auftreten, andererseits sind bei diesen teilimmunen Patienten auch asymptomatische Parasitämien oder oligosymptomatische Erkrankungen möglich.

Die klinische Verdachtsdiagnose ist unabhängig davon, ob monosymptomatisches Fieber vorliegt oder Fieber mit Begleitsymptomen. Auch der Fiebertyp spielt keine Rolle, da insbesondere bei der Malaria tropica das Fieber völlig unregelmäßig oder auch kontinu-

Tabelle 22-26. Diagnostik bei selteneren Protozoeninfektionen

\begin{tabular}{|c|c|c|c|}
\hline Krankheit (Erreger) & Ubertragung & Krankheitsbild & Diagnostik \\
\hline $\begin{array}{l}\text { Acanthamoebakeratitis } \\
\text { (Acanthamoeba spp.) }\end{array}$ & $\begin{array}{l}\text { Kontaktlinsen, Augenverlet- } \\
\text { zungen }\end{array}$ & $\begin{array}{l}\text { Akute und chronische ulzerie- } \\
\text { rende Keratitis (auch bei Im- } \\
\text { munkompetenten) }\end{array}$ & $\begin{array}{l}\text { Zytologisch und kulturell aus } \\
\text { Hornhautabstrichen und Biop- } \\
\text { sien }\end{array}$ \\
\hline $\begin{array}{l}\text { Babesiose } \\
\text { (Babesia microti u. a.) }\end{array}$ & Durch Zeckenbiß & $\begin{array}{l}\text { Hochfieberhafte Erkrankung } \\
\text { ähnlich Malaria tropica }\end{array}$ & $\begin{array}{l}\text { Erregernachweis im Blutau- } \\
\text { strich + in dicken Tropfen }\end{array}$ \\
\hline $\begin{array}{l}\text { Balantidiasis } \\
\text { (Balantidium coli) }\end{array}$ & $\begin{array}{l}\text { Schmierinfektion, Reservoir: } \\
\text { Schweine }\end{array}$ & $\begin{array}{l}\text { Dysenterische Kolitis ähnlich } \\
\text { Amöbenruhr, Leberabszesse }\end{array}$ & $\begin{array}{l}\text { Erregernachweis im Stuhl (pa- } \\
\text { rasitologische Untersuchung) }\end{array}$ \\
\hline $\begin{array}{l}\text { Cyclosporiasis } \\
\text { (Cyclospora cayetanensis) }\end{array}$ & $\begin{array}{l}\text { Schmierinfektion über Wasser } \\
\text { oder Nahrungsmittel }\end{array}$ & $\begin{array}{l}\text { Akute und protrahierte Durch- } \\
\text { falle, bei Immunkompromit- } \\
\text { tierten wie Kryptosporidiose }\end{array}$ & $\begin{array}{l}\text { Erregernachweis im Stuhl (Spe- } \\
\text { zialfärbung: z. B. mod. nach } \\
\text { Ziehl-Neelsen, Calcofluor) }\end{array}$ \\
\hline $\begin{array}{l}\text { Granulomatöse Amöbenenze- } \\
\text { phalitis } \\
\text { (Acanthamoeba castellani u. a. } \\
\text { Arten) }\end{array}$ & $\begin{array}{l}\text { Kommensalen im Nasopha- } \\
\text { rynx, Saprophyten im Boden } \\
\text { (freilebende Amöben) }\end{array}$ & $\begin{array}{l}\text { Bei Immunkompromittierten: } \\
\text { fokale granulomatöse oder ab- } \\
\text { szedierende Läsionen im Ge- } \\
\text { hirn mit variabler Herdneuro- } \\
\text { logie, Hautläsionen }\end{array}$ & $\begin{array}{l}\text { Bildgebende Diagnostik (CCT, } \\
\text { MRT), Erregernachweis histo- } \\
\text { logisch und kulturell aus Biop- } \\
\text { sien (Hirn, Haut) }\end{array}$ \\
\hline $\begin{array}{l}\text { Isosporiasis } \\
\text { (Isospora belli) }\end{array}$ & $\begin{array}{l}\text { Schmierinfektion über Wasser } \\
\text { oder Nahrungsmittel }\end{array}$ & $\begin{array}{l}\text { Akute + protrahierte Durchfal- } \\
\text { le, bei Immunkompromittier- } \\
\text { ten wie Kryptosporidiose }\end{array}$ & $\begin{array}{l}\text { Erregernachweis im Stuhl (pa- } \\
\text { rasitologische Untersuchung) }\end{array}$ \\
\hline $\begin{array}{l}\text { Primäre Amöbenmeningo- } \\
\text { enzephalitis } \\
\text { (Naegleria fowleri u. a. Arten) }\end{array}$ & $\begin{array}{l}\text { Baden in warmen Süßgewäs- } \\
\text { sern (freilebende Amöben) }\end{array}$ & $\begin{array}{l}\text { Fulminante diffuse Meningo- } \\
\text { enzephalitis (meist eitriger Li- } \\
\text { quor), häufig rasch fataler Ver- } \\
\text { lauf }\end{array}$ & $\begin{array}{l}\text { Mikroskopischer Direktnach- } \\
\text { weis beweglicher Amöben im } \\
\text { Liquor, Spezialfärbungen, Kul- } \\
\text { tur (kommt meist zu spät) }\end{array}$ \\
\hline
\end{tabular}


Tabelle 22-27. Intestinale Wurminfektionen

\begin{tabular}{|c|c|c|c|}
\hline Krankheit (Erreger) & Obertragung & Krankheitsbild & Diagnostik \\
\hline $\begin{array}{l}\text { Enterobiasis } \\
\text { (Enterobius vermicularis, Ma- } \\
\text { denwurm) }\end{array}$ & $\begin{array}{l}\text { Verschlucken von Eiern } \\
\text { (Schmier-/Kontaktinfektion, } \\
\text { Autoinfektion) }\end{array}$ & $\begin{array}{l}\text { Analpruritus, perianales Ekzem, } \\
\text { Proktitis; Komplikationen: ektope } \\
\text { Lokalisation (Vaginitis u. a.) }\end{array}$ & $\begin{array}{l}\text { Einachweis im Analab- } \\
\text { strich, Adultwürmer } \\
\text { im Stuhl }\end{array}$ \\
\hline $\begin{array}{l}\text { Trichuriasis } \\
\text { (Trichuris trichiura, Peitschen- } \\
\text { wurm) }\end{array}$ & $\begin{array}{l}\text { Ingestion embryonierter }{ }^{\mathrm{a}} \text { Eier } \\
\text { (über Vegetabilien oder Wasser) }\end{array}$ & $\begin{array}{l}\text { Kolitis, Durchfälle, Tenesmen, Kom- } \\
\text { plikationen: Rektalprolaps, Dysente- } \\
\text { rie, Anämie, Eiweißverlust }\end{array}$ & Einachweis im Stuhl ${ }^{b}$ \\
\hline $\begin{array}{l}\text { Askariasis } \\
\text { (Ascaris lumbricoides, Spul- } \\
\text { wurm) }\end{array}$ & $\begin{array}{l}\text { Ingestion embryonierter }{ }^{\mathrm{a}} \text { Eier } \\
\text { (über Vegetabilien oder Wasser) }\end{array}$ & $\begin{array}{l}\text { Löffler-Syndrom, Bauchschmerzen, } \\
\text { Komplikationen: Ileus, Volvulus, ek- } \\
\text { tope Lokalisalion (Gallenwege) }\end{array}$ & Einachweis im Stuhl ${ }^{b}$ \\
\hline $\begin{array}{l}\text { Hakenwurminfektion } \\
\text { (Ancylostoma duodenale, Neca- } \\
\text { tor americanus) }\end{array}$ & $\begin{array}{l}\text { Perkutane Invasion der Larven } \\
\text { (Barfußlaufen) }\end{array}$ & $\begin{array}{l}\text { Löffler-Syndrom, Anämie, Eiweiß- } \\
\text { verlust, abdominale Beschwerden }\end{array}$ & Einachweis im Stuhl ${ }^{b}$ \\
\hline $\begin{array}{l}\text { Strongyloidiasis } \\
\text { (Strongyloides stercoralis, } \\
\text { Zwergfadenwurm) }\end{array}$ & $\begin{array}{l}\text { Perkutane Invasion der Larven } \\
\text { (Barfußlaufen) Autoinfektion }\end{array}$ & $\begin{array}{l}\text { Löffler-Syndrom, Duodenitis, } \\
\text { Durchfälle, Komplikationen: Hyper- } \\
\text { infektionssyndrom }\end{array}$ & $\begin{array}{l}\text { Larvennachweis im } \\
\text { Stuhl }^{\mathrm{b}} \text {, Koprokultur }\end{array}$ \\
\hline $\begin{array}{l}\text { Taeniasis } \\
\text { (Taenia saginata, Rinderband- } \\
\text { wurm; Taenia solium, Schwei- } \\
\text { nebandwurm) }\end{array}$ & $\begin{array}{l}\text { Genuß von rohem oder unge- } \\
\text { nügend erhitztem Rind-bzw. } \\
\text { Schweinefleisch }\end{array}$ & $\begin{array}{l}\text { Uncharakteristische abdominale Be- } \\
\text { schwerden, bei Taenia solium Infek- } \\
\text { tionsgefahr (Zystizerkose, } \\
\text { s. Abschn. 22.6.12) }\end{array}$ & $\begin{array}{l}\text { Bandwurmglieder im } \\
\text { Stuhl, Einachweis im } \\
\text { Stuhl oder im Analab- } \\
\text { strich }\end{array}$ \\
\hline $\begin{array}{l}\text { Diphyllobothriasis } \\
\text { (Diphyllobothrium latum, } \\
\text { Fischbandwurm) }\end{array}$ & $\begin{array}{l}\text { Genuß von rohem oder unge- } \\
\text { nügend erhitztem Fisch }\end{array}$ & $\begin{array}{l}\text { Megaloblastäre Anämie (Vitamin- } \\
\mathrm{B}_{12} \text {-Entzug aus der Nahrung) }\end{array}$ & Einachweis im Stuhl ${ }^{b}$ \\
\hline $\begin{array}{l}\text { Hymenolepiasis } \\
\text { (Hymenolepis nana, Zwerg- } \\
\text { bandwurm) }\end{array}$ & $\begin{array}{l}\text { Verschlucken von Eiern } \\
\text { (Schmierinfektion, Autoinfek- } \\
\text { tion) }\end{array}$ & Tenesmen, Durchfälle, Anorexie & Einachweis im Stuhl ${ }^{b}$ \\
\hline $\begin{array}{l}\text { Fasciolopsiasis } \\
\text { (Fasciolopsis buski, großer } \\
\text { Darmegel) }\end{array}$ & $\begin{array}{l}\text { Verzehr roher Wasserpflanzen } \\
\text { (z. B. Wassernuß) }\end{array}$ & Bauchschmerzen, Durchfälle & Einachweis im Stuhl ${ }^{b}$ \\
\hline $\begin{array}{l}\text { Kleine Darmegel } \\
\text { (zahlreiche Arten) }\end{array}$ & $\begin{array}{l}\text { Genuß roher oder ungenügend } \\
\text { erhitzter Fische oder Schnecken }\end{array}$ & Bauchschmerzen, Durchfälle & Einachweis im Stuhl ${ }^{b}$ \\
\hline
\end{tabular}

${ }^{a}$ Eireifung im Freien erforderlich (mindestens 3 Wochen).

${ }^{\mathrm{b}}$ Stuhlanreicherung (z. B. MIF-Anreicherung).

Tabelle 22-28. Diagnostik bei selteneren Wurminfektionen

\begin{tabular}{|c|c|c|c|c|}
\hline $\begin{array}{l}\text { Krankheit } \\
\text { (Erreger) }\end{array}$ & Verbreitung & Ubertragung & $\begin{array}{l}\text { Krankheitsbild und Symptoma- } \\
\text { tik }\end{array}$ & Diagnostik \\
\hline $\begin{array}{l}\text { Nematodeninfektionen } \\
\text { Anisakiasis } \\
\text { (Anisakis simplex, } \\
\text { Pseudoterranova deci- } \\
\text { piens, Heringswurm) }\end{array}$ & $\begin{array}{l}\text { Küstenländer (be- } \\
\text { sonders Japan } \\
\text { und Holland) }\end{array}$ & $\begin{array}{l}\text { Genuß roher oder un- } \\
\text { genügend erhitzter } \\
\text { larvenhaltiger Fische }\end{array}$ & $\begin{array}{l}\text { Larvengranulome in Magen- oder } \\
\text { Darmwand mit abdominellen } \\
\text { Schmerzen, Passagestörungen, } \\
\text { Durchfälle, Komplikation: Perfo- } \\
\text { ration }\end{array}$ & $\begin{array}{l}\text { Endoskopischer Nach- } \\
\text { weis der Larven in der } \\
\text { Mukosa, (Serologie) }\end{array}$ \\
\hline $\begin{array}{l}\text { Capillariasis } \\
\text { (Capillaria philippinen- } \\
\text { sis) }\end{array}$ & $\begin{array}{l}\text { Südostasien, spo- } \\
\text { radisch weltweit }\end{array}$ & $\begin{array}{l}\text { Genuß roher oder un- } \\
\text { genügend erhitzter Fi- } \\
\text { sche }\end{array}$ & $\begin{array}{l}\text { Profuse Durchfälle, exsudative } \\
\text { Enteropathie, Malabsorption, } \\
\text { ausgeprägte Bluteosinophilie }\end{array}$ & $\begin{array}{l}\text { Nachweis von Larven, } \\
\text { Eiern und Adulten im } \\
\text { Stuhl }\end{array}$ \\
\hline $\begin{array}{l}\text { Kutane Larva migrans } \\
\text { (Ancylostoma brazilien- } \\
\text { se u. a.) }\end{array}$ & $\begin{array}{l}\text { Weltweit, beson- } \\
\text { ders in Tropen } \\
\text { und Subtropen }\end{array}$ & $\begin{array}{l}\text { Perkutane Larvenin- } \\
\text { vasion (meist an den } \\
\text { Füssen) }\end{array}$ & $\begin{array}{l}\text { Irreguläre kutane Migration der } \\
\text { Larven mit serpiginöser Dermati- } \\
\text { tis, allergische Reaktionen, bakte- } \\
\text { rielle Sekundärinfektion }\end{array}$ & Klinisch \\
\hline $\begin{array}{l}\text { Toxocariasis } \\
\text { (Toxocara canis u. a.) }\end{array}$ & Weltweit & Ingestion & $\begin{array}{l}\text { Endophthalmitis (okuläre Larva } \\
\text { migrans); granulomatöse Hepati- } \\
\text { tis, pulmonale und ZNS-Granulo- } \\
\text { me (viszerale Larva migrans) }\end{array}$ & $\begin{array}{l}\text { Klinisch, ophthalmo- } \\
\text { logisch, bildgebende } \\
\text { Diagnostik; Serologie }\end{array}$ \\
\hline $\begin{array}{l}\text { Trematodeninfektionen } \\
\text { Fascioliasis } \\
\text { (Fasciola hepatica, gro- } \\
\text { Ber Leberegel) }\end{array}$ & Weltweit & $\begin{array}{l}\text { Genuß eßbarer Was- } \\
\text { serpflanzen (z. B. } \\
\text { Wasserkresse) }\end{array}$ & $\begin{array}{l}\text { Akute Invasionsphase: Fieber, } \\
\text { Hepatitis; chronisches Stadium: } \\
\text { Cholangitiden, Leberabszesse }\end{array}$ & $\begin{array}{l}\text { Einachweis im Stuhl } \\
\text { und im Gallensaft, Se- } \\
\text { rologie }\end{array}$ \\
\hline $\begin{array}{l}\text { Clonorchiasis/Opisthor- } \\
\text { chiasis } \\
\text { (kleine Leberegel) }\end{array}$ & $\begin{array}{l}\text { Südostasien, Ost-/ } \\
\text { Nordasien, Osteu- } \\
\text { ropa }\end{array}$ & $\begin{array}{l}\text { Genuß roher oder un- } \\
\text { genügend erhitzter Fi- } \\
\text { sche }\end{array}$ & $\begin{array}{l}\text { Cholangitiden, Leberabszesse, } \\
\text { Präkanzerose (Cholangiokarzino- } \\
\text { me) }\end{array}$ & $\begin{array}{l}\text { Einachweis im Stuhl } \\
\text { und im Gallensaft, } \\
\text { (Serologie) }\end{array}$ \\
\hline $\begin{array}{l}\text { Paragonimiasis } \\
\text { (Paragonimus wester- } \\
\text { mani u. a. Lungenegel) }\end{array}$ & $\begin{array}{l}\text { Südostasien, spo- } \\
\text { radisch Afrika und } \\
\text { Lateinamerika }\end{array}$ & $\begin{array}{l}\text { Genuß roher oder un- } \\
\text { genügend erhitzter } \\
\text { Krebse und Krabben }\end{array}$ & $\begin{array}{l}\text { Chronische kavernöse Pneumo- } \\
\text { nie, ektope Lokalisation (Leber, } \\
\text { Peritoneum, ZNS) }\end{array}$ & $\begin{array}{l}\text { Einachweis im Spu- } \\
\text { tum und im Stuhl, Se- } \\
\text { rologie }\end{array}$ \\
\hline
\end{tabular}


ierlich verlaufen kann. Häufige Symptome sind Kopf-, Glieder- und Rückenschmerzen, Schüttelfröste und Schweißausbrüche. Vor allem bei Malaria tropica können andere Symptome oder Komplikationen ganz im Vordergrund stehen (z. B. trockener Husten, Durchfälle, Ikterus, Bewußtseinsstörungen, Oligurie, Herzkreislaufversagen). Der klinische Untersuchungsbefund ist anfangs meist unauffällig; im Verlauf kann eine Hepatosplenomegalie, bei komplizierter Malaria tropica auch Ikterus, Schock und neurologische Ausfälle auftreten. Die Laborbefunde sind uncharakteristisch, lediglich eine Thrombopenie ist häufig.

\section{Diagnostik}

Entscheidend ist der mikroskopische Parasitennachweis im nach Giemsa gefärbten dicken Tropfen und/ oder im (nach Giemsa oder panoptisch) gefärbten Blutausstrich. Bei negativen Befunden und anhaltendem Verdacht muß die Diagnostik kurzfristig (1- bis 2mal pro Tag) über 3-4 Tage wiederholt werden. Andere Nachweismethoden wie PCR, QBC (quantitative Buffycoat-Analyse) oder Malariaschnelltests (immunologischer Nachweis parasitärer Antigene) dürfen die mikroskopische Diagnose weder ersetzen noch verzögern. Der Antikörpernachweis ist für die Diagnostik einer aktuellen Malaria ungeeignet.

Zusatzdiagnostik: Eine nachgewiesene Malaria muß klassifiziert werden (mikroskopische Plasmodienspezifizierung im Blutausstrich); bei Malaria tropica zusätzlich vollständiges Blutbild mit Thrombozyten, Kreatinin, Blutzucker, Transaminasen, Elektrolyte und LDH sowie EKG und Thoraxröntgenaufnahme. Zudem ist eine Quantifizierung der Parasiten erforderlich (Angabe als Parasiten $/ \mu$ oder als Promille der infizierten Erythrozyten), die zur Beurteilung von Verlauf und Effektivität der Therapie mindestens einmal täglich kontrolliert werden muß. In-vitro-Resistenzbestimmung bei Rekrudeszenz, plasmodienspezifische PCR in parasitologisch unklaren Fällen.

\subsection{2}

\section{Leishmaniosen}

22.6.2.1

\section{Kutane Leishmaniosen}

- Einzelne oder multiple chronische Hautulzera mit derb infiltriertem Randwall (z. T. auch papulöse oder flächig-infiltrative Hauteffloreszenzen ohne Ulzeration) vorwiegend an unbedeckter Haut (Stichstellen der Überträgermücke).

- Aufenthalt in Verbreitungsgebiet (Orient, Afrika, Mittelmeerländer und Lateinamerika).

\section{Diagnostik}

Mikroskopischer Direktnachweis, Isolierung (Kultur) und PCR aus Tupfpräparaten und Hautbiopsien (am be- sten aus Ulkusrandwall). Serologie meist negativ. Artdifferenzierung (mittels Zymodembestimmung, monoklonaler Antikörper oder PCR ) v. a. bei in Lateinamerika erworbenen Erkrankungen empfehlenswert.

\subsubsection{2}

\section{Mukokutane Leishmaniose}

Der klinische Verdacht ergibt sich bei

- granulomatös-entzündlichen Veränderungen (z. T. destruierend) an Haut und Schleimhäuten im Bereich des Nasen-Rachen-Raumes (Nase, Mundhöhle, Pharynx) und

- Herkunft bzw. Aufenthalt in den mittel- und südamerikanischen Verbreitungsgebieten (Inkubation: Monate bis Jahre).

\section{Diagnostik}

Mikroskopischer Direktnachweis (z. T. schwierig), Isolierung (Kultur) und PCR aus Biopsien und Abstrichen der Läsionen, Serologie (s. unten) meist positiv. Artdifferenzierung mittels Zymodembestimmung, monoklonaler Antikörper oder PCR.

\subsubsection{3}

\section{Viszerale Leishmaniose (Kala-Azar)}

Ein Krankheitsverdacht ergibt sich bei

- Fieber (variabler Verlauf, z. T. undulierend), Hepatosplenomegalie und Panzytopenie; z. T. auch Lymphadenopathie; gehäuftes Auftreten bei AidsPatienten.

- Herkunft oder Aufenthalt in Verbreitungsgebieten (weltweit in Tropen und Subtropen inklusive Mittelmeerländer); sehr variable Inkubationszeit (bis zu mehreren Jahren).

\section{Diagnostik}

Mikroskopischer Direktnachweis (z. T. schwierig), Isolierung (Kultur, evtl. Tierversuch) und PCR aus Biopsaten bzw. Punktaten von Knochenmark, Leber, Lymphknoten und Milz (gelegentlich auch direkt aus Blut). Die Serologie (IFT, ELISA, Immunoblot) ist fast immer positiv; Ausnahme: Immunkompromittierte, z. B. Aids-Patienten.

\subsection{3}

\section{Schlafkrankheit}

Ein Krankheitsverdacht ergibt sich bei:

- Herkunft oder Aufenthalt in den afrikanischen Verbreitungsgebieten (Tsetsegebiete).

- Im akuten Stadium: Fieber, Lymphadenopathie und Splenomegalie (Komplikation: Myokarditis); 
bei einem Teil der Patienten initialer Trypanosomenschanker (schmerzhafte Hautschwellung) an der Stichstelle der Tsetsefliege.

- Im chronischen Stadium (oft erst nach Monaten oder Jahren): chronisch progrediente Enzephalitis mit fokalneurologischen und psychotischen Störungen, Persönlichkeitsveränderungen, Demenz, Schlafstörungen, Lethargie und Bewußtseinsstörungen.

\section{Diagnostik}

- Der parasitologische Erregernachweis im Blut (Ausstrich, dicker Tropfen, Anreicherungsmethoden), Lymphknotenpunktat und Liquor ist entscheidend.

- Serologisch (spezifische IgM-Antikörper und Gesamt-IgM meist stark erhöht), PCR.

\subsection{4}

\section{Chagas-Krankheit}

Krankheitsverdacht besteht bei

- Herkunft oder Aufenthalt in den Verbreitungsbegieten in Lateinamerika.

- Klinische Manifestationen des akuten Krankheitsstadiums (am ehesten bei Kleinkindern): schmerzhafte Hautschwellung (Chagom) oder Konjunktivitis an der Eintrittspforte, Fieber, Lymphadenopathie, Hepatosplenomegalie, Myokarditis, gelegentlich Meningoenzephalitis.

- Im chronischen Krankheitsstadium (meist jahrebis jahrzehntelange Latenz): dilatative Kardiomyopathie, Megaösophagus, Megakolon.

\section{Diagnostik}

Der Parasitennachweis (Blutausstrich, dicker Tropfen, verschiedene Anreicherungsmethoden, Hämokultur) gelingt meist nur im akuten Stadium; im chronischem Stadium stets positive Serologie (IFT, ELISA, Immunoblot), Xenodiagnose, PCR.

\subsection{5}

\section{Amöbiasis}

\section{Krankheitsverdacht besteht hinsichlich}

- intestinaler Amöbiasis (Amöbenruhr) bei blutigschleimigen Durchfällen mit oder ohne Fieber (akute wie protrahierte Verläufe möglich) insbesondere nach Aufenthalt in Tropen und Subtropen (selten autochthone Infektionen in Deutschland, z. B. bei Kanalarbeitern); Komplikationen sind massive intestinale Blutungen, Perforation, Amöbom (lokalisierter entzündlicher Tumor der gesamten Kolonwand), Strikturen und extraintestina- le Absiedlungen (meist als Amöbenleberabszeß, selten andere Organe).

- Amöbenleberabszeß bei hohem Fieber (z. T. mit Schüttelfrost), Schmerzen im rechten Oberbauch und Druck- bzw. Klopfschmerzhaftigkeit der Leber (kann fehlen, Projektion in Thorax möglich); oft ohne Zusammenhang mit intestinaler Amöbiasis (sehr variable Inkubationszeit von wenigen Tagen bis zu über einem Jahr).

\section{Diagnostik}

- Bei intestinaler Amöbiasis:

Erregernachweis im frischen oder fixierten (z. B. in MIF-Lösung) Stuhl bzw. endoskopisch gewonnenen Material oder mittels Koproantigen-ELISA; ggf. Differenzierung der morphologisch identischen apathogene Art (E. dispar) von der pathogenen (E. histolytica sensu strictu) mittels PCR, monoklonaler Antikörper oder Zymodembestimmung.

- Bei Amöbenleberabszessen und anderen extraintestinalen Absiedlungen:

Lokalisation mittels bildgebender Verfahren (Sonographie, CT, NMR) und Nachweis hoher Antikörperspiegel (bei perakutem Verlauf initial gelegentlich noch negativ; ggf. kurzfristige Wiederholung). Ein Amöbennachweis im Abszeßeiter gelingt häufig nicht (diagnostische Punktion nur bei Verdacht auf bakterielle Infektion erforderlich).

\subsection{6}

\section{Giardiasis (Lambliasis)}

Krankheitsverdacht besteht bei akuten, chronischen oder chronisch rezidivierenden Durchfällen ohne Fieber oder Blutbeimengungen. Gelegentlich entwickelt sich ein Malabsorptionssyndrom (besonders bei Kindern, IgAMangel, Hypogammaglobulinämie und Immunkompromittierten) sowie eine Duodenitis mit Papillitis und Begünstigung von Gallenwegsentzündungen.

\section{Diagnostik}

Nachweis der Trophozoiten und/oder Zysten im frischen oder fixierten (z. B. MIF-Lösung) Stuhl oder Duodenalsaft. Der Nachweis löslicher Antigene im Stuhl (Koproantigen-ELISA) ist sehr sensitiv (auch in nicht frischen und unkonservierten Proben). Der Erregernachweis ist zudem histologisch in Duodenal- bzw. Dünndarmbiopsien möglich (für die Diagnostik jedoch nicht erforderlich). Die Serologie ist ohne diagnostische Aussagekraft.

\subsection{7}

\section{Schistosomiasis (Bilharziose)}

Der Verdacht einer Infektion ergibt sich aus der Anamnese einer Exposition zu potentiell verseuchten Süßge- 
wässern in Endemiegebieten (Schwimmen, Durchwaten, gelegentlich auch durch Trinken) sowie ggf. aus der klinischen Symptomatik, die allerdings je nach Erregerart und Infektionsstadium sehr unterschiedlich sein kann:

- Zerkariendermatitis:

juckendes papulöses Exanthem an der Eintrittsstelle der Infektionslarven (Stunden bis Tage nach Infektion).

- Akute Schistosomiasis (Katayama-Syndrom): Fieber, Schüttelfrost, Myalgien, Urtikaria, trockener Husten, Oberbauchschmerzen und Durchfälle (2-8 Wochen nach Infektion).

- Blasenbilharziose:

Hämaturie, Dysurie, Pollakisurie und Schmerzen im Urogenitalbereich; aszendierende Infektionen, Hydronephrose, gehäuft Blasenkarzinome (Präkanzerose).

- Darmbilharziose:

Durchfälle (z. T. blutig), abdominelle Schmerzen (Kolitis, Hepatosplenomegalie), Symptome der portalen Hypertonie (Aszites, Anämie, Ösophagusvarizenblutung).

- Komplikationen und Spätschäden:

Lungenfibrose (Dyspnoe, Cor pulmonale), ZNS-Beteiligung: Krampfanfälle und andere fokalneurologische Symptome (besonders bei S. japonicum), transverse Myelitis (besonders bei S. mansoni).

\section{Diagnostik}

Definitive Diagnose einschließlich Artdifferenzierung beruhen auf dem Nachweis der Eier im Stuhl oder Urin (Anreicherungsmethoden) oder Gewebe. Am sensitivsten ist der Einachweis aus Darmbiopsien (z. B. Rektumbiopsie mit submukösen Anteilen) bzw. Blasenbiopsien (histologische Serienschnitte oder mikroskopische Quetschpräparate unfixierter Biopsate). Spezifische Antikörper (ELISA, IFT, Immunoblot) lassen sich in über $95 \%$ nachweisen. Die Immundiagnostik kann bei akuter Schistosomiasis, schwachen Infektionen und während der Präpatenzzeit (zwischen Infektion und Beginn der Eiablage) den einzigen Hinweis geben. Eine Bluteosinophilie ist bei akuter Schistosomiasis meist ausgeprägt, während sie in den chronischen Stadien oft fehlt.

Bei der urogenitalen Schistosomiasis können sonographisch Verdickungen der Blasenwand und Stauungen der ableitenden Hamwege darstellbar sein. Periportale Fibrose und die Zeichen der portalen Hypertonie lassen sich ebenfalls sonographisch gut erfassen. Eigranulome im Gehirn oder Rückenmark können kernspintomographisch nachweisbar sein.

\subsection{8}

Filariosen

Die Diagnostik bei Filariosen ist in Tabelle 22-29 wiedergegeben.

\subsection{9}

Trichinose

Krankheitsverdacht: hohes Fieber, z. T. initial Durchfälle, Muskelschmerzen, allergische Erscheinungen (häufig Gesichtsödeme), Komplikationen: Myokarditis (Rhythmusstörungen) und ZNS-Beteiligung (fokalneurologische Symptomatik, Bewußtseinsstörungen); Labor: meist ausgeprägte eosinophile Leukozytose, massive CK-Erhöhung; häufig Gruppeninfektion (Kleinepidemien).

\section{Diagnostik}

- Im akuten Stadium Nachweis von Larven im Blut (Membranfiltration) und von Darmtrichinen im Stuhl (nur initial),

- Serologie (ELISA als Suchtest, Immunoblot als Bestätigungstest), initial kann die Serologie noch negativ sein, ist aber innerhalb von 1-2 Wochen in allen Fällen positiv.

- Nachweis enzystierter Larven in der Muskelbiospie (z. B. M. gastrocnemius).

- Nachweis von Trichinenlarven in der Infektionsquelle (rohe oder geräucherte Fleisch- oder Wurstwaren, meist vom Schwein, Wildschwein oder Bär).

\subsubsection{0}

\section{Echinokokkose}

\subsubsection{1}

\section{Zystische Echinokokkose}

Bei der zystischen Echinokokkose (Infektion mit dem Larvenstadium des Hundebandwurms Echinococcus granulosus) ist die Symptomatik meist wenig charakteristisch. Durch Heranwachsen der flüssigkeitsgefüllten Zysten (Hydatiden) meist in Leber und/oder Lunge, seltener in Niere, Gehirn und anderen Organen, kommt es zu sehr variablen Krankheitserscheinungen aufgrund von Raumforderungs- und Kompressionserscheinungen, Sekundärinfektion oder spontaner oder iatrogener Zystenruptur (Anaphylaxie möglich).

\section{Diagnostik}

Zum Teil typische radiologische, sonographische oder computer- bzw. kernspintomographische Befunde; die Serologie (ELISA u. a. Verfahren als Suchtest, spezifischer Bestätigungstest: Immunoblot) ist in $80-90 \%$ der Fälle positiv. Keine diagnostische Zystenpunktion (Gefahr der Ruptur mit Anaphylaxie und Aussaat).

\subsubsection{2 \\ Alveoläre Echinokokkose}

Bei der alveolären Echinokokkose (Infektion mit dem Larvenstadium des Fuchsbandwurms Echinococcus multilocularis) wird primär die Leber befallen mit dif- 
Tabelle 22-29. Diagnostik der Filariosen

\begin{tabular}{|c|c|c|c|c|c|}
\hline Infektion & Erreger & Verbreitung & $\begin{array}{l}\text { Vektor } \\
\text { (Ùberträger) }\end{array}$ & Klinik & $\begin{array}{l}\text { Diagnostik } \\
\text { (MF: Mikrofilarien) }\end{array}$ \\
\hline $\begin{array}{l}\text { Lymphatische } \\
\text { Filariosen } \\
\text { (tropische Ele- } \\
\text { fantiasis) }\end{array}$ & $\begin{array}{l}\text { Wuchereria ban- } \\
\text { crofti, } \\
\text { Brugia malayi, } \\
\text { Brugia timori }\end{array}$ & $\begin{array}{l}\text { Feuchtwarme Tro- } \\
\text { pen in Asien, Ozea- } \\
\text { nien, Afrika und } \\
\text { Lateinamerika (ca. } \\
120 \text { Mio. Infizierte) }\end{array}$ & $\begin{array}{l}\text { Stechmücken } \\
\text { (Aedes, Ano- } \\
\text { pheles, Culex, } \\
\text { Mansonia) }\end{array}$ & $\begin{array}{l}\text { Chronische Lymphangii- } \\
\text { tis/-adenitis, chronisches } \\
\text { Lymphödem (Elefantia- } \\
\text { sis), Hydrozele, Chylurie, } \\
\text { tropische pulmonale Eosi- } \\
\text { nophilie; Komplikationen: } \\
\text { Sekundärinfektionen, } \\
\text { Nephritis }\end{array}$ & $\begin{array}{l}\text { MF-Nachweis (be- } \\
\text { sonders nachts) im } \\
\text { Blut (dicker Tropfen, } \\
\text { Mikrohämatokritme- } \\
\text { thode, Membranfil- } \\
\text { tration), Antigen- } \\
\text { nachweis, Serologie }\end{array}$ \\
\hline $\begin{array}{l}\text { Onchozerkose } \\
\text { (Flußblindheit) }\end{array}$ & $\begin{array}{l}\text { Onchocerca vol- } \\
\text { vulus }\end{array}$ & $\begin{array}{l}\text { Tropisches Afrika, } \\
\text { Jemen, Lateiname- } \\
\text { rika } \\
\text { (18 Mio. Infizierte) }\end{array}$ & $\begin{array}{l}\text { Kriebelmücken } \\
\text { (Simulien) }\end{array}$ & $\begin{array}{l}\text { Onchozerkome, Oncho- } \\
\text { dermatitis (generalisiert, } \\
\text { lokal = Sowda), sklerosie- } \\
\text { rende Keratitis, Uveitis, } \\
\text { Retinitis, Optikusneuritis }\end{array}$ & $\begin{array}{l}\text { MF-Nachweis in der } \\
\text { Haut ( skin snip }{ }^{\alpha} \text { ) } \\
\text { und mit der Spalt- } \\
\text { lampe, Onchozerko- } \\
\text { mentfernung, Serolo- } \\
\text { gie }\end{array}$ \\
\hline Loiasis & $\begin{array}{l}\text { Loa loa (Wan- } \\
\text { derfilarie) }\end{array}$ & $\begin{array}{l}\text { Regenwaldregion in } \\
\text { Zentral-/Westafrika }\end{array}$ & $\begin{array}{l}\text { Bremsen (Chry- } \\
\text { sops) }\end{array}$ & $\begin{array}{l}\text { Calabarschwellungen, Au- } \\
\text { genpassage (Adultwurm), } \\
\text { Enzephalopathie }\end{array}$ & $\begin{array}{l}\text { MF-Nachweis (be- } \\
\text { sonders mittags) im } \\
\text { Blut (s. oben), Sero- } \\
\text { logie }\end{array}$ \\
\hline Dracunculiasis & $\begin{array}{l}\text { Dracunculus me- } \\
\text { dinensis (Medi- } \\
\text { nawurm) }\end{array}$ & $\begin{array}{l}\text { Tropisches Afrika, } \\
\text { Indien }\end{array}$ & $\begin{array}{l}\text { Süsswasserkreb- } \\
\text { se (Cyclops) }\end{array}$ & $\begin{array}{l}\text { Ulkus (meist untere Extre- } \\
\text { mität im Knöchel- und } \\
\text { Fußbereich), Komplika- } \\
\text { tion: Sekundärinfektionen }\end{array}$ & $\begin{array}{l}\text { Klinisches Bild, (Lar- } \\
\text { vennachweis) }\end{array}$ \\
\hline $\begin{array}{l}\text { "Apathogene }{ }^{\alpha} \\
\text { Filariosen }\end{array}$ & $\begin{array}{l}\text { - Mansonella } \\
\text { perstans, } \\
\text { - M. ozzardi, } \\
\text { - M. strepto- } \\
\text { cerca }\end{array}$ & $\begin{array}{l}\text { - Afrika, Latein- } \\
\text { amerika, } \\
\text { - Lateinamerika } \\
\text { - West-/Zentral- } \\
\text { afrika }\end{array}$ & $\begin{array}{l}\text { Stechmücken } \\
\text { (Culicoides } \\
\text { u. a.) }\end{array}$ & $\begin{array}{l}\text { Pruritus, Fieber, Eosino- } \\
\text { philie, } \\
\text { Dermatitis (M. strepto- } \\
\text { cerca) }\end{array}$ & $\begin{array}{l}\text { MF-Nachweis im Blut } \\
\text { (s. oben), Serologie } \\
\text { MF-Nachweis in der } \\
\text { Haut (M. strepto- } \\
\text { cerca) }\end{array}$ \\
\hline $\begin{array}{l}\text { Zoonotische } \\
\text { Filariosen }\end{array}$ & $\begin{array}{l}\text { - Dirofilaria re- } \\
\text { pens, } \\
\text { - D. immitis } \\
\text { u. a. }\end{array}$ & Weltweit & Stechmücken & $\begin{array}{l}\text { - Subkutane Knoten } \\
\text { - Lungenrundherde }\end{array}$ & Exstirpation \\
\hline
\end{tabular}

Bei den meisten Filariosen besteht eine oft ausgeprägte Bluteosinophilie; zudem können Allgemeinsymptome wie Fieber, generalisierter oder lokalisierter Pruritus, regionale oder generalisierte Lymphadenopathie und Arthritiden auftreten.

fuser tumorartiger Infiltration des schwammartigen Parasitengewebes. Symptome sind Gewichtsabnahme, Ikterus und Oberbauchbeschwerden. Komplikationen: Metastasierung in andere Organe (z. B. Per itoneum, andere Bauchorgane, Lunge, Gehirn).

\section{Diagnostik}

Die bildgebende Diagnostik zeigt ein Bild ähnlich einem primären Leberkarzinom, z. T. fallen jedoch kleinzystische Areale und Verkalkungen auf. Die Serodiagnostik (Em2-ELISA) ist sehr sensitiv und spezifisch; eine serologische Differenzierung gegenüber zystischer Echinokokkose ist in der Mehrzahl der Fälle möglich.

\subsubsection{1}

\section{Zystizerkose}

Infektion durch das Larvenstadium des Schweinebandwurms (Taenia solium, siehe Tabelle 22-27). Der klinische Verdacht einer Neurozystizerkose ergibt sich bei variabler, häufig fokaler neurologischer Symptomatik
(Epilepsien, fokale und meningeale Syndrome, Hirndruckzeichen u. a.) oder Visusminderung bei Augenbeteiligung und Herkunft aus bzw. Aufenthalt in den Verbreitungsgebieten. Bei meningealer Beteiligung besteht oft eine eosinophile Pleozytose (meist keine Bluteosinophilie).

\section{Diagnostik}

- Computer- bzw. kernspintomographischer Nachweis intrazerebraler Zysten (meist multipel, z. T. mit Verkalkungen); gelegentlich auch intraokulär, intramuskulär oder subkutan (z. T. tastbar), selten in anderen Organen.

- Antikörpernachweis im Serum, Liquor oder Augenkammerwasser. Methoden: ELISA (Suchtest, Kreuzreaktionen möglich), Bestätigungstest: Immunoblot (hohe Spezifität). Positive Serologie jedoch nur in 50-70\% der Fälle (etwas höhere Sensitivität im Liquor).

- Definitive histologische Diagnose an operativ (neurochirurgisch, ophthalmochirurgisch) entfernten Zysten. 